\title{
Yellowstone Volcano Observatory 2018 Annual Report
}

Circular 1474

Version 1.1, March 2021

\section{U.S. Department of the Interior U.S. Geological Survey \\ 20.5:}
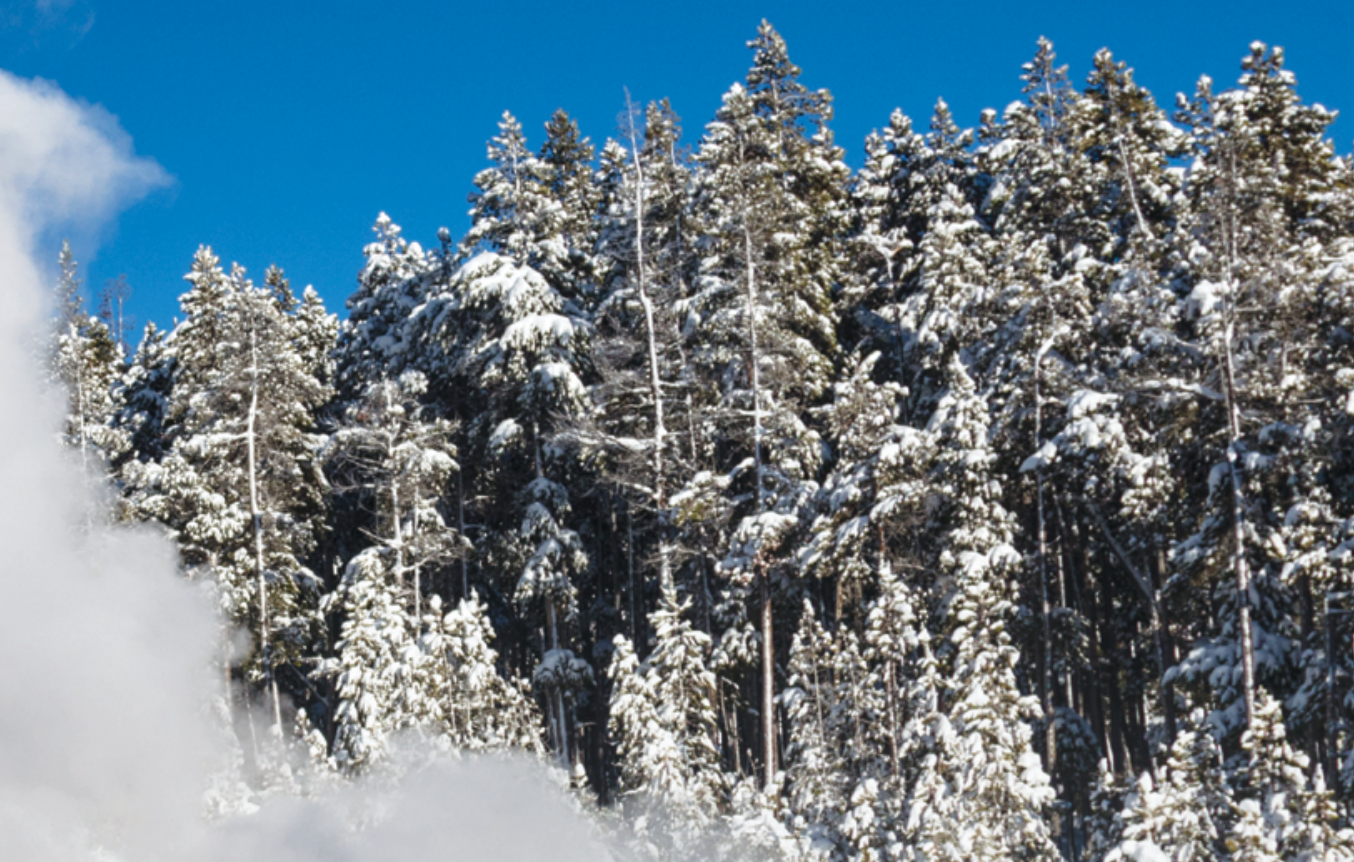

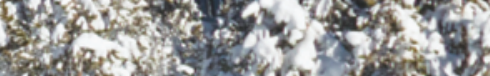

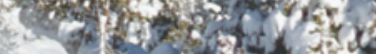
7nor 240

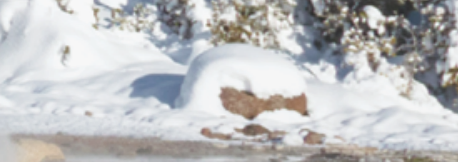

(1) 


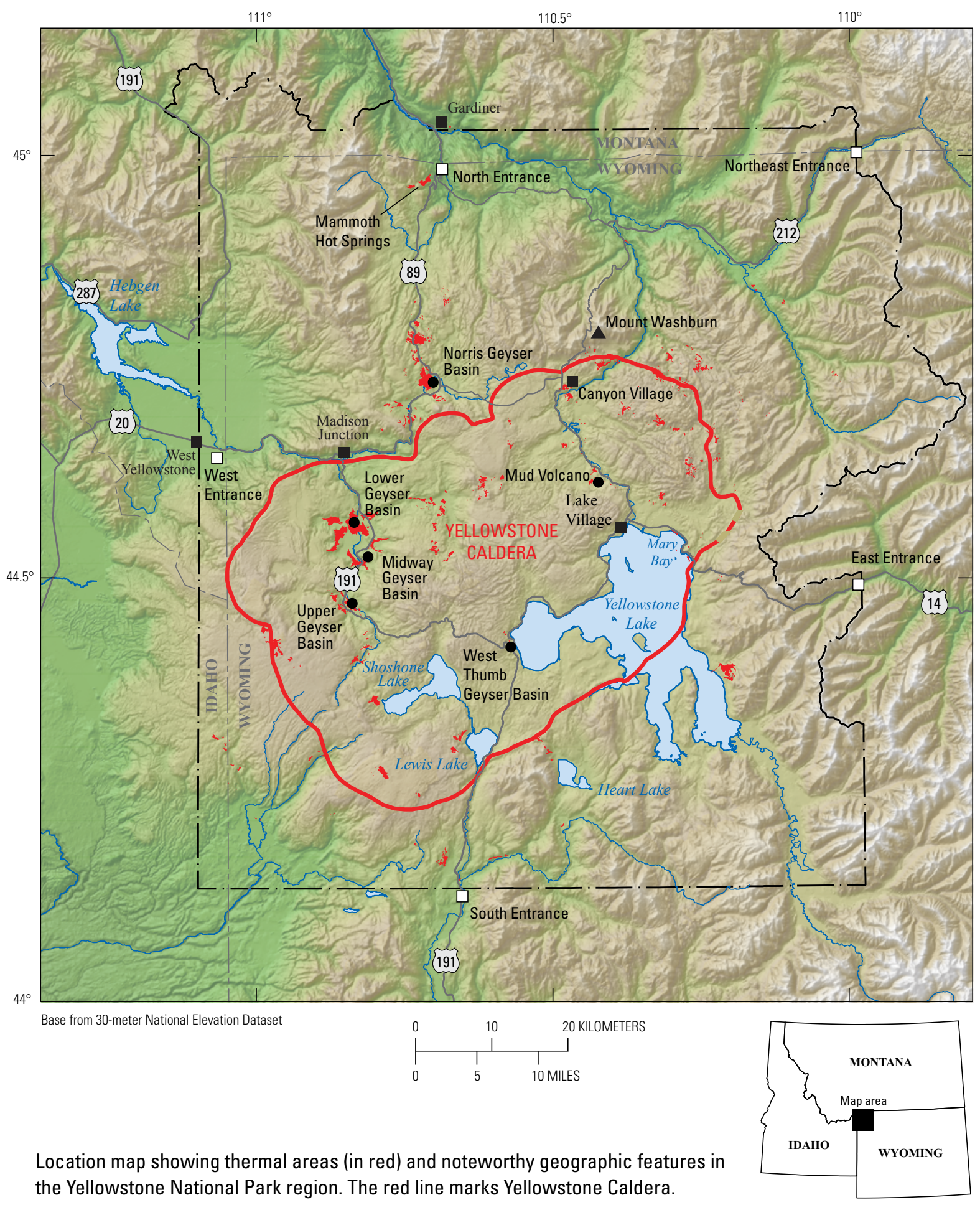
the Yellowstone National Park region. The red line marks Yellowstone Caldera.

Cover. National Park Service photograph of Steamboat Geyser by Jacob W. Frank.

Facing page. National Park Service photograph of Black Pool at West Thumb Geyser Basin by Jim Peaco. 


\section{Yellowstone Volcano Observatory 2018 Annual Report}

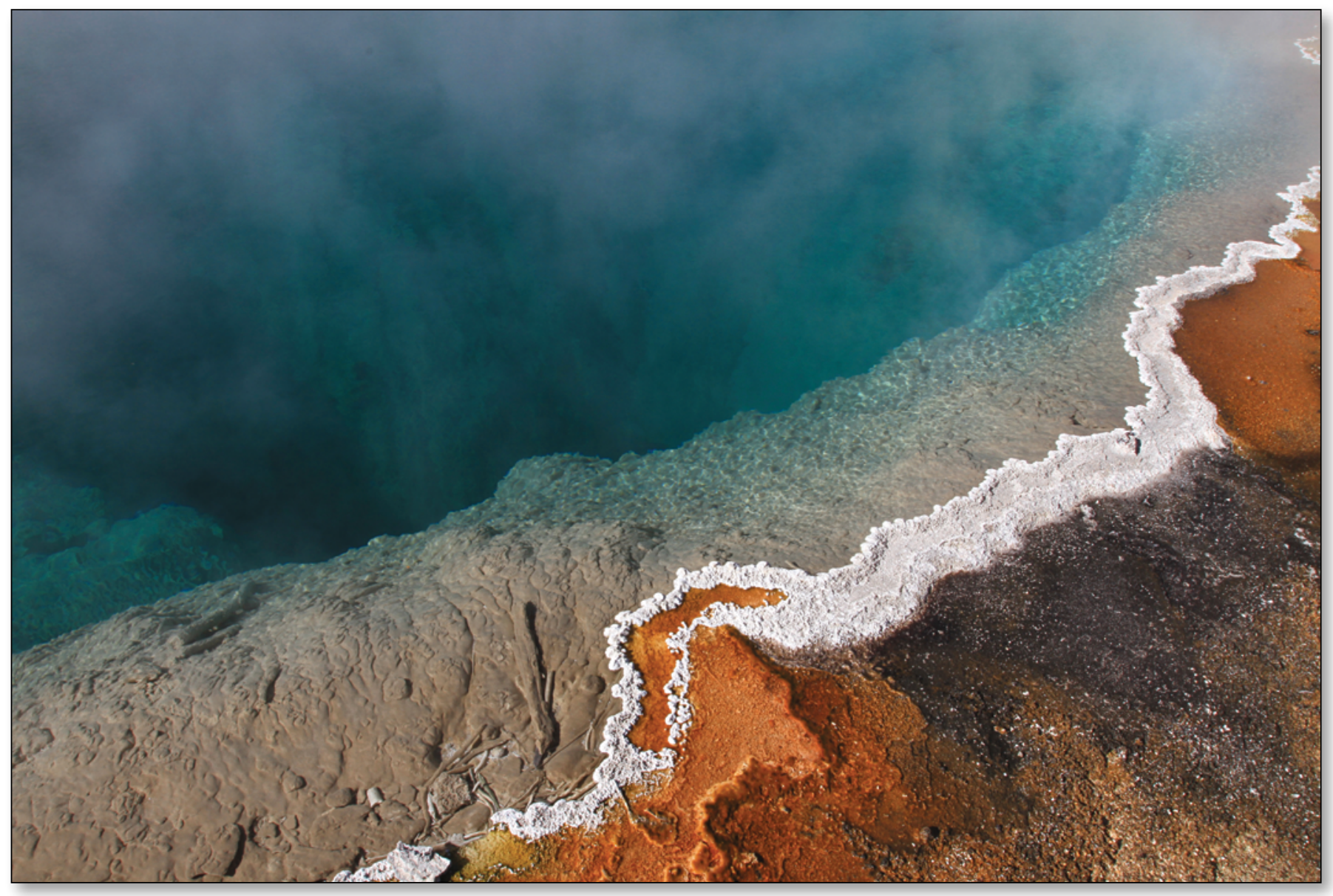

Circular 1474

Version 1.1, March 2021

U.S. Department of the Interior

U.S. Geological Survey 


\section{U.S. Geological Survey, Reston, Virginia \\ First release: 2021, online \\ Revised: March 2021 (ver. 1.1), online and in print}

For more information on the USGS — the Federal source for science about the Earth, its natural and living resources, natural hazards, and the environment-visit https://www.usgs.gov or call 1-888-ASK-USGS.

For an overview of USGS information products, including maps, imagery, and publications, visit https://store.usgs.gov.

Any use of trade, firm, or product names is for descriptive purposes only and does not imply endorsement by the U.S. Government.

Although this information product, for the most part, is in the public domain, it also may contain copyrighted materials as noted in the text. Permission to reproduce copyrighted items must be secured from the copyright owner.

Suggested citation:

Yellowstone Volcano Observatory, 2021, Yellowstone Volcano Observatory 2018 annual report (ver. 1.1, March 2021):

U.S. Geological Survey Circular 1474, 38 p., https://doi.org/10.3133/cir1474.

ISSN 1067-084X (print)

ISSN 2330-5703 (online) 


\section{Contents}

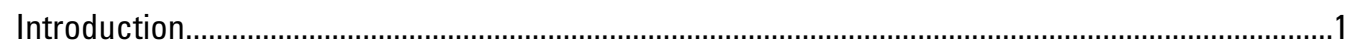

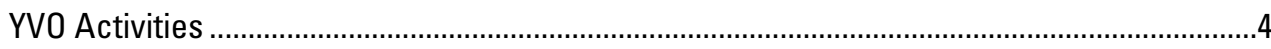

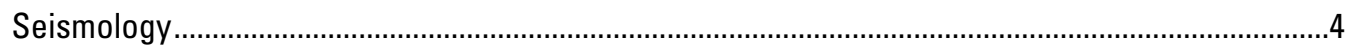

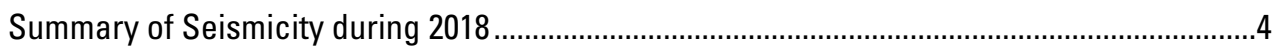

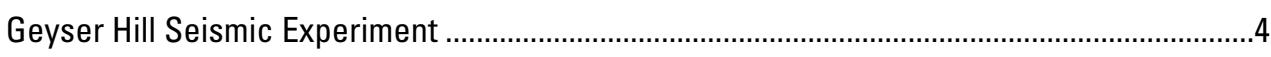

Steamboat Geyser Seismic Experiment..................................................................................

Yellowstone Lake Seismic Experiment................................................................................

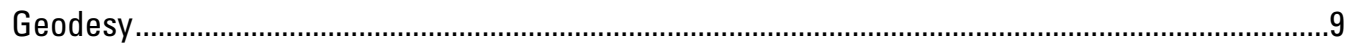

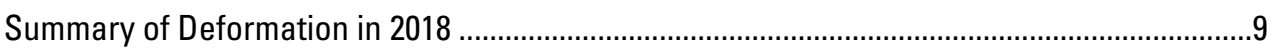

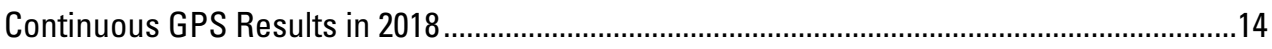

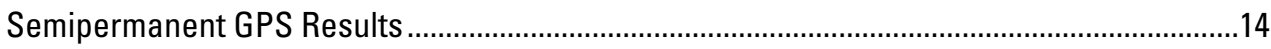

Interferometric Synthetic Aperture Radar (InSAR) Results ............................................... 15

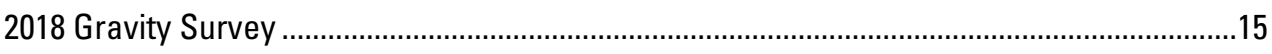

Yellowstone Lake Gage Results.....................................................................................



Summary of Geochemistry Activities in 2018 …………...................................................16

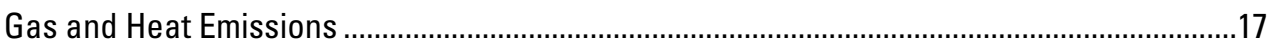

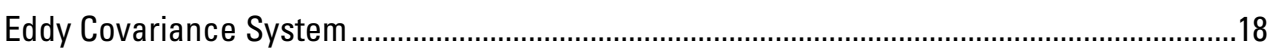

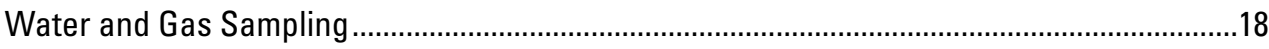

Geology

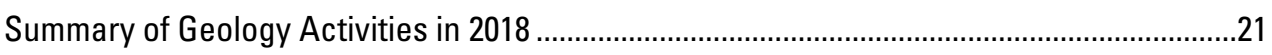

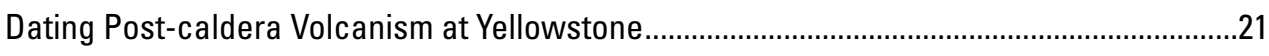

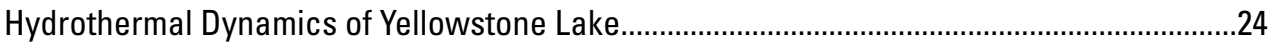

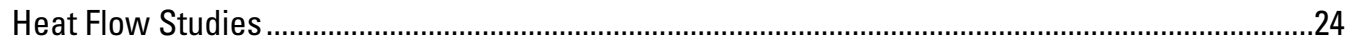

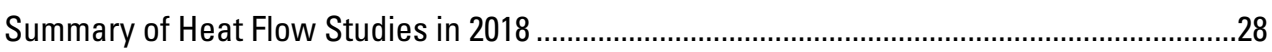

Thermal Infrared Remote Sensing .................................................................................2

Tern Lake Thermal Area...................................................................................................

Chloride Flux Measurements ............................................................................................

Geysers and Hot Springs ....................................................................................................

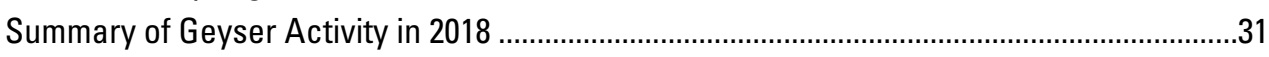

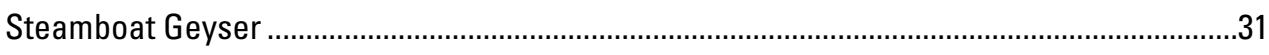

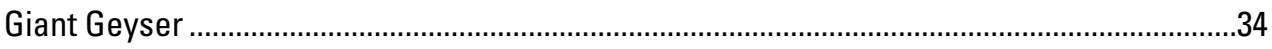

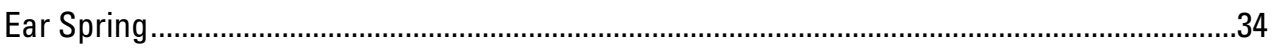

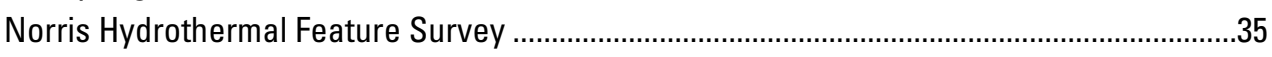

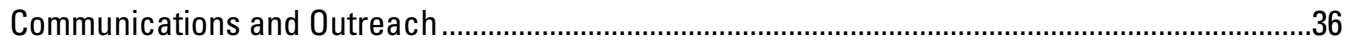

Summary

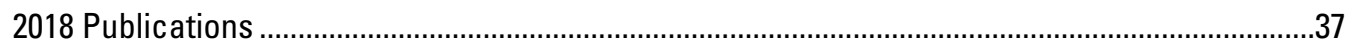

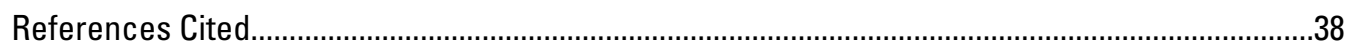




\section{Figures}

1. Map of earthquakes that occurred during 2018 in the Yellowstone National Park region ....5

2. Plot of Doublet Pool seismic signals from 2015-2018 ..................................................

3. Plot showing eruptions of Steamboat Geyser recorded at a nodal seismic station .........8

4. Spectrogram from a nodal seismic station during the 2018 Yellowstone Lake deployment....9

5. Map of GPS stations showing the deformation observed in Yellowstone National Park in 2018.

6. Map of semipermanent GPS stations showing the deformation observed in Yellowstone National Park during 2017 and 2018.

7. Interferogram created from data collected on October 20, 2017, and September 21, 2018, by the Sentinel-1 satellite system

8. Map of gravity stations occupied in Yellowstone National Park during 2018 ..................17

9. Plot of Yellowstone Lake level from July 2017 to December 2018 ..................................17

10. Maps of $\log$ soil $\mathrm{CO}_{2}$ flux and soil temperature at Bison Flat study area of Norris Geyser Basin.

11. Plots of eddy covariance $\mathrm{CO}_{2}$ flux versus wind direction and time.

12. Photographs of a pool that has alkaline water depositing silica sinter along the Ferris Fork of the Bechler River.

13. Shaded-relief map of Yellowstone Caldera showing the age and location of intra-caldera rhyolites that erupted after the Lava Creek Tuff

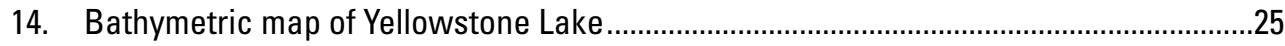

15. High-resolution bathymetric map of West Thumb basin in Yellowstone Lake .................25

16. Satellite thermal infrared temperature image of Yellowstone National Park based on a

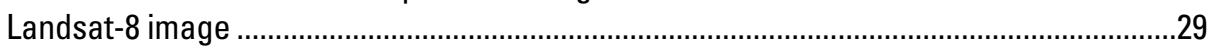

17. Map of Tern Lake thermal area and proximal surroundings .........................................30

18. Pie diagram and boxplot showing the 2018 chloride flux in Yellowstone rivers ..............31

19. Temperature and seismic records of the March 15, 2018, eruption of Steamboat Geyser...32

20. Photograph of Steamboat Geyser in eruption ....................................................................3

21. Aerial view of Steamboat Geyser and surroundings looking north ..................................33

22. Temperature record for Steamboat Geyser during July-August 2018 .............................34

23. Photographs of Ear Spring before and after its September 15, 2018, eruption ....................35

24. Photograph of human-derived debris erupted from Ear Spring on September 15, 2018 .....35

25. Photograph of a CBS News film crew interviewing YVO scientists in front of Steamboat Geyser

\section{Table}

1. Water eruptions of Steamboat Geyser in 2018 


\section{Sidebars}

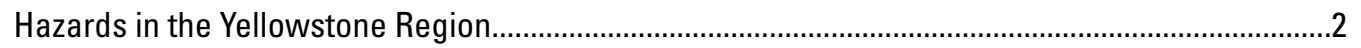

What is the Yellowstone Volcano Observatory?........................................................................

Seismicity in Yellowstone Plateau .................................................................................................

Monitoring Geodetic Change in Yellowstone ..........................................................................

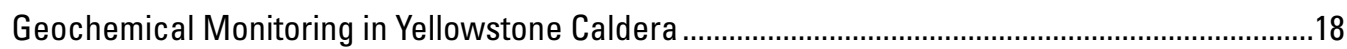

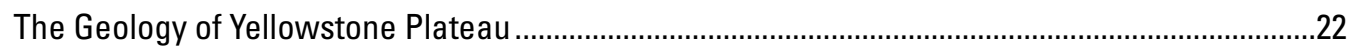

Monitoring Thermal Changes at Yellowstone Caldera ..................................................................26

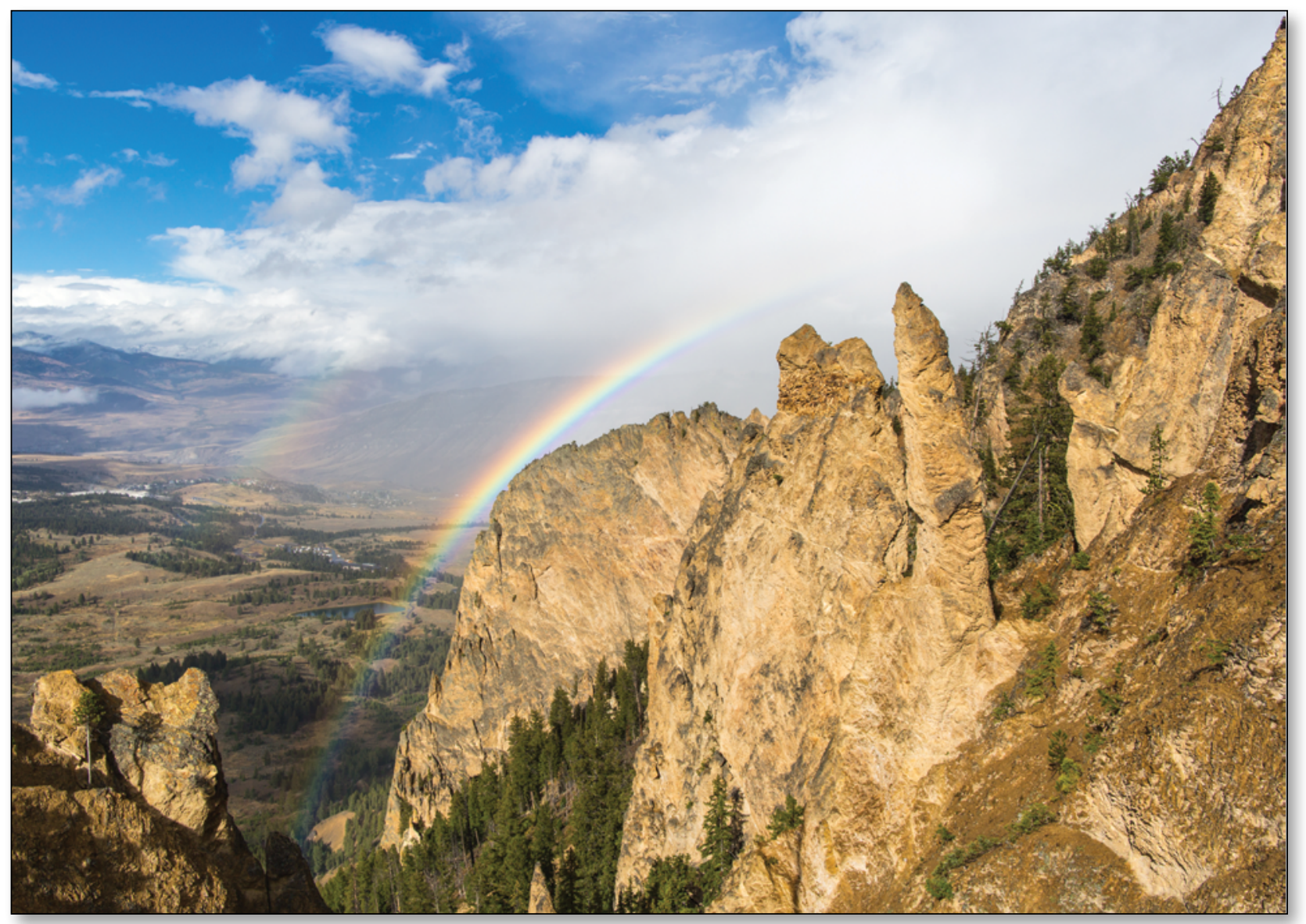

Rainbows from Bunsen Peak, Mammoth Hot Springs. National Park Service photograph by Neal Herbert. 


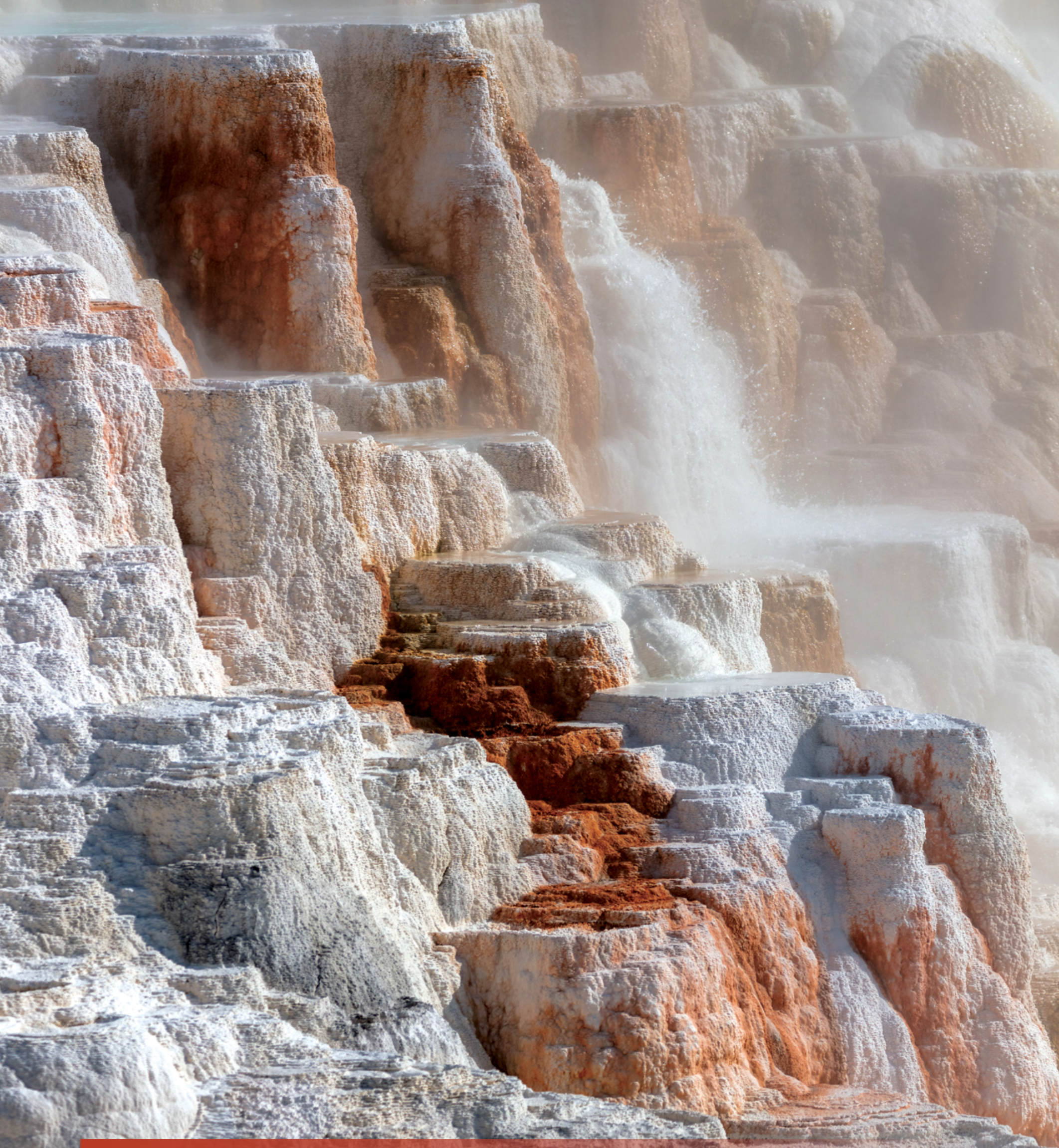

23. Terraces of Canary Spring. National Park Service photograph by Jacob W. Frank.

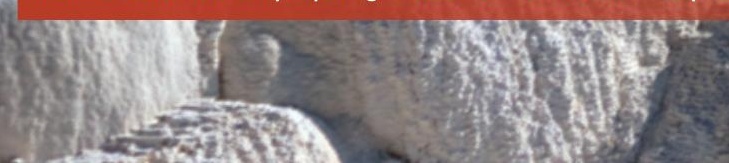




\section{Yellowstone}

Volcano

By the Yellowstone Volcano Observatory²

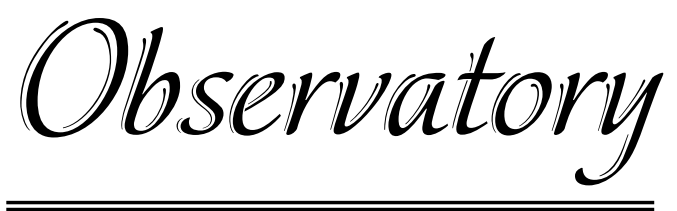

2018 Annual Report

\section{Introduction}

The Yellowstone Volcano Observatory (YVO) monitors volcanic and hydrothermal activity associated with the Yellowstone magmatic system, conducts research into magmatic processes occurring beneath Yellowstone Caldera, and issues timely warnings and guidance related to potential future geologic hazards (see sidebar on volcanic hazards on p. 2). The observatory is a collaborative consortium made up of the U.S. Geological Survey (USGS), National Park Service, University of Utah, University of Wyoming, UNAVCO, Wyoming State Geological Survey, Montana Bureau of Mines and Geology, and Idaho Geological Survey (see sidebar on YVO on p. 3). The USGS arm of YVO also has the operational responsibility for monitoring volcanic activity in the intermountain west of the United States, including Arizona, New Mexico, Utah, and Colorado.

This report summarizes the activities and findings of YVO during the year 2018, focusing on the Yellowstone magmatic system. The most noteworthy seismic activity of the year was a February swarm of hundreds of earthquakes in the same area as the 2017 Maple Creek earthquake swarm, about 15 kilometers (9 miles) north-northwest of West Yellowstone, Montana. The February 2018 activity is viewed as a continuation of the 2017 swarm. Ground deformation trends were mostly unchanged throughout the year, with uplift of the Norris Geyser Basin area and subsidence of the caldera, both at rates of a few centimeters (1-2 inches) per year. Although caldera subsidence continued all year long, uplift at Norris Geyser Basin ended in October and no uplift or subsidence occurred there throughout the remainder of the year.

Field work in 2018, conducted under research permits granted by the National Park Service, included routine maintenance visits to seismic and geodetic stations as well as

- Deployment of a semipermanent Global Positioning System (GPS) network during the summer months,
- Installation of an eddy covariance system for tracking carbon dioxide $\left(\mathrm{CO}_{2}\right)$ emissions and heat flux near Norris Geyser Basin,

- Deployment of nodal seismic arrays on Geyser Hill in the Upper Geyser Basin, near Steamboat Geyser in Norris Geyser Basin, and around Yellowstone Lake, and

- Collection of water and gas samples from the Bechler River area in the southwest part of Yellowstone National Park.

In addition, examination of satellite thermal imagery resulted in the discovery of a new thermal area on the east side of the Sour Creek resurgent dome, near west Tern Lake. This thermal area appears to have started forming in the early 2000s; before then it was an area of healthy forest.

The year might best be remembered, however, for some extraordinary geyser and hot spring activity, specifically at Steamboat Geyser and Ear Spring. Except for periods in the 1960s and 1980s, water eruptions of Steamboat Geyser, in Norris Geyser Basin, have been rare, sometimes with years between eruptions. Starting in March 2018, however, Steamboat Geyser began a sequence of eruptions that had only days to weeks between major events. By the end of 2018, the geyser had erupted 32 times, setting an individual record for water eruptions in a single calendar year. In September 2018, Ear Spring, located on Geyser Hill in the Upper Geyser Basin, experienced a rare eruption, which was all the more noteworthy for bringing decades of human debris to the surface, including coins, a piece of a cinder block, and a baby's pacifier. A new thermal feature formed nearby and the boardwalk on Geyser Hill was briefly closed, but by the end of the month activity had returned to pre-event levels.

Throughout 2018, the aviation color code for Yellowstone Caldera remained at "green" and the volcano alert level remained at "normal." Total seismicity—2,007 located earthquakes—was average relative to previous years.

\footnotetext{
${ }^{2}$ This report was prepared jointly by members of the Yellowstone Volcano Observatory consortium, including Michael Poland, Daniel Dzurisin, Deborah Bergfeld, Shaul Hurwitz, Jennifer Lewicki, Blaine McCleskey, Lisa Morgan, Pat Shanks, Mark Stelten, Wendy Stovall, R. Greg Vaughan, and Charles Wicks of the U.S. Geological Survey; Jefferson Hungerford, William Keller, and Behnaz Hosseini of the National Park Service; Jamie Farrell of the University of Utah; and David Mencin of UNAVCO. Jacob Lowenstern and Seth Moran of the U.S. Geological Survey reviewed this report.
} 


\section{Sidebar Hazards in the Yellowstone Region}

The Yellowstone Plateau in the northern Rocky Mountains of Wyoming, Montana, and Idaho is centered on a youthful, active volcanic system with subterranean magma (molten rock), boiling and pressurized waters, and a variety of active faults. This combination creates a diversity of hazards, but the most catastrophic eventslarge volcanic explosions - are also the least likely to occur.

Over the past 2.1 million years, Yellowstone Caldera has had three immense explosive volcanic eruptions that blanketed large parts of the North American continent with ash and debris and created sizable calderas. Yellowstone Caldera, which comprises nearly one third of the land area in Yellowstone National Park, formed 631,000 years ago during the most recent of these large explosive phases. Its formation was followed by dozens of less explosive but massive lava flows, the latest of which erupted 70,000 years ago.
Tectonic extension of the western United States is responsible for large earthquakes in the Yellowstone region along faults such as the Teton and Hebgen Faults. Most recently, a devastating magnitude 7.3 earthquake in 1959 killed 28 people, and a strong magnitude 6.1 earthquake near Norris Geyser Basin in 1975 was widely felt.

Yellowstone National Park's famous geothermal waters create fabulous hot springs and geysers but occasionally explode catastrophically to create craters found throughout the park. At least 25 explosions that left craters greater than 100 meters ( 328 feet) wide have occurred since the last ice age ended in the Yellowstone area 16,000-14,000 years ago. Much smaller explosions, which leave craters only a few meters (yards) across, happen every few years in the Yellowstone area.

\section{SMALL HYDROTHERMAL EXPLOSIONS}

(Several to many per century)

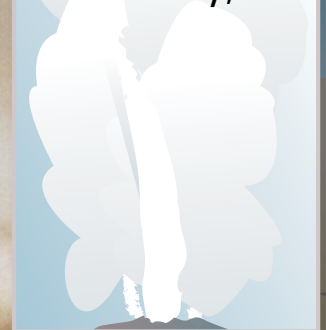

\section{STRONG} EARTHQUAKES

(One to several per century)

\section{LAVA FLOWS}

( 100 per million years)

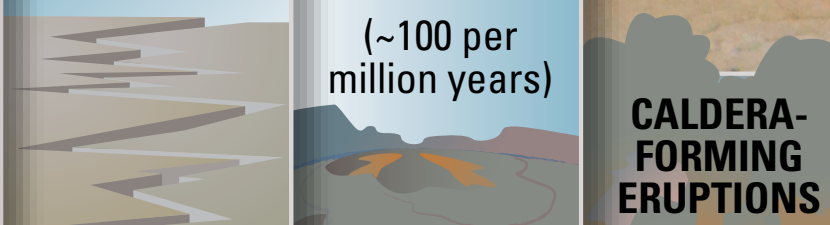

(1 or 2 per million years)
The most destructive hazards in the Yellowstone area, including volcanic explosions and lava flow eruptions, are also the least likely to occur. On human timescales, the most likely hazards are small hydrothermal explosions and strong earthquakes. Modified from U.S. Geological Survey Fact Sheet 2005-3024 (Lowenstern and others, 2005). 


\section{Sidebar What is the Yellowstone Volcano Observatory?}

The Yellowstone Volcano Observatory (YVO) was formed on May 14, 2001, to strengthen the longterm monitoring of volcanic and seismic unrest in the Yellowstone National Park region. YVO is a "virtual" observatory that does not have an on-site building to house employees. Instead, it is a consortium of eight organizations spread throughout the western United States that join together to monitor and study Yellowstone's volcanic and hydrothermal systems, as well as disseminate data, interpretations, and accumulated knowledge to the public. The partnership provides for improved collaborative study and monitoring of active geologic processes and hazards of the Yellowstone Plateau volcanic field, which is the site of the largest and most diverse collection of natural thermal features on Earth, the world's first national park, and the United States' first World Heritage Site.

Each of the eight consortium agencies offers unique skill sets and expertise to YVO. The U.S. Geological
Survey has the Federal responsibility to provide warnings of volcanic activity and holds the ultimate authority over YVO operations. Key geophysical monitoring sites were established and are maintained by the University of Utah and UNAVCO, and scientists from these two organizations analyze and provide data to the public. Yellowstone National Park, operated by the National Park Service, is the land manager and is responsible for emergency response to natural disasters within the national park boundaries. The Wyoming State Geological Survey, Montana Bureau of Mines and Geology, and Idaho Geological Survey provide critical hazards information and outreach products to their respective citizens. The University of Wyoming supports research into Yellowstone's volcanic and hydrothermal activity, as well as the geologic history of the region. YVO agencies also aid and collaborate with scientists outside the consortium.
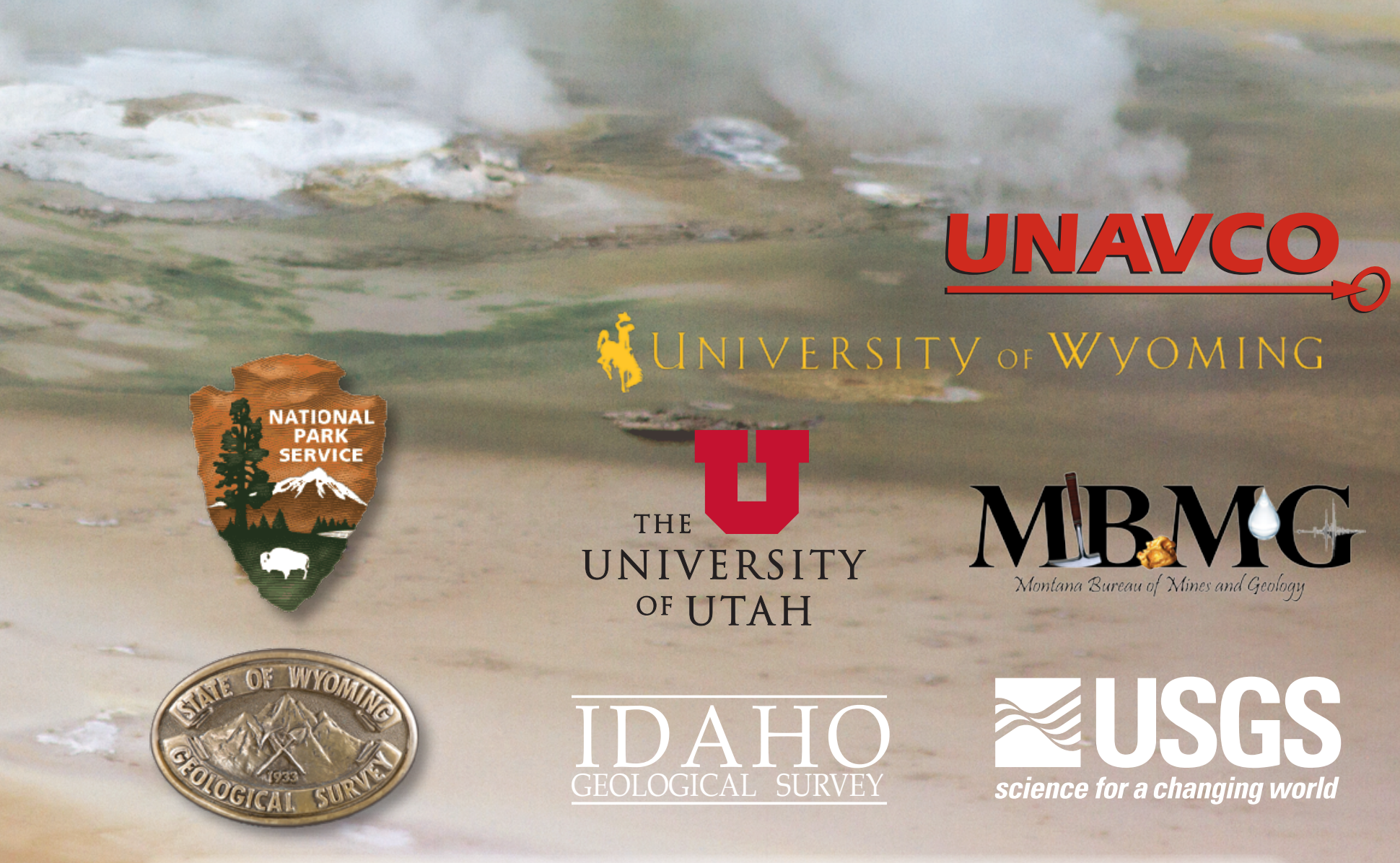

Member agencies of the Yellowstone Volcano Observatory.

Background photograph of thermal features in Porcelain Basin at Norris Geyser Basin by Diane Renkin, National Park Service. 


\section{YVO Activities}

The 2018 biennial YVO meeting took place on May 7-9 at Mammoth Hot Springs in Yellowstone National Park. More than 30 YVO scientists, collaborators, and other interested parties gathered for scientific discussions, field work, and interactions with the local community. Among the topics discussed were the subsurface structure of Old Faithful as revealed by the 2017 Upper Geyser Basin seismic experiment (see the 2017 YVO annual report [YVO, 2019], available at https://doi.org/10.3133/cir1456), new findings that indicate some of Yellowstone's past lava eruptions were more clustered in time than previously thought, and the role of hydrogen released from fractures and fault zones in supporting thermophiles (microorganisms that live in many Yellowstone hot springs). Looking to the future, participants agreed that hydrothermal systems should receive more attention as a portal into Yellowstone's deeper roots. To that end, several research efforts will be focused at Norris Geyser Basin in coming years. A highlight of the meeting occurred on the evening of May 7 , when about 70 members of the public gathered at the community center in Gardiner, Mont., to ask questions and interact with YVO scientists (see Communications and Outreach section). The twoway communication was fun and informative for all who participated and had the effect of "putting a face" on scientists and citizens alike.

In late 2018, Erin White joined the staff of Yellowstone National Park as the park hydrologist. YVO is pleased to welcome Erin to the team!

\section{Seismology}

Earthquakes have been monitored in the Yellowstone area since the 1970s (see sidebar on seismicity on p. 6-7). The Yellowstone Seismic Network is maintained and operated by the University of Utah Seismograph Stations, which records data from 46 stations in the Yellowstone region. On average, about 1,500-2,500 earthquakes - most of which are too small to be felt by humans - are located in and around Yellowstone National Park every year, making the Yellowstone region one of the most seismically active areas in the United States.

\section{Summary of Seismicity during 2018}

During 2018, the University of Utah Seismograph Stations located 2,007 earthquakes in the Yellowstone region (fig. 1). Of these, three were felt, meaning that people reported some shaking. The largest event of the year was magnitude 3.1 outside the park just west of Hebgen Lake and occurred on December 20, 2018, at 9:36 a.m. local time.

About 65 percent of all the earthquakes that were located in 2018 occurred as part of 21 swarms, which are defined as the occurrence of many earthquakes in the same small area over a relatively short period. The largest of these was a continuation of the 2017 Maple Creek swarm, which was located on the west side of Yellowstone National Park a few miles north of West Yellowstone, Mont. The 2018 Maple Creek swarm, which included 739 located earthquakes, was most active in February, but earthquakes continued in this area throughout the rest of the year.

\section{Geyser Hill Seismic Experiment}

In response to the eruption of Ear Spring and the formation of a new hydrothermal feature on Geyser Hill in the Upper Geyser Basin (see Geysers and Hot Springs section), the University of Utah, in cooperation with Yellowstone National Park, deployed 29 nodal seismometers around Geyser Hill. The instruments were deployed on September 30 and were removed on November 5. The goal was to record seismic signals related to anomalous activity in the area of Geyser Hill. Compared to previous deployments in the same area, no anomalous signals were recorded with one possible exception. Doublet Pool, which exhibits periodic pulsing of water level with audible thumping, was more active than it had been in the past. During the late summer to early fall of 2018, the thumping was occurring about every 26.7 minutes, which is more than 10 minutes shorter than it was in $2015(\sim 39.3$ minutes) and 5 minutes shorter than it was the previous year ( $\sim 31.7$ minutes in 2017; fig. 2).

\section{Steamboat Geyser Seismic Experiment}

In response to the increased activity of Steamboat Geyser in the Norris Geyser Basin (see Geysers and Hot Springs section), the University of Utah, in cooperation with Yellowstone National Park, deployed 28 nodal seismometers around Steamboat Geyser. The instruments were deployed on May 5 and were removed on June 4. The goal was to record seismic signals associated with major eruptions of Steamboat Geyser (the tallest active geyser in the world). In total, the deployment spanned four eruptions (on May 13, May 19, May 27, and June 4). Although the University of Utah Seismograph Stations operate a permanent seismic station in the Norris Geyser Basin, it is $\sim 300$ meters ( $\sim 1,000$ feet) from Steamboat Geyser, which is not close enough to resolve small-scale changes local to the geyser system. The nodal deployment, including a station only 11 meters (36 feet) from the geyser vent, therefore provides the first nearby seismic recordings of eruptions of Steamboat Geyser (fig. 3). These data will be used to image the subsurface plumbing system of Steamboat Geyser and to look for anomalous signals that could be indicative of the reason for increased eruptive activity. In addition, the data will be used to investigate the subsurface connections of Steamboat Geyser to other nearby hydrothermal features, including Cistern Spring, which empties completely in the hours after major eruptions of Steamboat Geyser. 


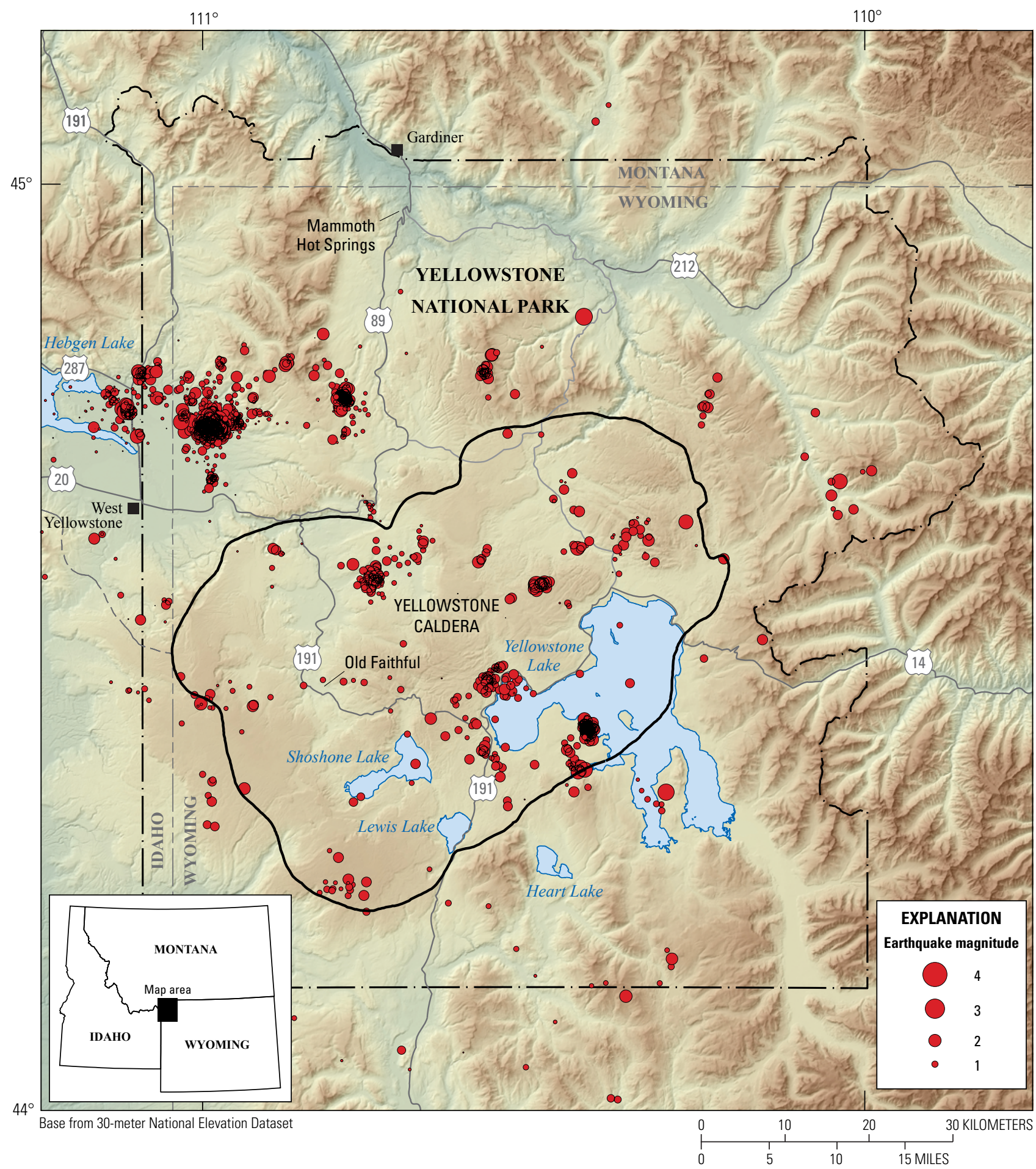

Figure 1. Map of earthquakes (red circles) that occurred during 2018 in the Yellowstone National Park region. 


\section{Sidebar Seismicity in Yellowstone Plateau}

Seismicity in the Yellowstone Plateau is monitored by the University of Utah Seismograph Stations. The earthquake monitoring network, known as the Yellowstone Seismic Network, consists of about 46 seismometers installed in the seismically active Yellowstone National Park and surrounding area. It is designed for the purpose of monitoring earthquake activity associated with tectonic faulting as well as volcanic and hydrothermal activity. Data are also used to study the subsurface processes of Yellowstone Caldera.
Seismic monitoring in the

Yellowstone area began in earnest during the early 1970s, when a seismic network was installed by the U.S. Geological Survey. This network operated until the early 1980s when it was discontinued for budgetary reasons. The network was re-established and expanded by the University of Utah in 1984 and has been in operation ever since. Over the years, the Yellowstone Seismic Network has been updated with modern digital seismic recording equipment, making it one of the most modern volcanomonitoring networks in the world.
Presently, data are transmitted from seismic stations in the Yellowstone area to the University of Utah in real-time using a sophisticated radio and satellite telemetry system. Given that Yellowstone Plateau is a high-elevation region that experiences heavy snowfall and frigid temperatures much of the year, and that many of the data transmission sites are located on tall peaks, it is a challenge to keep the data flowing during the harsh winter months. It is not uncommon for seismometers to go offline for short periods because the solar panels
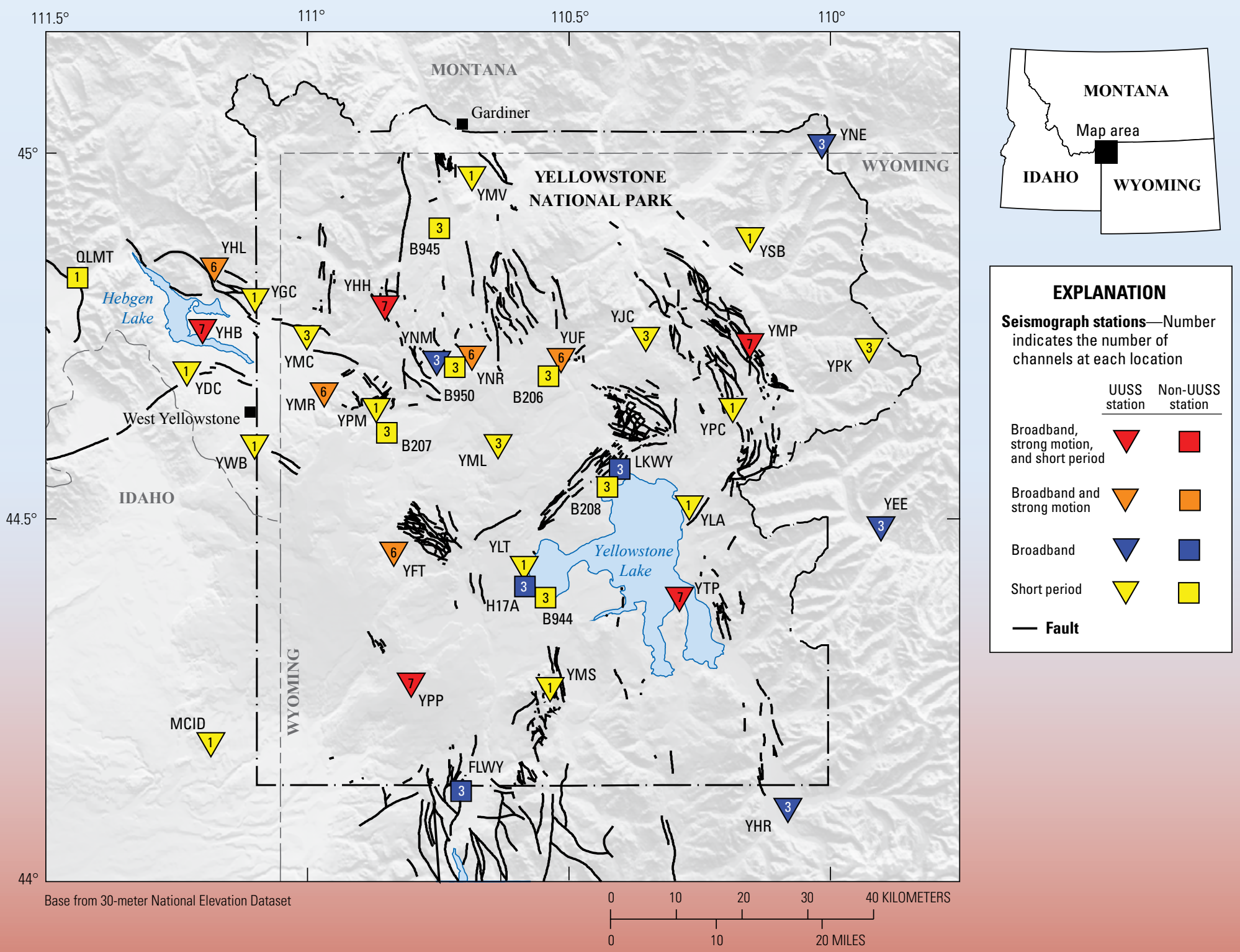
or antennas get covered in snow and ice. Sometimes seismometers that go offline during the winter cannot be accessed until the following spring.

Since 1973, there have been more than 50,000 earthquakes located in the Yellowstone region. More than 99 percent of those earthquakes are magnitude 2 or below and are not felt by anyone. Since 1973, there has been one magnitude 6 event - the 1975 magnitude 6.1 Norris earthquake located near Norris Geyser Basin (the largest earthquake ever recorded in Yellowstone National Park). There have also been two earthquakes in the magnitude 5 range, 29 earthquakes in the magnitude 4 range, and 384 earthquakes in the magnitude 3 range. The largest earthquake ever recorded in the Yellowstone area was the 1959 magnitude 7.3 Hebgen Lake earthquake, which was located just west of the national park boundary and north-northwest of West Yellowstone, Montana. That earthquake was responsible for 28 deaths and had a major impact on the hydrothermal systems of nearby Yellowstone National Park, including Old Faithful Geyser.
Earthquake swarms (earthquakes that cluster in time and space) account for about 50 percent of the total seismicity in the Yellowstone region. They are most common in the east-west band of seismicity between Hebgen Lake and the Norris Geyser Basin. Most swarms are small and short, containing 10-20 earthquakes and lasting for 1-2 days, although large swarms of thousands of earthquakes lasting for months do occur on occasion (for example, in 1985-86 and in 2017).

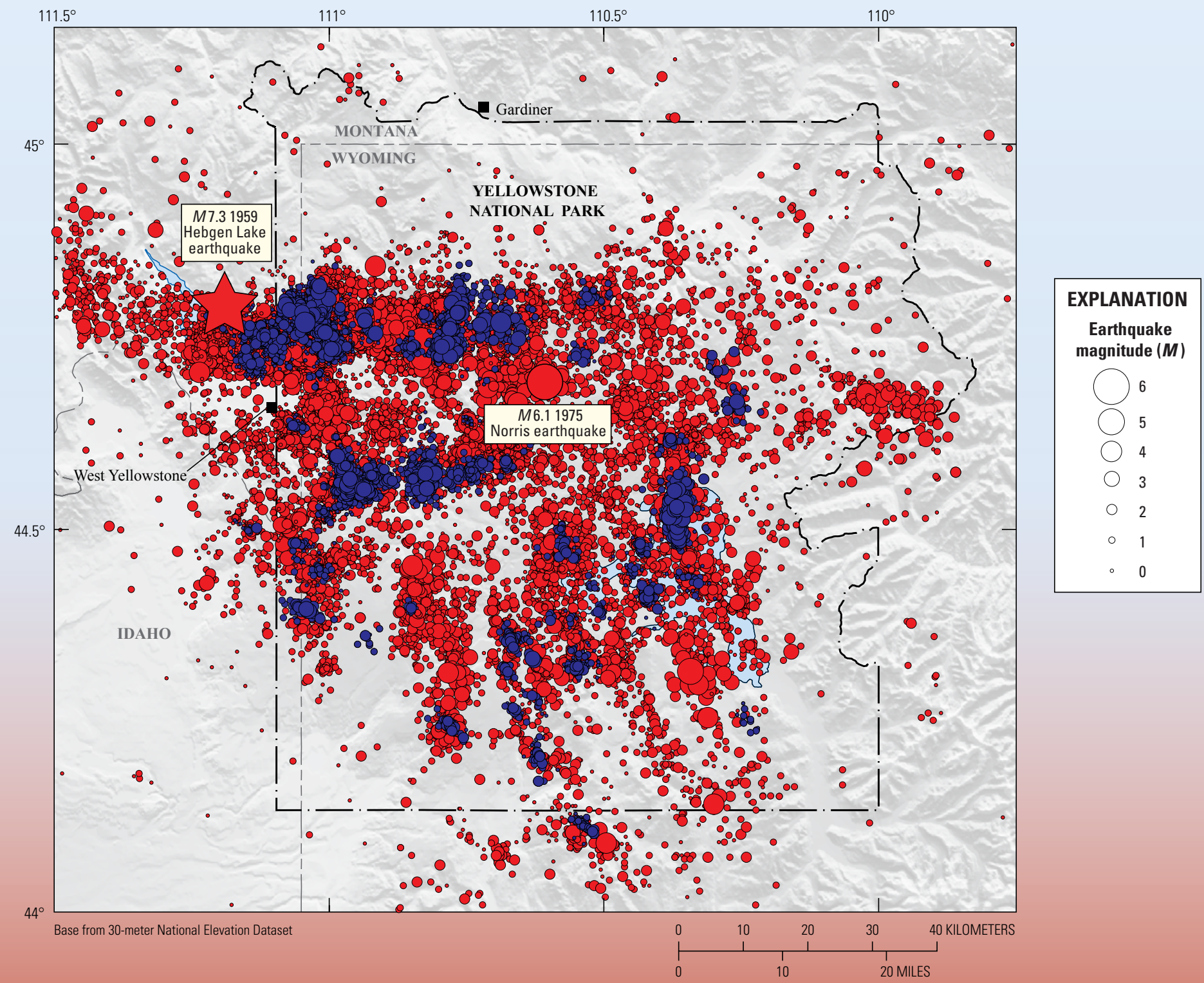



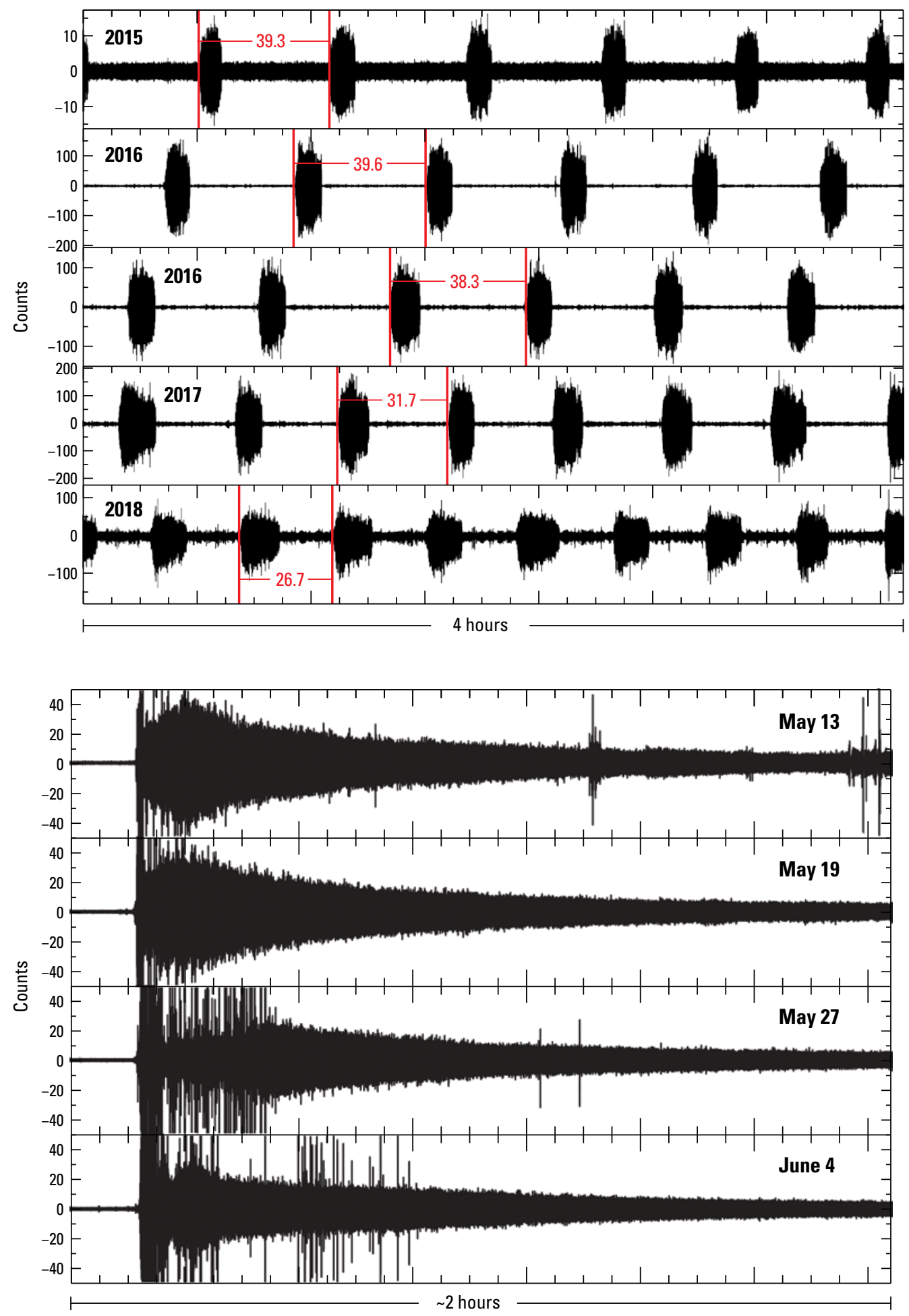

Figure 2. Plot of Doublet Pool seismic signals from 2015-2018. The interval between Doublet Pool activity decreased over time from $\sim 39$ minutes in 2015 to $\sim 27$ minutes in 2018.

Figure 3. Plot showing eruptions of Steamboat Geyser recorded at a nodal seismic station located about 11 meters ( 36 feet) from the geyser vent. In total, 28 stations were deployed for a month during the summer 2018 nodal deployment. Recording seismic signals related to Steamboat Geyser eruptions from such nearby distances can highlight subtle differences between eruptions and illuminate the subsurface plumbing system of the geyser.

\section{Yellowstone Lake Seismic Experiment}

As part of a project funded by the National Science Foundation, the University of Utah, in cooperation with the Woods Hole Oceanographic Institute (WHOI) and Yellowstone National Park, deployed a number of sensors around Yellowstone Lake during the summer of 2018 in order to record and identify microseismic signals generated by wave action on the lake. Seismic signals caused by wave action in the oceans (known as microseisms) have long been observed. Owing to the difficulty and high expense of getting the right instrumentation near where the signals are generated in the open ocean, however, the process that generates these signals is not well understood. Given the fact that microseisms generated in Yellowstone Lake 
were observed during previous years, it is possible that by instrumenting the lake, a better understanding of how these signals are generated can be achieved. With this goal in mind, 40 nodal seismic stations were deployed around the lake and on the islands in the lake. Four weather stations were also installed to record wind speed, wind direction, air temperature, and pressure (fig. 4). In addition, WHOI deployed two wave gauges that recorded wave height and direction. Together, these data offer an unprecedented opportunity to identify and locate the source of microseismic energy in Yellowstone Lake. It may also be possible to use this seismic energy to image the subsurface of Yellowstone Lake where three major hydrothermal basins are located (see Geology section).

\section{Geodesy}

Geodesy is the scientific discipline focused on changes in the shape of Earth's surface, called deformation, such as uplift, subsidence, and faulting. At Yellowstone, these changes are caused by a combination of magmatic, tectonic, and hydrothermal processes. Deformation is measured using networks of GPS ${ }^{2}$ stations, borehole tiltmeters and strainmeters, and a remote-sensing technique called interferometric synthetic aperture radar (InSAR) (see sidebar on monitoring geodetic change on p. 10-12). Geodesy also includes changes in Earth's gravity field, which can indicate variations in mass beneath the surface. Together, geodetic data are used to develop models of subsurface sources of deformation and gravity change, which in turn provide insights into the physical processes responsible for activity observed at the surface.

\section{Summary of Deformation in 2018}

Ground deformation in 2018 included continued subsidence of the floor of Yellowstone Caldera and uplift in the area around Norris Geyser Basin, both at rates of a few centimeters (1-2 inches) per year (fig. 5). Caldera subsidence was a continuation of the trend that, except for a brief period of uplift in 2014-2015, has persisted since 2010. The latest episode of uplift near Norris Geyser Basin began in late 2015 to early 2016 and gradually slowed over time; by the end of 2018 any ongoing deformation there was near background levels.

In 2018, there were five borehole tiltmeters and four borehole strainmeters operational within Yellowstone National Park. These stations are most useful for detecting short-term changes in deformation (for example, owing to earthquakes or sudden fluid movements), because the instruments can drift over periods of weeks to months and show trends that are not related to deformation. The tiltmeter and strainmeter networks did not detect any meaningful changes during 2018.

A high-precision gravity survey was performed in 2018 to repeat and compare results with similar surveys in 2017. No noteworthy changes were detected.

${ }^{2}$ In this report, we use GPS as a general and more familiar term for Global Navigation Satellite Systems (GNSS), even though GPS specifically refers to the Global Positioning System operated by the United States.

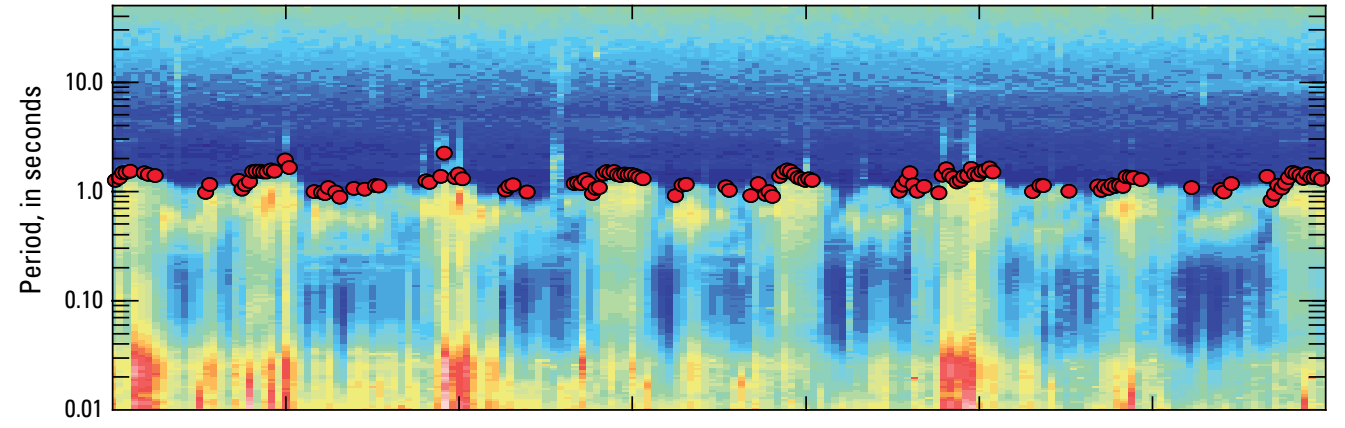

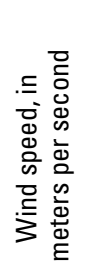
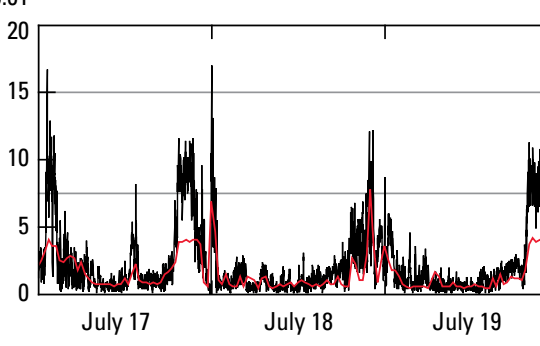

July 18

July 19
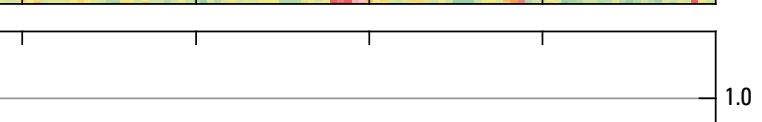

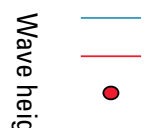

XPLANATION
Power, in decibels
-80
-90
-100
-110
-120
-130
-140

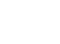
Wave height

Dominant period of the waves

Figure 4. Top, Spectrogram from a nodal seismic station recorded during the week of July 17-23 during the 2018 Yellowstone Lake deployment. Bottom, Plots of wind speed (black line) and wave height (red line) from a nearby weather station and wave gauge. The daily microseism, indicated by warm colors (a power of $\sim 110$ decibels) at a period of $\sim 1$ second, is correlated to increased wind speed and wave height. Similarly, the dominant period of the waves (red circles) is correlated to the dominant period of the microseism. 
Subtle changes to the shape of a volcano's surface, called deformation, can manifest as swelling, sinking, or cracking. This deformation can be caused by the accumulation, withdrawal, or migration of magma, gas, or other fluids (typically water) beneath the ground, or by movements in Earth's crust owing to motion along faults. Typically, this deformation is very small in magnitude - a few centimeters (inches) or less - and so can only be detected and monitored using very sensitive instruments. Changes in the amount of material beneath the ground also result in variations in gravity at the surface. Combining measurements of gravity change with deformation can help to reveal the type of fluid that is accumulating or withdrawing - for instance, magma versus gas.

By measuring the pattern and style of surface deformation, it is possible to determine the location of subsurface fluid storage areas. For example, as magma or water accumulates in a reservoir below ground, the surface above will swell. The pattern of this surface inflation can be used to identify the depth of fluid accumulation, and the scale of the deformation can provide information on how much and what type of fluid is accumulating. By monitoring changes in deformation over time, it is possible to assess how magma, water, and gas are moving in the subsurface. The technique is an important tool for forecasting potential future eruptions. In the days, months, and years before a volcanic eruption, many volcanoes inflate as magma accumulates underground. Rapid changes in deformation may be a sign that magma is ascending towards the surface. Yellowstone Caldera presents a complicated situation because deformation may be caused by magma, water, or gas.

A variety of instruments help to monitor ground deformation in the Yellowstone region. UNAVCO, a non-profit consortium funded by the National Science Foundation, operates and maintains a network of Global Positioning System (GPS) instrumentation, as well as borehole strainmeters and tiltmeters. Borehole strainmeters and tiltmeters are designed to detect very small changes in deformation style especially over short time intervals (even down to minutes), but they tend to drift over days to weeks so cannot track longterm ground deformation. This is where GPS, the backbone of the Yellowstone Caldera deformation monitoring network, comes into play. There are 15 continuously recording GPS stations within Yellowstone National Park and many more in the surrounding region. Data from these sites, as well as temporary deployments of GPS stations ("semipermanent GPS"), are employed to precisely record the horizontal and vertical positions of fixed points at the surface. Variation in the positions over time, relative to the rest of the North American continent, gives an indication of how the ground in the Yellowstone region deforms owing to local processes, such as subsurface fluid accumulation and withdrawal, and faulting caused by earthquakes. Data from continuous GPS stations in the Yellowstone region are transmitted via radio and satellite links to UNAVCO's archives, where they are made publicly available at https://www. unavco.org/data/dai/.

YVO scientists use satellite measurements, called interferometric synthetic aperture radar (InSAR), to take a broad snapshot of deformation. Two radar images of the same area that were collected at different times from similar vantage points in space are compared against each other. Any movement of the ground surface toward or away from the satellite is measured and portrayed as a "picture"- not of the surface itself but of how much the surface moved during the time between images. Unlike visible or infrared light, radar waves penetrate most weather clouds and are equally effective in darkness, so, using InSAR, it is possible to track ground deformation even in bad weather and at night.
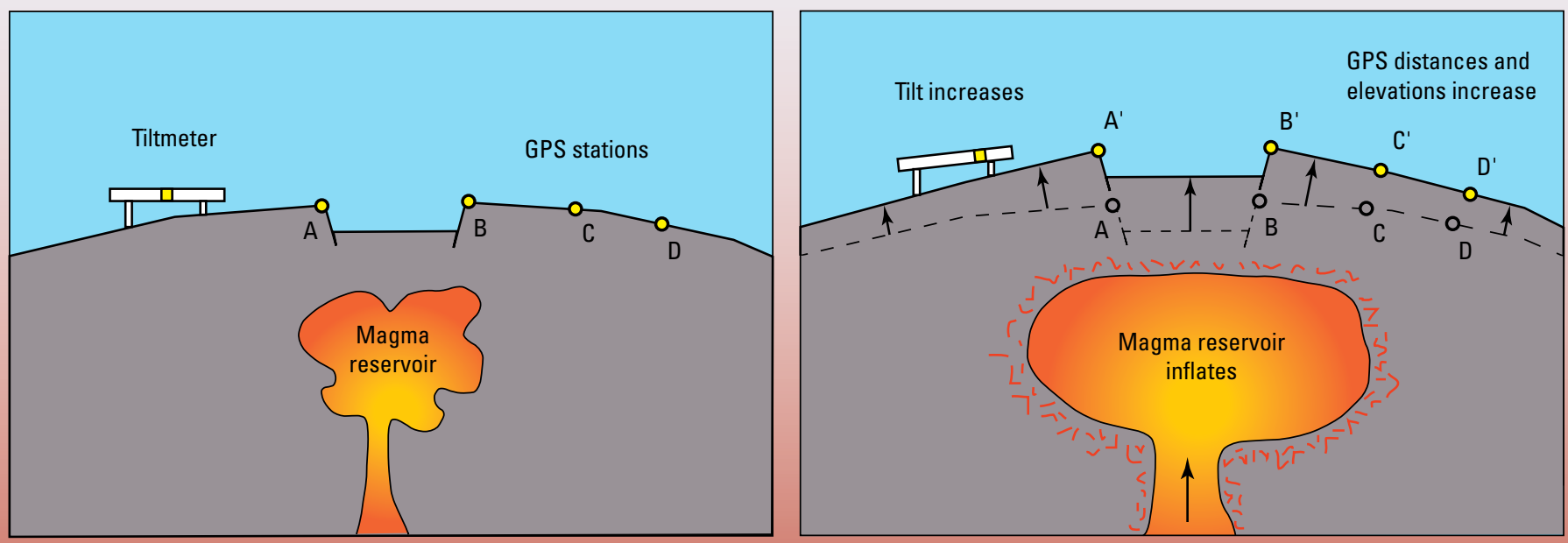
InSAR greatly extends scientists' ability to monitor volcanoes because, unlike other techniques that rely on measurements at a few points, InSAR produces a map of ground deformation that covers a very large area with centimeter-scale accuracy. This technique is especially useful at remote, difficult-to-access volcanoes and at locations where hazardous conditions prevent or limit ground-based volcano monitoring. However, unlike continuous GPS, which provides data all the time, InSAR data are only available once every few days or weeks - when one of several radar satellites is overhead.
Measurements of changes in Earth's gravity field are another means to study processes that occur underground, hidden from sight. When magma accumulates beneath the surface or a large amount of water is expelled from a geyser, for example, the redistribution of material causes subtle changes in the gravity field.

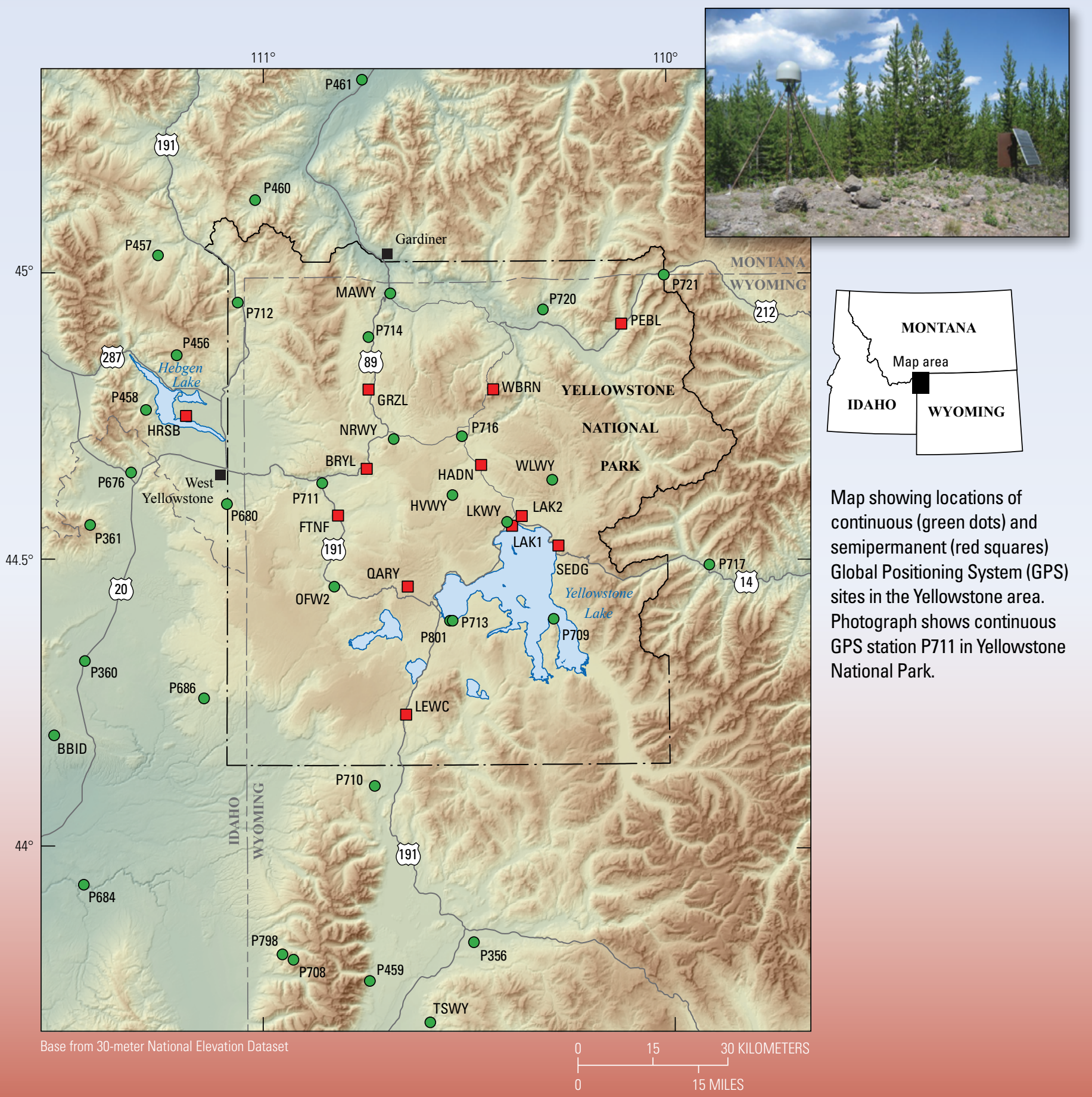




\section{Sidebar Monitoring Geodetic Change in Yellowstone}

The difference is miniscule, but gravity is stronger at the surface above areas of high mass than it is above less massive material. In a dynamic environment like Yellowstone, the distribution of mass can change over time. For example, gravity will increase if more magma accumulates in a shallow reservoir, or if porous rock fills with groundwater. Combining gravity measurements, which can record changes in subsurface mass, with deformation, which can indicate changes in subsurface volume, it is possible to calculate the density of the fluids that are driving the changes seen at the surface. High-density fluids are likely to be magma, whereas low-density fluids reflect the presence of water or gas.

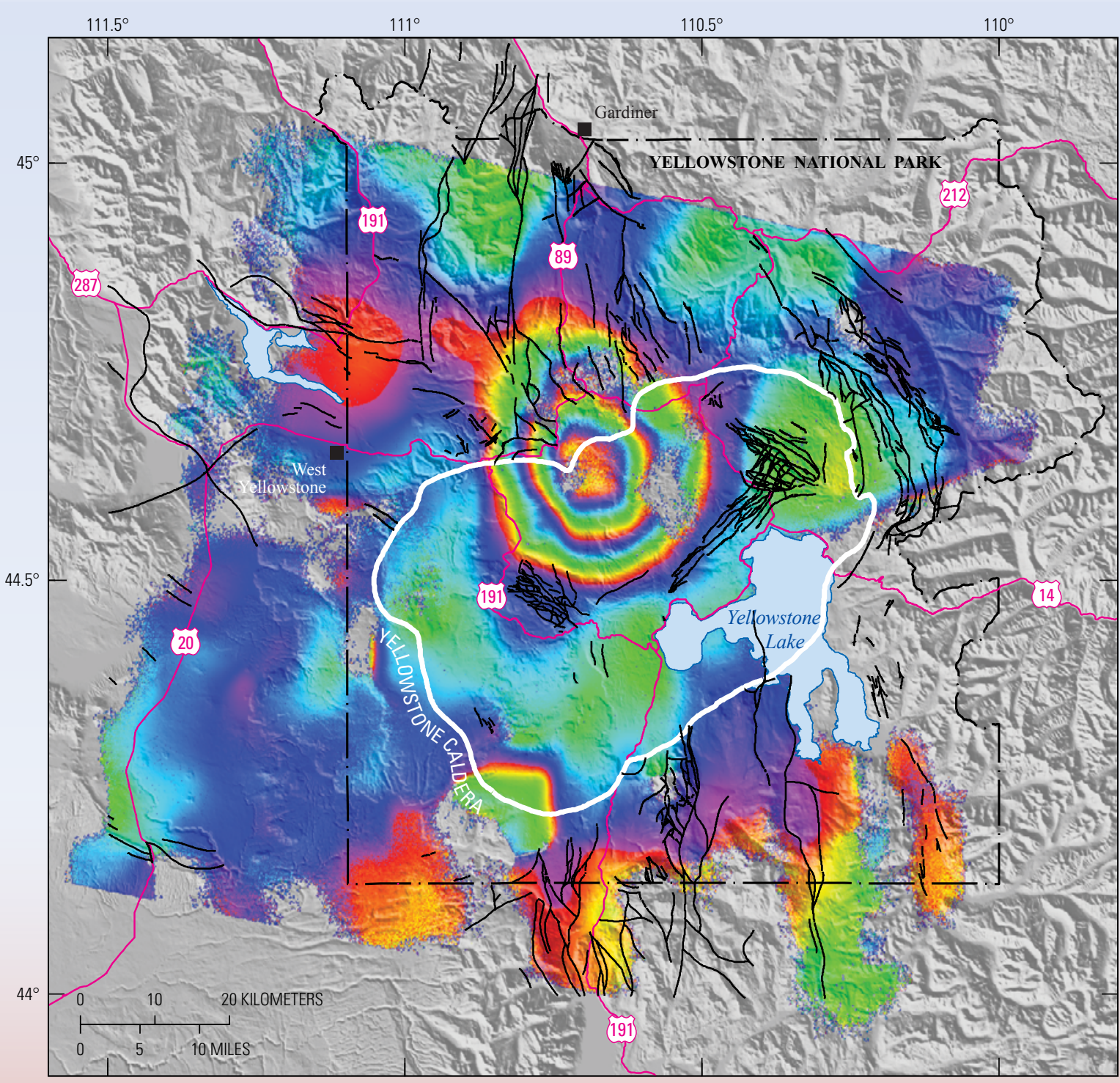

Base from 30-meter National Elevation Dataset

EXPLANATION

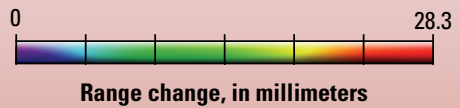

Fault

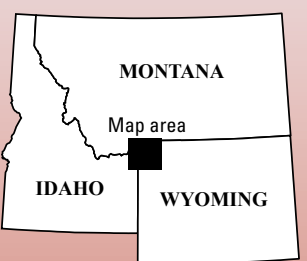

Map of past ground deformation in the Yellowstone region. This image was created using data from satellite passes in 1996 and 2000 . The image shows 125 millimeters (about 5 inches) of uplift centered near the north rim of Yellowstone Caldera, about 10 kilometers (6.2 miles) south of Norris Junction. Each full cycle of color (from red through green to purple) represents about 28 millimeters (1 inch) of surface movement toward or away from the satellite (mostly uplift or subsidence). Here, the bullseye centered along the north caldera rim near Norris Geyser Basin shows an area of uplift approximately 35×40 kilometers (22×25 miles) in size. Modified from U.S. Geological Survey Professional Paper 1788 (Dzurisin and others, 2012). 

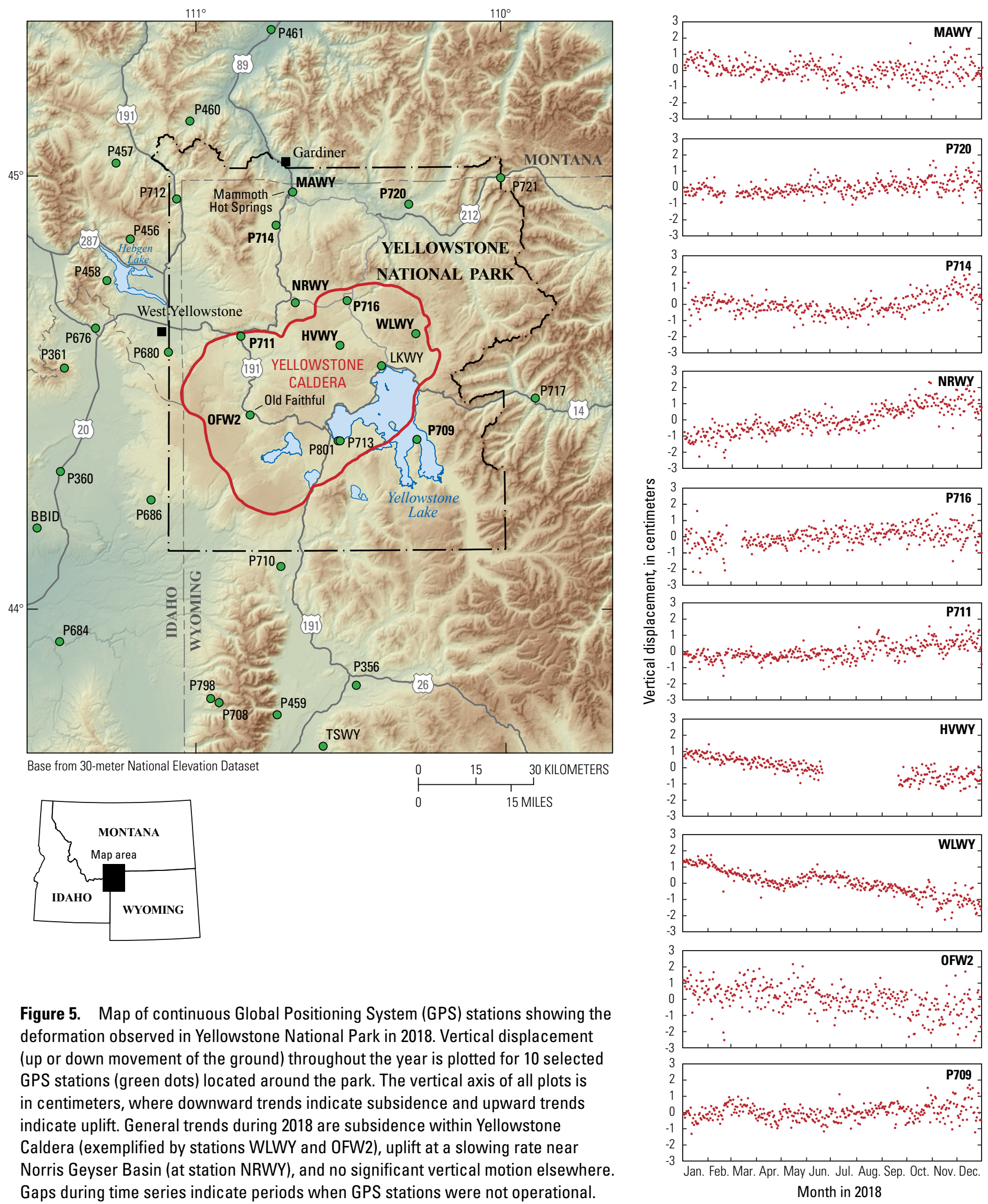

Figure 5. Map of continuous Global Positioning System (GPS) stations showing the deformation observed in Yellowstone National Park in 2018. Vertical displacement (up or down movement of the ground) throughout the year is plotted for 10 selected GPS stations (green dots) located around the park. The vertical axis of all plots is in centimeters, where downward trends indicate subsidence and upward trends indicate uplift. General trends during 2018 are subsidence within Yellowstone Caldera (exemplified by stations WLWY and OFW2), uplift at a slowing rate near Norris Geyser Basin (at station NRWY), and no significant vertical motion elsewhere. Gaps during time series indicate periods when GPS stations were not operational. 


\section{Continuous GPS Results in 2018}

Throughout 2018, surface deformation measured by 15 continuous GPS stations in Yellowstone National Park mostly followed trends established during previous years. Stations inside Yellowstone Caldera subsided at rates of a few centimeters per year, as they had since late 2015 or early 2016 (see stations OFW2, WLWY, and HVWY in fig. 5). After a brief episode of subsidence in early December 2017 during a multi-year period of net uplift that began in late 2015 to early 2016 (see the 2017 YVO annual report), the area around Norris Geyser Basin started rising again. An additional 2 centimeters (1 inch) of uplift occurred in 2018 at a rate that gradually declined to near zero by the end of the year (see station NRWY in fig. 5), bringing the total amount of uplift since $2015-16$ to about 8 centimeters. Station coordinates and daily time-series plots for Yellowstone continuous GPS stations are available at https://earthquake.usgs. gov/monitoring/gps/YellowstoneContin.

\section{Semipermanent GPS Results}

In 2018, the Yellowstone Semipermanent GPS network comprised 11 stations in the park and one in the adjacent Hebgen Lake Ranger District of Gallatin National Forest (fig. 6). Eleven of these temporary stations were deployed in early May; snow cover prevented installation of a station on

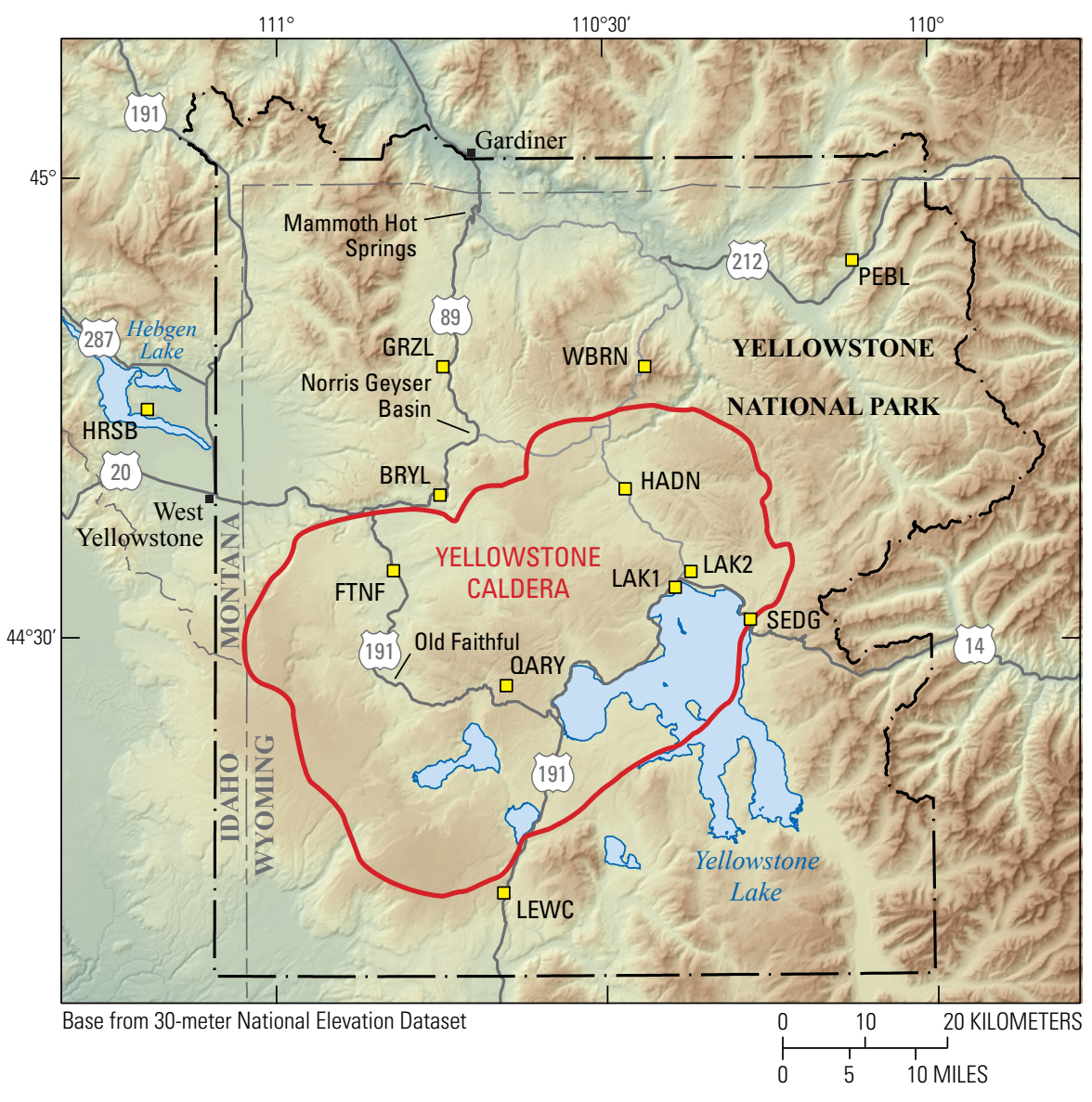

Figure 6. Map of semipermanent Global Positioning System (GPS) stations showing the deformation observed in Yellowstone National Park during 2017 and 2018. Vertical displacement (up or down movement of the ground) throughout the year is plotted for 10 selected semipermanent GPS stations (yellow squares on map) located around the park. The distance between tick marks is 5 centimeters. Downward trends indicate subsidence and upward trends indicate uplift. General trends during 2017 and 2018 are subsidence within Yellowstone Caldera (exemplified by stations FTNF and HADN), uplift at a slowing rate near Norris Geyser Basin (stations BYRL and GRZL), variable deformation near Yellowstone Lake (stations LAK1, LAK2, and SEDG), and no significant vertical motion elsewhere. Gaps during time series indicate periods when semipermanent GPS stations were not deployed during winter months.

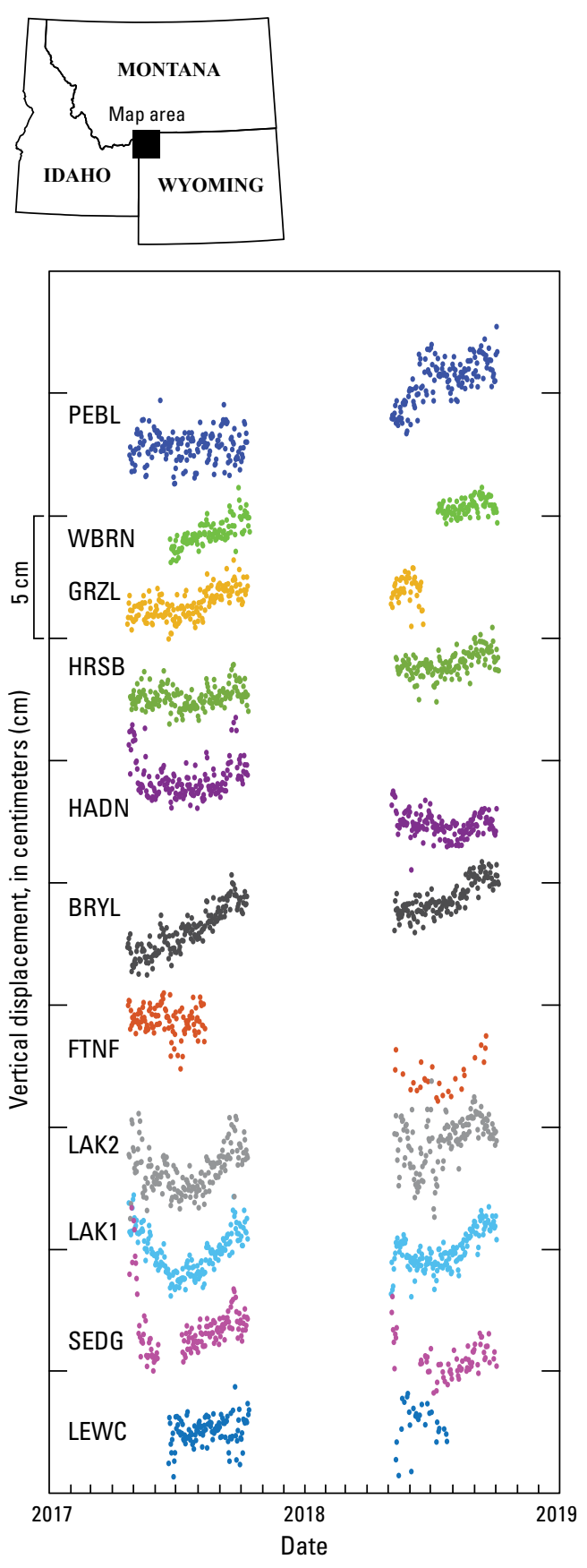


Mount Washburn until mid-July. All 12 stations were removed in early October, and all recorded at least 27 days of useful data; 7 recorded data for the entire time they were deployed (146-151 days). The remaining 5 stations had incomplete data records because of animal disturbance or equipment failure.

Overall, the success rate (actual data days divided by possible data days) was about 71 percent. This is low compared to previous years, when the success rate was typically about 90 percent. Above average loss owing to animal disturbance was the primary cause - a problem that will likely persist at some level regardless of mitigation strategies that are attempted.

The semipermanent GPS technique has both advantages and disadvantages compared to continuous GPS. Semipermanent GPS stations are less expensive, less intrusive on the landscape, and portable enough to be deployed in areas that might be off limits to a continuous GPS installation. When the semipermanent GPS station is not deployed, all that remains is a small steel pin attached to rock that serves as a benchmark. A clear disadvantage of semipermanent GPS compared to continuous GPS is that semipermanent GPS data are intermittent whereas continuous GPS data are collected year round. Also, semipermanent GPS data are not telemetered and so are available only after the stations have been retrieved in the fall. Together, however, the two approaches complement one another by providing precise ground deformation data from 28 sites (in 2018) in and around Yellowstone National Park. This large number of stations is necessary to adequately characterize complex deformation patterns at Yellowstone, which can change rapidly.

Station coordinates and daily time-series plots for Yellowstone semipermanent GPS stations are available at https:// earthquake.usgs.gov/monitoring/gps/Yellowstone_SPGPS. Results for 2018 are consistent with those from the continuous GPS network and show that previously established trends continued. Relative to their positions in 2017, stations inside the caldera (FTNF, HADN, and QARY) moved down and stations close to Norris Geyser Basin (BRYL and GRZL) moved up. Stations near Yellowstone Lake (LAK1, LAK2, and SEDG) responded to seasonal lake level changes by moving down when the level was rising (May-June) and up when it was falling (JulyOctober) - a response of the crust to the changing load of water in the lake (see the 2017 YVO annual report). Stations farther from the caldera and Norris Geyser Basin (HRSB, LEWC, PEBL, and WBRN) showed little or no year-to-year movement.

\section{Interferometric Synthetic Aperture Radar (InSAR) Results}

Satellite InSAR uses data from orbiting satellites to map ground deformation by comparing satellite-to-ground distances at different times. Resulting images are called interferograms and show how much the surface moved during the time between satellite observations, along with uncertainty introduced by atmospheric variations. Surface movements from InSAR are less precise than those from GPS, but InSAR has two big advantages. First, whereas GPS measures changes at specific points, InSAR shows the entire pattern of surface deformation as a spatially continuous image. Second, InSAR does not require access or installations in the study area; observations are made remotely with no impact on the landscape or environment. When deformation is rapid, a disadvantage is that current InSAR satellites have repeat times measured in days, whereas GPS data are continuous. Another disadvantage is that, in the Yellowstone region, InSAR data are not usable during winter months because most of the surface is covered with snow. The best InSAR images typically span one or more years, with observations in summer or fall when the surface is mostly free of snow.

Radar interferograms spanning 2018 reveal a deformation pattern consistent with that indicated by GPS observationssubsidence of the caldera and uplift of the area around Norris Geyser Basin (fig. 7).

\section{Gravity Survey}

High-precision gravity measurements have been collected in Yellowstone National Park since the 1970s. A subset of stations that cover the Norris Geyser Basin area as well as the Sour Creek and Mallard Lake resurgent domes in the caldera was occupied four times at 6-week intervals during 2017. The goal of the 2017 work was to assess whether or not seasonal variations were major sources of gravity change at Yellowstone; results indicated that seasonal changes were of the same order as measurement uncertainty. The work was also useful in identifying the most stable gravity monitoring sites, and these stations have become the main survey points since the 2017 measurements. Annual repeat surveys of these stations are intended to look for long-term changes associated with magmatic or hydrothermal activity. The 2018 survey (fig. 8) identified no significant changes relative to data collected in 2017.

\section{Yellowstone Lake Gage Results}

Prior to 2017, the water level in Yellowstone Lake was determined by intermittent measurements or inferred from a streamgage at the lake's outlet near Fishing Bridge. In 2017, a pressure-depth gage was installed at the Grant Village dock (see the 2017 YVO annual report), enabling lake-level measurements at 1-minute intervals. Thus, 2018 was the first full year of lake level measurements, and they showed normal spring and early summer lake level increases owing to snowmelt influx, and then late summer to early fall decreases (fig. 9). The overall variations were about 1.5 meters ( 5 feet).

As observed previously, a seiche was measured more or less continuously over the year (fig. 9 inset). Seiches are standing waves that cause short-term variations in the surface level of Yellowstone Lake, thus far observed to range from a few centimeters to 15 centimeters (peak-to-peak) during storms or atmospheric events. They are too subtle and slow to be noticed by the human eye but change the distribution of water in the lake over time. Deformation patterns recorded by borehole strainmeters throughout Yellowstone National Park reveal the 


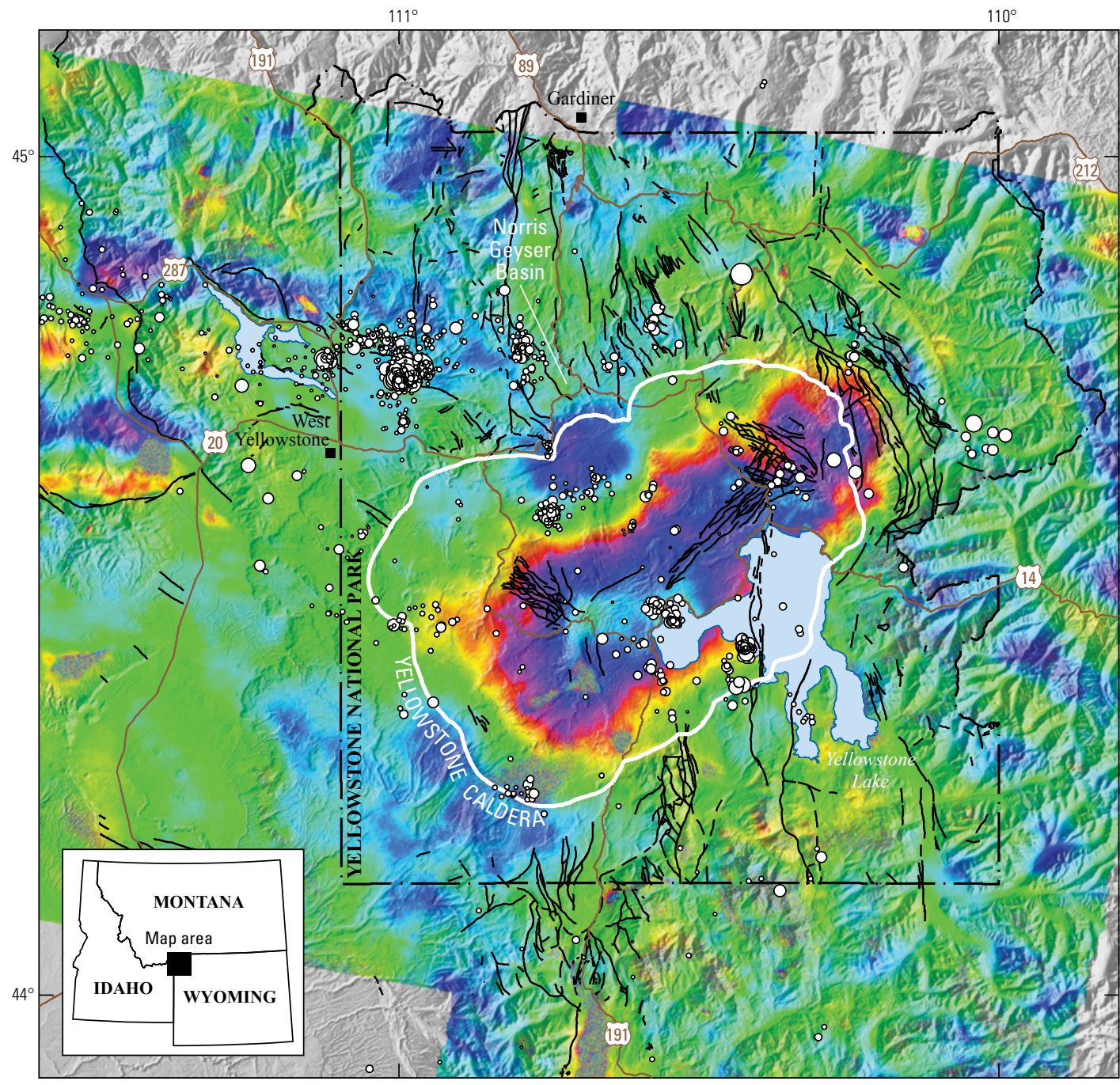

\section{EXPLANATION}

Earthquake magnitude

- 0

$\circ 1$

○ 2

3

Range change,

in millimeters

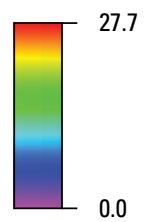

0.0

Fault

Base from 30-meter National Elevation Dataset

Figure 7. Interferogram created from data collected on October 20, 2017, and September 21, 2018, by the Sentinel-1 satellite system. Colored fringes indicate a change in distance (called range change) between the satellite and ground surface that is caused by surface deformation. In this interferogram, the fringes indicate subsidence (an increase in the range between the ground and the satellite) of Yellowstone Caldera and uplift (a decrease in the range between the ground and the satellite) in the area of Norris Geyser Basin during the time period spanned by the images. White circles show earthquakes that occurred during that time. Circle size scales with magnitude; the largest is about magnitude 3.

presence of these seiches and have been used to provide insights into the structure of the subsurface- for example, the depth and viscosity of the magma reservoir beneath Yellowstone Caldera.

\section{Geochemistry}

Geochemical studies of Yellowstone's diverse and dynamic thermal features are aimed at better understanding the interface between its hydrothermal and magmatic systems, with the ultimate goal of investigating processes that are hidden from direct observation (see sidebar on geochemical monitoring on p. 18).

Thermal features provide a window into Yellowstone's depths, and geochemistry is a powerful tool for illuminating those depths.

\section{Summary of Geochemistry Activities in 2018}

In 2018, YVO scientists surveyed geothermal gas and heat emissions and made continuous measurements of gas emissions in selected areas, sampled gases and thermal waters for analysis, and explored remote thermal features along Bechler River in the southwest corner of Yellowstone National Park. Soil $\mathrm{CO}_{2}$ flux and temperature surveys were conducted in the so-called Bison Flat area of Norris Geyser Basin (about 200 meters southwest of the bridge over the Gibbon River north of Norris Geyser Basin), and an eddy covariance system was installed there to make continuous measurements of $\mathrm{CO}_{2}, \mathrm{H}_{2} \mathrm{O}$, and heat fluxes. Water and gas samples were collected, and chloride flux was measured at several locations in the Bechler River area. 

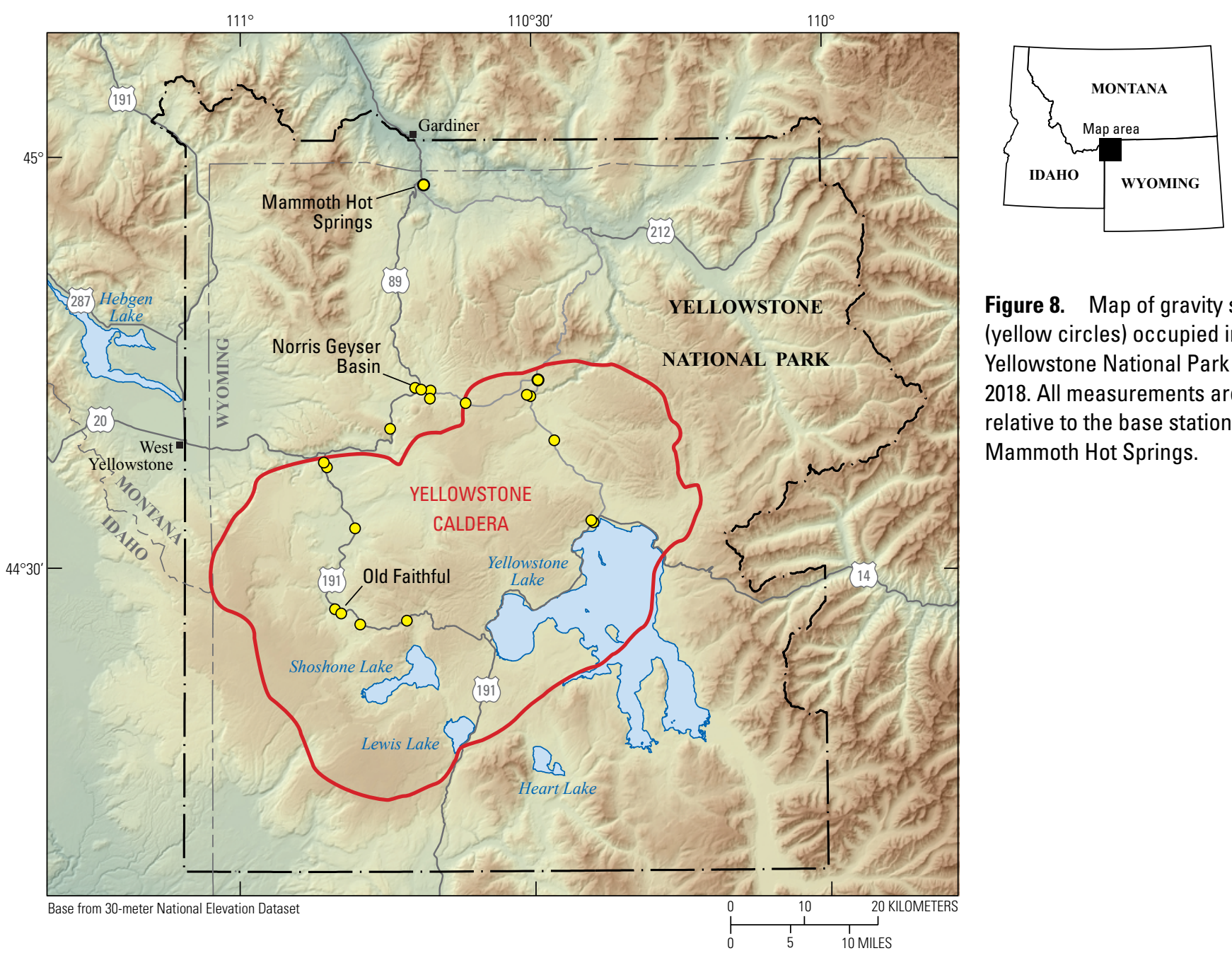

Figure 8. Map of gravity stations (yellow circles) occupied in Yellowstone National Park during 2018. All measurements are relative to the base station near Mammoth Hot Springs.

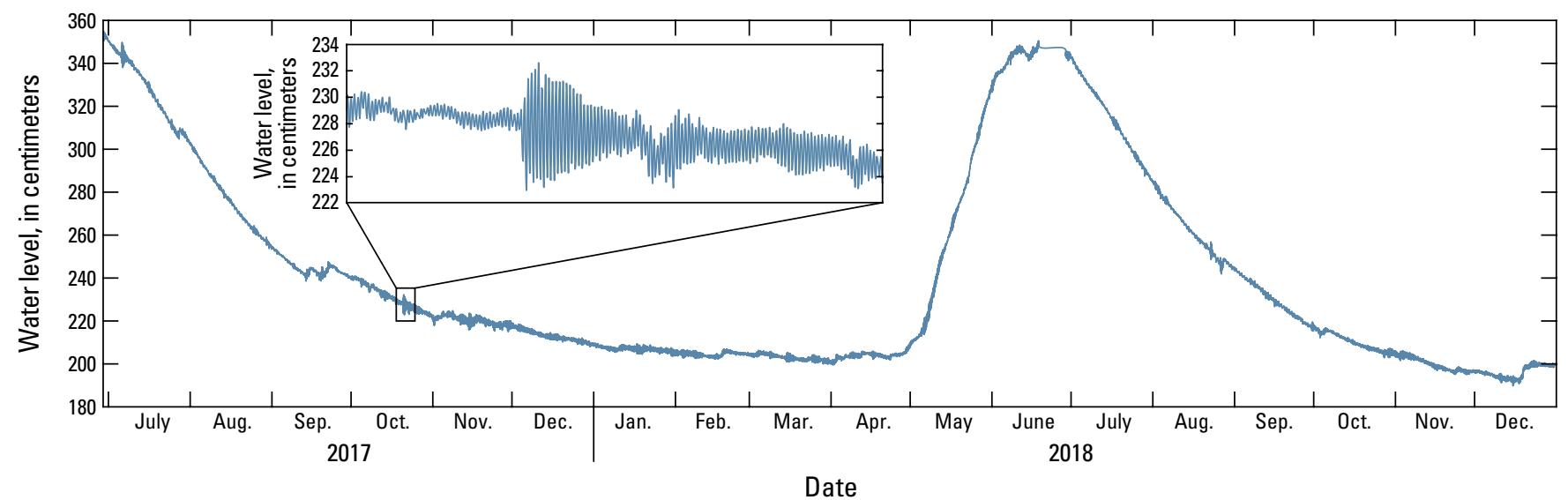

Figure 9. Plot of Yellowstone Lake level from July 2017 to December 2018 recorded by a gage located at the Grant Village boat dock. Overall variations are related to snowmelt influx (spring) and water outflux (summer to fall), whereas minor variations (inset, spanning October 18-26, 2017) show seiche waves of a few centimeters in height that occurred throughout the period.

\section{Gas and Heat Emissions}

After last year's study of gas and heat emissions at the Solfatara Plateau thermal area (see the 2017 YVO annual report), a similar study began in July 2018 at the Bison Flat area of Norris Geyser Basin. The primary objectives of this work were to (1) document background variations that occur in response to changes in temperature, precipitation, and barometric pressure 


\section{Sidebar Geochemical Monitoring in Yellowstone Caldera}

Deep beneath the surface, gasses are dissolved in magma, but as magma rises toward the surface the pressure decreases and gases separate from the liquid to form bubbles. Because gas is less dense than magma, the bubbles can rise more quickly and be detected at the surface of the Earth.

Similarly, water can also transport material up to the surface where it can be studied by scientists. Groundwater circulates deep within the Earth's crust in volcanic regions, where it can be heated by magma to over $200^{\circ} \mathrm{C}$ (around $400{ }^{\circ} \mathrm{F}$ ). This causes it to rise along fractures, bringing dissolved material up toward the surface. By studying the chemical makeup of this thermal water, scientists can gain a better picture of the conditions deep within a volcano.

In Yellowstone Caldera, volcanic gas emissions are usually sampled by hand directly from fumaroles (gas vents), although some temporary automated measurements of certain types of gases have been employed. Likewise, measurements of water chemistry are typically done by collecting samples and analyzing the chemical makeup of the water in the laboratory.

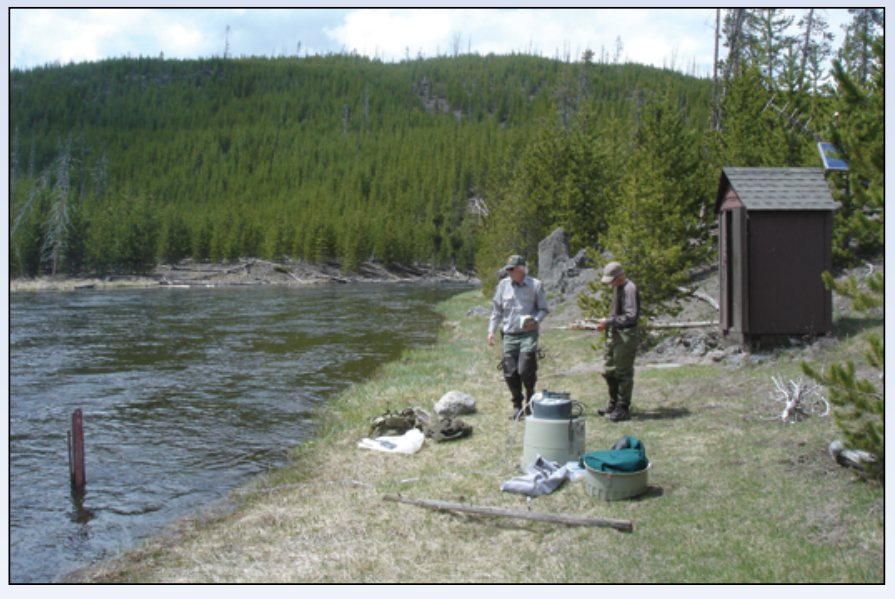

Scientists collect water samples from the Firehole River in Yellowstone National Park. U.S. Geological Survey photograph by Jim Ball, 2014. on daily to seasonal time scales, and (2) detect any anomalous changes that might occur during periods of unrest.

Soil $\mathrm{CO}_{2}$ flux and temperature at 30 centimeters (12 inches) depth were measured at equally spaced intervals on a grid across the study area. Figure 10 shows maps of the results based on measurements made at the black dots on July 11-12, 2018. Integrating soil $\mathrm{CO}_{2}$ flux over the study area (0.04 square kilometers) yielded a total $\mathrm{CO}_{2}$ emission rate of 2.4 metric tons per day-substantially lower than that determined for the same area in October 2016, which was 9.8 metric tons per day (Lewicki and others, 2017).

\section{Eddy Covariance System}

In July 2018, an eddy covariance system was deployed in the Bison Flat area adjacent to an area of high soil $\mathrm{CO}_{2}$ flux and temperature (see fig. 10). Eddy covariance is a meteorological technique that measures the turbulent flux of $\mathrm{CO}_{2}, \mathrm{H}_{2} \mathrm{O}$, and heat emitted from ground areas (on the order of tens of hectares in scale, in the Yellowstone case) upwind of the sensors. For the remainder of the year, winds were dominantly from the southwest or east, so the eddy covariance system was well situated downwind of the area of high soil $\mathrm{CO}_{2}$ flux and temperature.

Half-hourly measurements of eddy covariance $\mathrm{CO}_{2}$ flux are plotted versus wind direction in figure $11 \mathrm{~A}$ and were relatively high when wind was from the southwest, such that the sensor was directly downwind of several steam vents. Whereas eddy covariance $\mathrm{CO}_{2}$ fluxes were highly variable on a half-hourly basis, the seasonally smoothed data, constructed using a 90-day window, was stable at around 180 grams per square meter per day (fig. 11B). These measurements provide useful background information against which future measurements can be compared.

\section{Water and Gas Sampling}

In July and September, scientists from the USGS and the National Park Service sampled gases and waters at four thermal areas in the southwest corner of Yellowstone National Park. These thermal areas are around Lewis Lake, the Three Forks area of the Bechler River, Bechler Meadows, upper Snake River, and Phantom Fumarole (fig. 12). Additionally, measurements of chloride flux were made upstream and downstream from some of the thermal areas along Bechler River and Mountain Ash Creek. Field observations were augmented with satellite-derived thermal infrared images.

Most of the hot springs and fumaroles in the study area are within the 2.1-million-year-old Huckleberry Ridge Caldera, and outside the inferred structural boundary of the 631,000-year-old Yellowstone Caldera. The area is characterized by different rock types, including some of the youngest rhyolites in the Yellowstone Plateau volcanic field. Thermal areas in the Bechler River drainage mostly occur along the edges of rhyolite flows. Springs along Spirea and Crawfish Creeks occur where Lava Creek Tuff and the Lewis Canyon lava flow are juxtaposed, separated by north-trending faults. Thermal areas on the Snake River are adjacent to outcrops of Paleozoic limestones, and the springs deposit travertine. Phantom Fumarole, at the top of the Pitchstone Plateau at an elevation of about 2,600 meters $(8,530$ feet), vigorously discharges steam and gas at a temperature of about 137 degrees Celsius $\left({ }^{\circ} \mathrm{C}\right.$ ) (about $280^{\circ} \mathrm{F}$ ), making it one of the hottest ever measured in Yellowstone.

All data acquired in this study are available as USGS data releases for spring water chemistry and isotopic composition (McCleskey and others, 2019) and gas chemistry and isotopic compositions (Bergfeld and others, 2019), or via USGS Earth Explorer (earthexplorer.usgs.gov) for satellite thermal infrared data (Vaughan and others, 2014). 

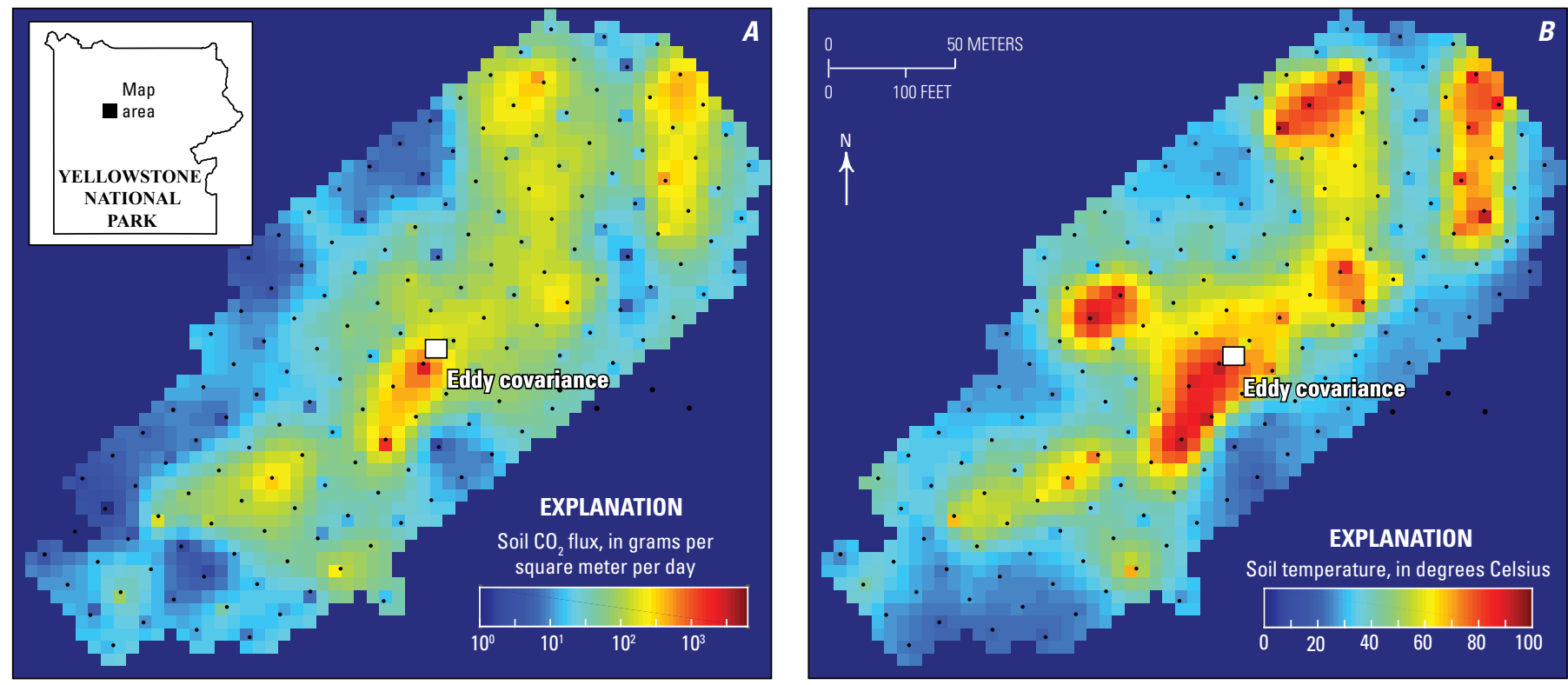

Figure 10. Maps of log soil $\mathrm{CO}_{2}$ flux $(A)$ and soil temperature at 30 centimeters (1 foot) depth $(B)$ at the so-called Bison Flat study area of Norris Geyser Basin, simulated from measurements made at locations marked by the black dots. White squares show the location of an eddy covariance station.
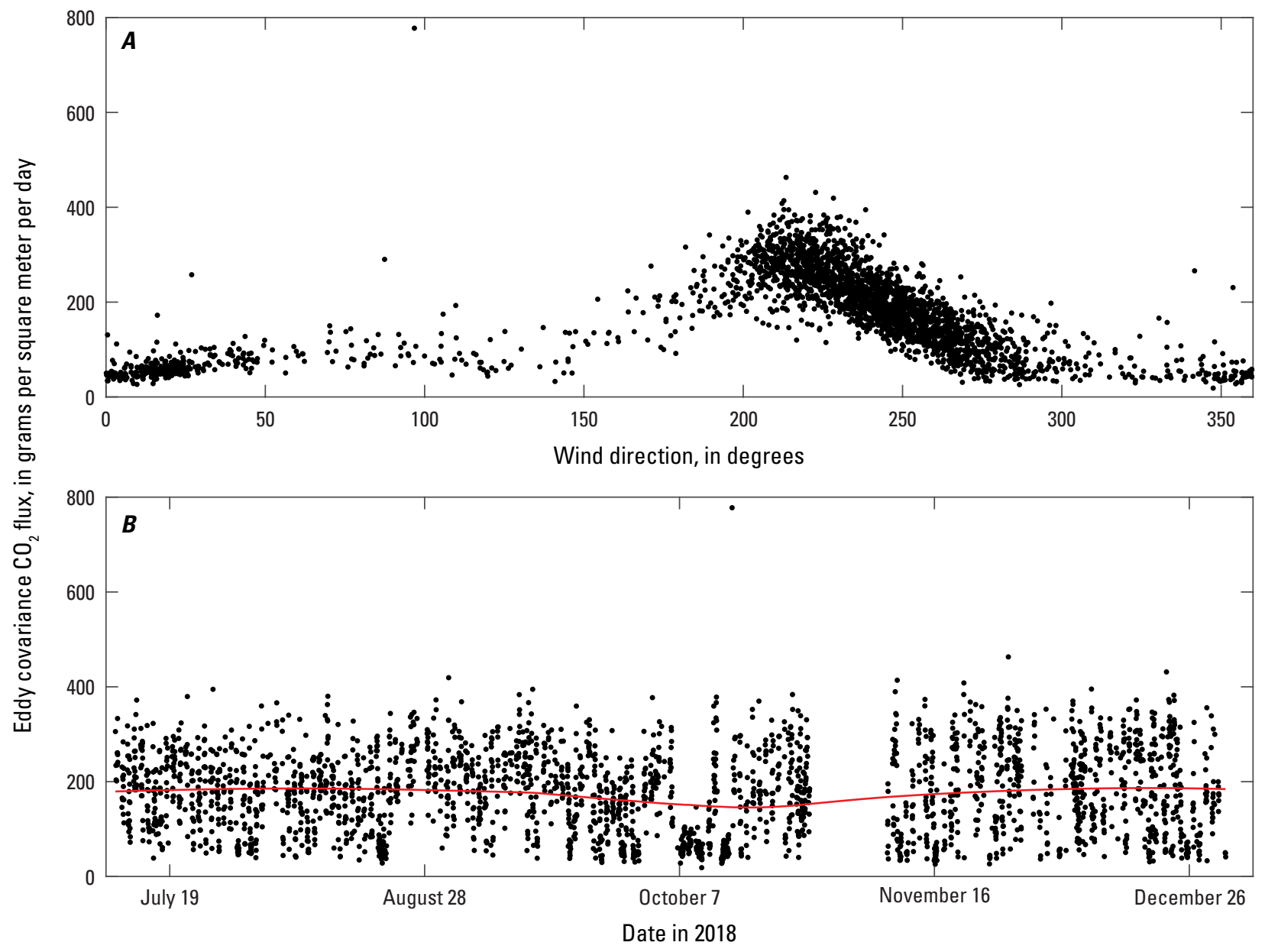

Figure 11. Plots of eddy covariance $\mathrm{CO}_{2}$ flux versus wind direction $(A)$ and time $(B)$. The measured flux is highest when wind is from the southwest ( 225 degrees), which places the sensor downwind of an area of high soil $\mathrm{CO}_{2}$ flux and temperature (see fig. 10). The large variation in individual time-series measurements reflects mostly short-term changes in wind direction. Red line is smoothed data using a 90-day (seasonal) window and is nearly constant at a presumed background level. 

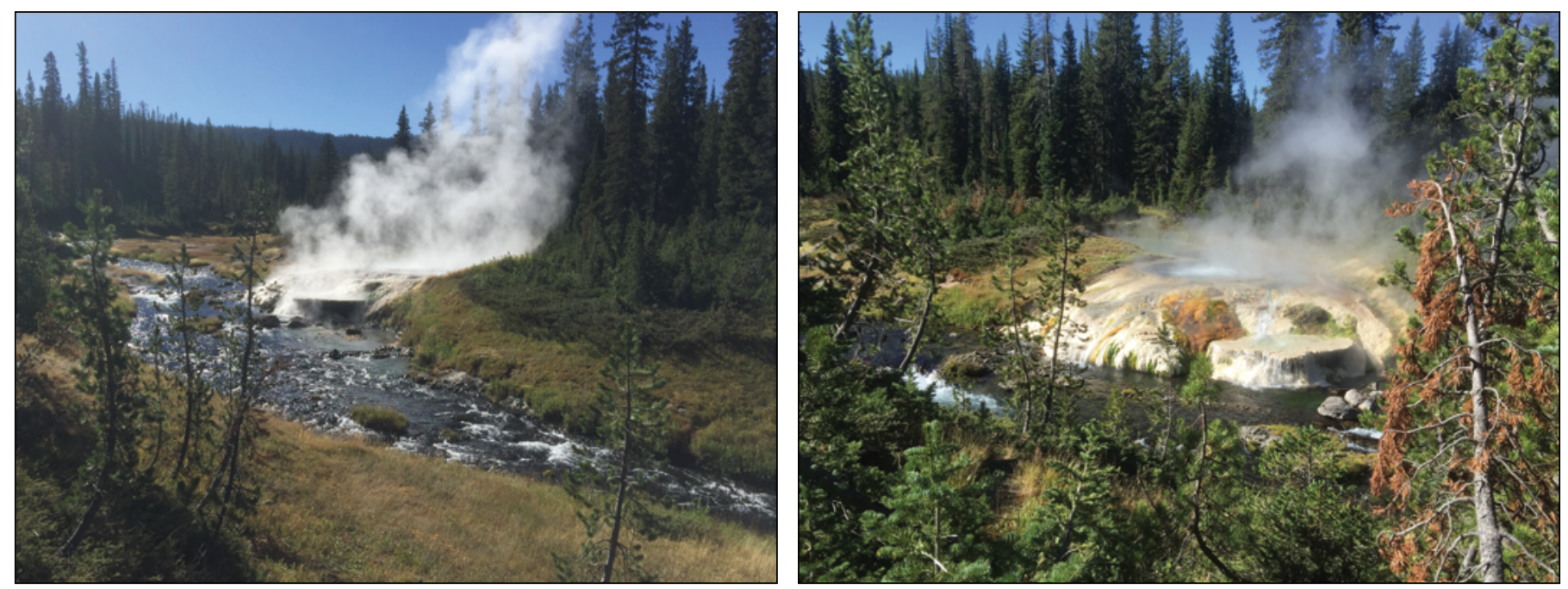

Figure 12. Photographs of a pool that has alkaline water depositing silica sinter along the Ferris Fork of the Bechler River. U.S. Geological Survey photographs by Shaul Hurwitz on September 17, 2018.

The main conclusions derived from the 2018 field work are as follows.

1. The chemical and isotopic composition of thermal waters and gases in southwest Yellowstone National Park reflect the diverse rock compositions through which groundwater flow occurred, the temperatures in which groundwater and rocks equilibrated, the amount of magmatic, crustal, biogenic, and meteoric gases dissolved in deep circulating groundwater, the degree of mixing between thermal and non-thermal groundwater end members, and the topographic position of discharge.

2. Similar to most thermal springs within the Yellowstone Caldera, most thermal springs in southwest Yellowstone National Park (outside the caldera) discharge at or near rhyolite flow terminations. Exceptions include Phantom Fumarole (in the center of the Pitchstone Plateau rhyolite flow), the springs along the upper Snake River, possibly the springs at Spirea Creek that discharge along an area of north-trending faults that separate a rhyolite flow from Lava Creek Tuff, and the springs at Bechler Meadow that discharge near basalt outcrops. The springs west of Lewis Lake discharge at higher topographic elevation and are therefore vapor dominated with acid-sulfate alteration.

3. The lack of upper crustal magma in southwest Yellowstone National Park (based on geophysical imaging) suggests that heat discharge by springs and fumaroles originates from within the Yellowstone Caldera. Heat and gases are then advected laterally, mainly along the base of rhyolite flows across the inferred Yellowstone Caldera boundaries.

4. Gas compositions of samples collected in the upper Bechler River area resemble gas from locations in other parts of the Yellowstone Caldera that highlight mixing between helium-rich and air-saturated meteoric water end members. The helium isotope ratios are similar to the ratios in gases from the Yellowstone Caldera and have magmatic values. In contrast, the very low ratio of the helium-3 to helium-4 isotopes when corrected for atmospheric helium (0.73) of gas in a vent near Phantom Fumarole at the top of Pitchstone Plateau suggests significant addition of crustalderived helium.

5. The waters are of meteoric origin and the hydrogen $(\delta \mathrm{D})$ and oxygen $\left(\delta^{18} \mathrm{O}\right)$ stable-isotope compositions of nearly all samples are within 1.5 per mil of the Global Meteoric Water Line, which is considerably less than the difference for most thermal water samples from Yellowstone's geyser basins.

6. Samples from the upper Bechler River and Spirea Creek have isotopic compositions that plot along a line connecting a non-thermal end member with a thermal water end member that equilibrated at $160-170^{\circ} \mathrm{C}$. These equilibrium temperatures are lower than the calculated temperatures in the Upper Geyser Basin $\left(200 \pm 15^{\circ} \mathrm{C}\right)$ and Heart Lake Geyser Basin $\left(205 \pm 10^{\circ} \mathrm{C}\right)$.

In addition to the water samples collected from southwest Yellowstone National Park, four were collected from the hillside north of Nymph Lake, six from Norris Geyser Basin, and three from Gibbon Geyser Basin. The water samples were analyzed for major and trace elements, anions, and arsenic and sulfur redox species. Samples have been collected from these sites for 8 years to monitor changes in chemistry and to support investigations of microbial populations.

\section{Geology}

Geologic research at Yellowstone National Park is focused on interpreting the rock record as a means of better understanding the conditions that preceded and accompanied past eruptions. The primary tools for this work include mapping 
rock compositions and structures and determining the ages of specific rock units. This work established the foundation for understanding eruptions in the Yellowstone area (see sidebar on the geology of Yellowstone Plateau on p. 22-23) and continues to be refined as new analytical tools become available.

\section{Summary of Geology Activities in 2018}

Geologic research in 2018 included precise dating of lava flows in Yellowstone Caldera and continuation of the Hydrothermal Dynamics of Yellowstone Lake (HD-YLAKE) project to explore the geology and hydrothermal features of Yellowstone Lake. Preliminary results indicate that the postcaldera lava-flow eruptions were clustered in time during five discrete episodes - a finding similar to that for flows and domes erupted after the previous caldera-forming eruption 1.3 million years ago (see the 2017 YVO annual report). The focus of HD-YLAKE activities shifted from the area known as "Deep Hole" in 2016 and 2017 to the West Thumb basin area in 2018.

\section{Dating Post-caldera Volcanism at Yellowstone}

The most recent episode of rhyolite volcanism within the Yellowstone Plateau volcanic field occurred from about 170,000 to 70,000 years ago, producing the Central Plateau Member rhyolites. These consist of more than 20 rhyolite eruptions that issued from two approximately 40-kilometerlong, northwest-southeast-aligned, structurally controlled vent zones located within the present-day Yellowstone Caldera (fig. 13). In total, more than 350 cubic kilometers of rhyolite erupted during this timeframe.

Geochronology for the Central Plateau Member rhyolites reported in prior studies constrains the general timing of eruptions during this episode but lacks the precision to constrain individual episodes of volcanism. For example, the large uncertainties on eruption ages estimated in prior studies hamper our ability to assess whether eruptions during this volcanic episode were clustered in time, such that multiple eruptions occurred over a short time interval, as is observed in older intra-caldera

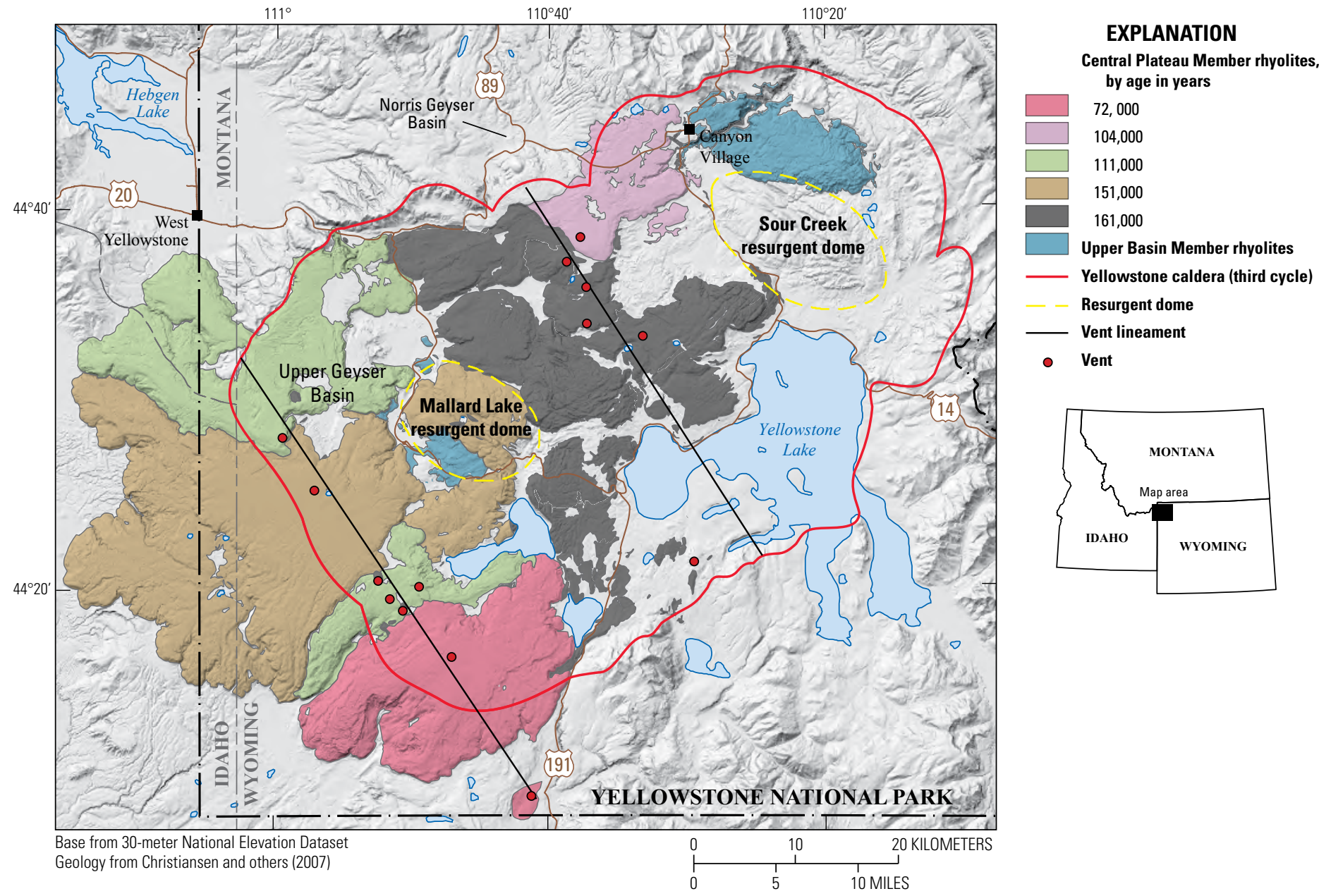

Figure 13. Shaded-relief map of Yellowstone Caldera showing the age and location of intra-caldera rhyolites that erupted after the Lava Creek Tuff. The Upper Basin Member rhyolites are the first episode of post-Lava Creek Tuff volcanism, occurring from approximately 630,000 to 255,000 years ago. The Central Plateau Member rhyolites erupted in a second episode and are shown by eruption age estimated via recent high-precision ${ }^{40} \mathrm{Ar} /{ }^{39} \mathrm{Ar}$ dating. The Central Plateau Member rhyolites erupted from structurally controlled vent zones. 


\section{Sidebar The Geology of Yellowstone Plateau}

The Yellowstone Plateau volcanic field developed through three volcanic cycles that span more than 2 million years and include two of the world's largest known eruptions. About 2.1 million years ago, eruption of the Huckleberry Ridge Tuff produced more than 2,450 cubic kilometers (588 cubic miles) of volcanic depositsenough material to cover the entire state of Wyoming in a layer 10 meters (30 feet) thick - and created the large, approximately 75 kilometer (47 mile) wide, Huckleberry Ridge Caldera.

A second cycle concluded with the eruption of the much smaller Mesa Falls Tuff around 1.3 million years ago and resulted in formation of the Henrys Fork Caldera. Activity subsequently shifted to the present Yellowstone Plateau and culminated 631,000 years ago with the eruption of the $>1,000$ cubic kilometer ( 240 cubic mile) Lava Creek Tuff and consequent formation of the $45 \times 85$ kilometer $(28 \times 53$ mile $)$ Yellowstone Caldera.
The three extraordinarily large explosive eruptions in the past 2.1 million years each created a giant caldera and spread enormous volumes of hot, fragmented volcanic rocks as pyroclastic flows over vast areas. The accumulated hot ash, pumice, and other rock fragments welded together from their heat and the weight of overlying material to form extensive sheets of hard lavalike rock. In some sections, these welded ash-flow tuffs are more than 400 meters (1,300 feet) thick. The ash-flow sheets

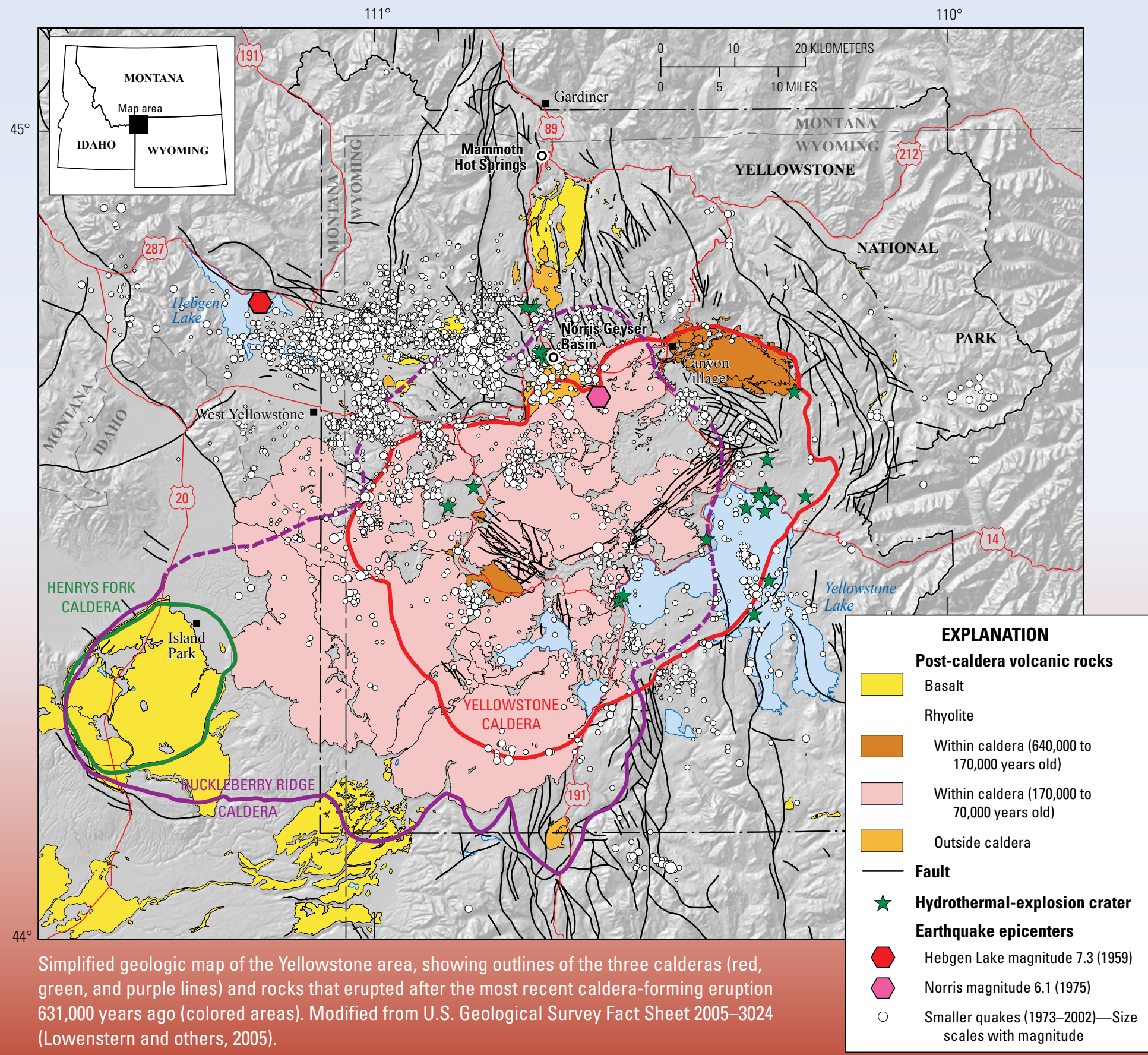


account for more than half the material erupted from Yellowstone Caldera.

Before and after these calderaforming events, eruptions in the Yellowstone area produced rhyolitic and basaltic rocks - large rhyolite lava flows (pink and orange colors on simplified geologic map on previous page), some smaller rhyolite pyroclastic flows in and near where the calderas collapsed, and basalt lava flows (yellow color on simplified geologic map) around the margins of the calderas. Large volumes of rhyolitic lava flows (approximately 600 cubic kilometers, or 144 cubic miles) were erupted in the most recent caldera between 170,000 and 70,000 years ago. No magmatic eruptions have occurred since then, but large hydrothermal explosions have taken place since the end of the last ice age in the Yellowstone region, 16,000-14,000 years ago.

Yellowstone Caldera's volcanism is only the most recent in a 17-millionyear history of volcanic activity that has occurred progressively from near the common border of southeastern Oregon, northern Nevada, and southwestern Idaho to Yellowstone National Park as the North America Plate has drifted over a hot spot - a stationary area of melting within Earth's interior. At least six other large volcanic centers along this path generated calderaforming eruptions; the calderas are no longer visible because they are buried beneath younger basaltic lava flows and sediments that blanket the Snake River Plain.

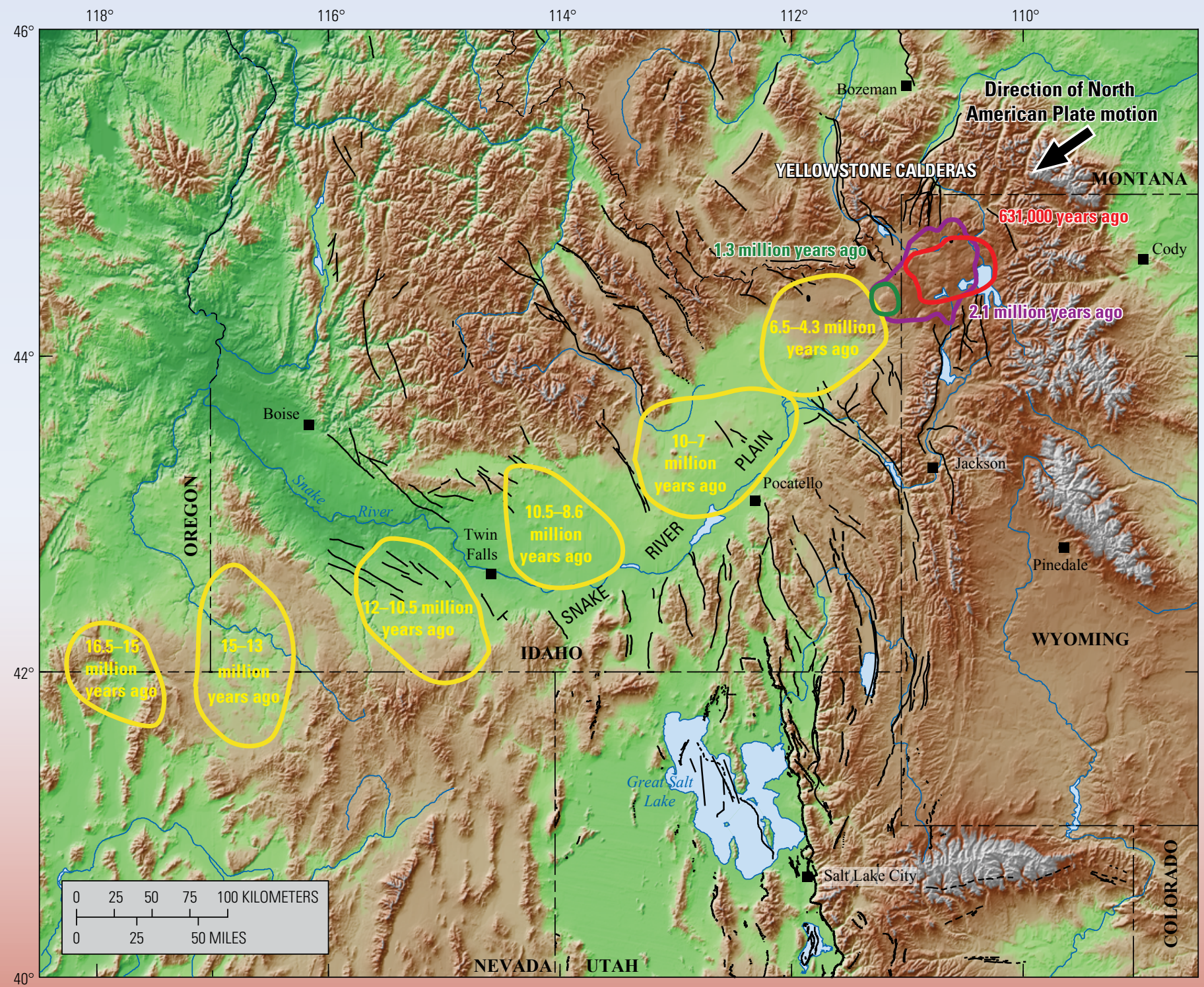

Volcanic centers are outlined where the Yellowstone Hot Spot produced one or more caldera eruptions-essentially "ancient Yellowstones" during the time periods indicated. As the North American Plate drifted southwest over the hot spot, the volcanism progressed northeast, from the common border of southeastern Oregon, northern Nevada, and southwestern Idaho 16.5 million years ago and reaching Yellowstone National Park about 2 million years ago. Mountains (whites, browns, and tans) surround the low elevations (greens) of the seismically quiet Snake River Plain. The low elevations of the Snake River Plain mark the alignment of past calderas that have since been filled in by lava flows and sediments. Black lines show faults within the region. Modified from Smith and Siegel (2000) with permission. 
volcanic episodes at Yellowstone (see the 2017 YVO annual report). Understanding the timing and potential clustering of eruptions during post-caldera volcanic episodes is important for understanding potential volcanic hazards at Yellowstone and the mechanisms and timescales of magma generation and storage.

To improve our understanding of the timing of post-caldera rhyolite eruptions at Yellowstone, YVO scientists applied modern, high-precision ${ }^{40} \mathrm{Ar}{ }^{\beta 9} \mathrm{Ar}$ dating techniques to the Central Plateau Member rhyolites to constrain their eruption ages. Preliminary results indicate that the rhyolites erupted in five pulses, at approximately $161,000,151,000,111,000,104,000$, and 72,000 years ago. During each of these eruptive pulses, as many as seven rhyolites erupted over a span of approximately 1,000 years or less. Interestingly, during each of these pulses, volcanism occurred along only one of the two vent axes - in other words, both vent axes were never active at the same time. These results are similar to those obtained from six post-caldera rhyolites that were part of the second volcanic cycle at Yellowstone and erupted from an approximately 30-kilometer-long vent zone over the course of a few hundred years (see the 2017 YVO annual report). Future work will focus on dating all Central Plateau Member rhyolites.

In a parallel and complementary effort, mapping and stratigraphic studies of the Central Plateau Member flows indicated that extensive hydrothermal activity was present during this time interval and that water and (or) ice was readily available during the emplacement of many flows, much of which occurred during the Bull Lake glaciation (about 200,000 to 130,000 years ago). In 2018, work focused mostly on continued mapping as well as preparing and submitting additional samples for dating, chemical characterization, isotope measurements, and thin section production. These ongoing efforts are likely to improve our understanding of the chronology and magmatic processes involved in the latest episode of lava-flow emplacement at Yellowstone.

\section{Hydrothermal Dynamics of Yellowstone Lake}

Several YVO researchers continued to play an active role in the Hydrothermal Dynamics of Yellowstone Lake (HD-YLAKE) project during 2018. HD-YLAKE, which began in late 2015 and will continue through 2019, is funded by the National Science Foundation, with support from the USGS and the National Park Service. The project seeks to understand how Yellowstone Lake hydrothermal systems respond to geological and environmental changes by observing how the temperature and compositions of hydrothermal fluids, the heat flow of the system, seismicity and water column processes, and the microbial communities inhabiting the vent fields change over time. The field strategy uses a two-pronged approach: (1) geophysical and geochemical monitoring of the active hydrothermal system over a continuous 2-year period (instruments deployed annually), and (2) analyses of sediment cores to study the postglacial ( 15,000-year) history of sedimentary, tectonic, and hydrothermal activity beneath the lake.

In 2018, using The Global Foundation for Ocean

Exploration (TGFOE) research vessel (RV) Annie and the submersible remotely operated vehicle (ROV) Yogi, the project recovered a network of monitoring instrumentation that was deployed over a year during 2017-2018. This included a lake-wide network of pressure-temperature gauges, heat-flow equipment, ten lake-bottom seismometers, and two chemical sensors in active hydrothermal vents (fig. 14). The state-of-the-art technology developed by TGFOE engineers allowed precise location of sites on the lake bottom and provided the ability for high-definition videos, dynamic positioning of the RV Annie, and multiple instruments designed to lift heavy objects (samples and equipment). Work that continued from 2017 into 2018 included analysis of these data and samples. In 2016 and 2017, all samples and most data were collected from an area in the northern part of Yellowstone Lake known as "Deep Hole." Fluids, temperatures, and solids were collected from the Deep Hole site at water depths of about 110 meters (361 feet), where hydrothermal fluids discharge at temperatures as high as $174^{\circ} \mathrm{C}$. These temperatures are the hottest hydrothermal vent fluids yet measured in Yellowstone National Park.

In the summer of 2018, the HD-YLAKE project left the Deep Hole focus area and moved into three distinct hydrothermal areas of West Thumb basin in Yellowstone Lake (fig. 15), where six additional gravity cores, geochemical fluids and temperatures from active vent systems, 15 rock samples, and microbial samples were collected.

Additional 2018 HD-YLAKE highlights included

- Detailed sampling of hydrothermal vents in the Deep Hole focus site southeast of Stevenson Island, and piston and gravity coring of hydrothermally altered sediments and associated pore fluids,

- Analysis of seismic data from 10 lake-floor stations positioned in and around the Deep Hole hydrothermal site,

- Analyses of eight sediment cores collected in 2016 from six different geologic environments in the northern basin of Yellowstone Lake, and

- Temperature time-series data from 16 sites within the Deep Hole hydrothermal field. These data revealed that the bottom-water temperature in the lake is highly variable on a wide range of time scales, from annual cycles down to tens of minutes.

\section{Heat Flow Studies}

The more than 10,000 on-land thermal features of the Yellowstone region range in temperature from just a few degrees Celsius above the normal background temperature to well above boiling (as hot as $138^{\circ} \mathrm{C}$, or about $280{ }^{\circ} \mathrm{F}$ ). Studies of thermal features are accomplished by ground-based monitoring (including both intermittent observations and continuous temperature monitoring), thermal infrared remote sensing observations from satellite and aircraft, and proxy measurements of chloride in Yellowstone National Park's rivers (see sidebar on monitoring thermal changes on p. 26-27). 

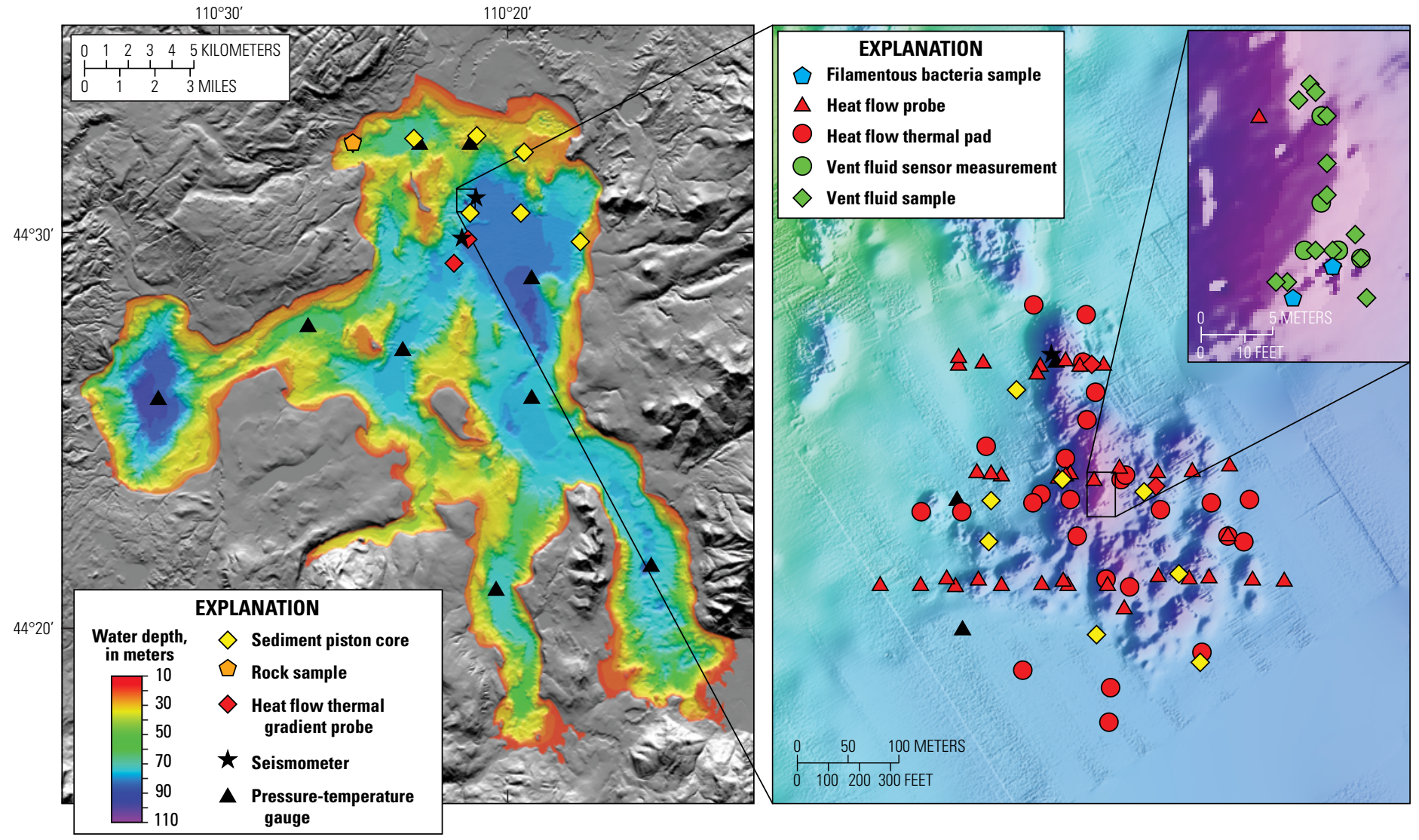

Figure 14. Left, Bathymetric map of Yellowstone Lake showing locations of instruments deployed in 2017 and recovered in 2018. Locations of the sediment piston cores are also shown. Right, High-resolution bathymetric map of the area known as "Deep Hole" and locations of instruments deployed in 2017 and collected in 2018.

Figure 15. High-resolution bathymetric map of West

Thumb basin in Yellowstone Lake (Morgan and others, 2003) showing 2018 sampling sites of the Hydrothermal Dynamics of Yellowstone Lake (HD-YLAKE) project. Sampling sites are marked by white stars, where leader lines point to sample locations.

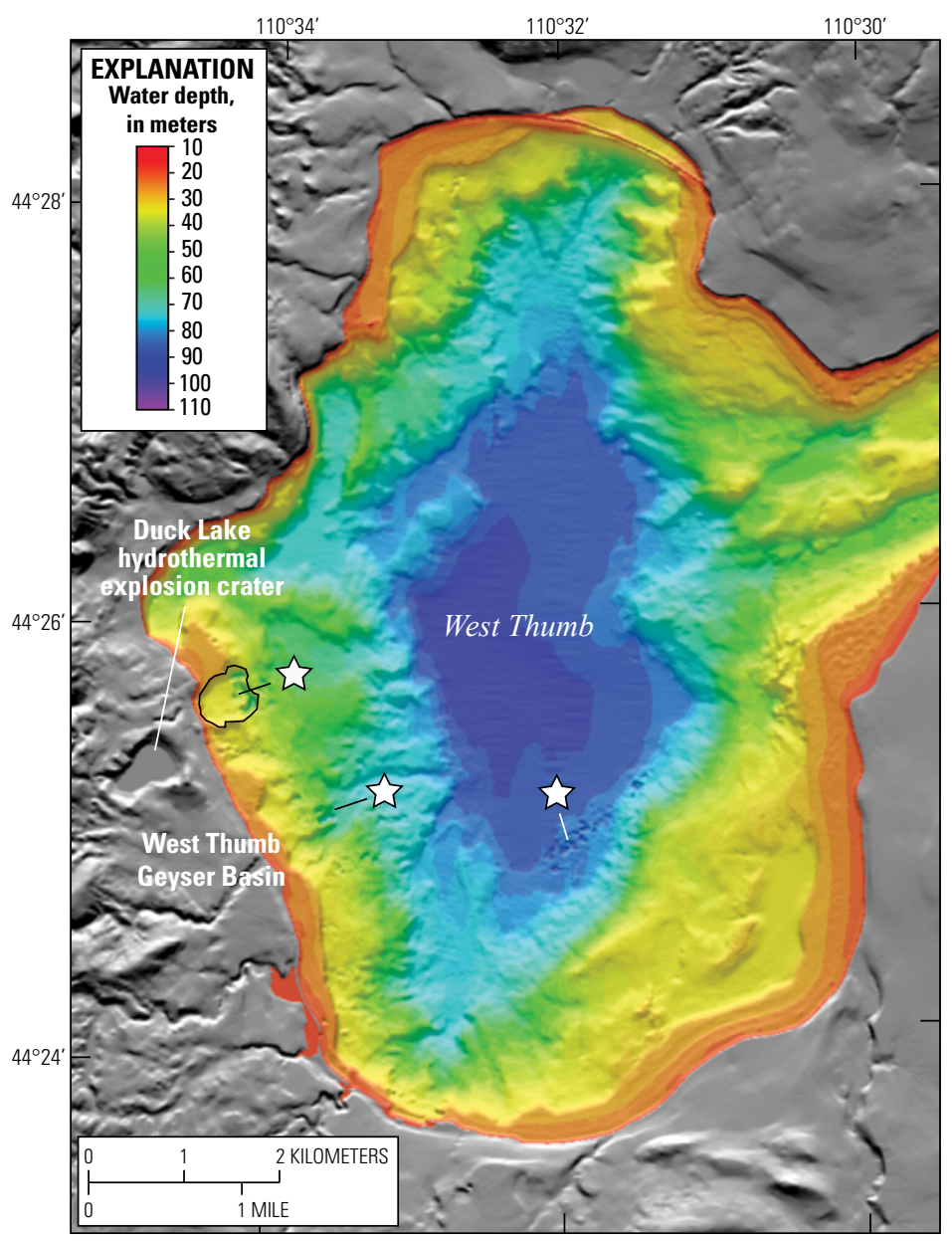




\section{Sidebar Monitoring Thermal Changes at Yellowstone Caldera}

A lot of heat is released from Earth's surface in the Yellowstone area. The evidence of this heat flow includes thermal features like hot springs, geysers, mud pots, and fumaroles. Tracking the temperatures and sizes of thermal areas is critical for monitoring Yellowstone Caldera's hydrothermal activity and also for understanding and preserving these spectacular features. The task is challenging, however, given that there are more than 10,000 individual thermal features spread out over a large and mostly inaccessible area within Yellowstone National Park.

Some specific thermal features are continuously monitored with temperature sensors, such as at Norris Geyser Basin. There, thermal probes are connected via radio links so that data within the thermal-monitoring network can be viewed at all times. These thermal probes have proven useful for detecting geyser eruptions when visual observations are impossible (owing to weather or time of day).

Temperature probes can only be used to measure the output of a few specific features. To look at overall thermal output of Yellowstone, other techniques are employed-for instance, tracking the chemistry of Yellowstone

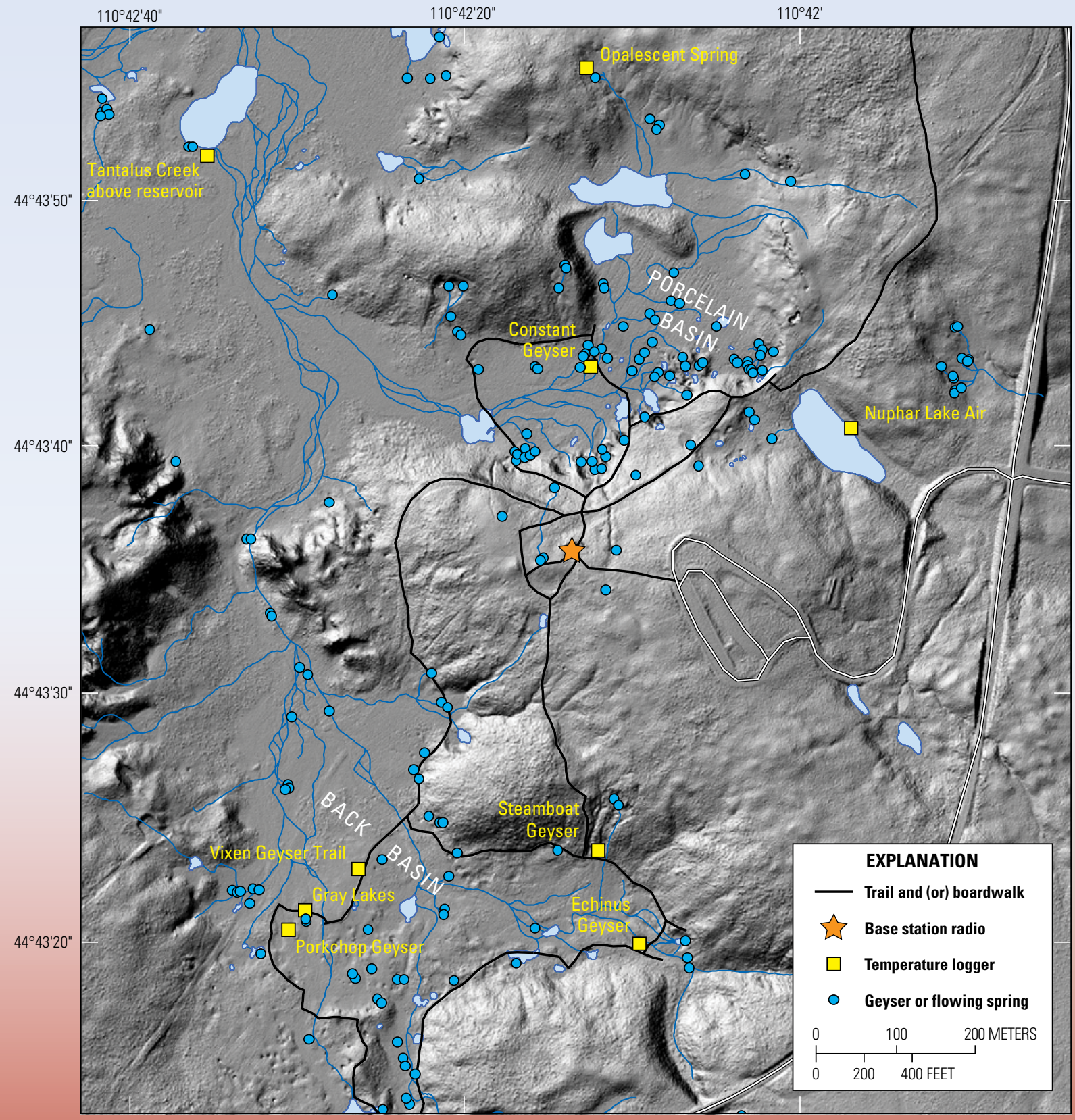

Base from 2009 EarthScope lidar datase

Map of temperature measurement sites in Norris Geyser Basin. 
area's major rivers. Since the hot water from thermal features ultimately ends up in rivers, changes in river chemistry are used to track overall hydrothermal activity. The most useful chemical indicator is the chloride composition of the river water, because hydrothermal water has a high concentration of chloride. In fact, nearly all (95 percent) of the chloride in Yellowstone rivers comes from thermal features. Thus, monitoring the chloride flux in the major rivers in Yellowstone National Park provides an overview of hydrothermal activity. River water samples were once collected periodically and manually to measure chloride, but now measurements of specific conductance (a proxy for chloride) are collected continuously by automated monitoring stations on all the park's major rivers.

Another method for obtaining broad views of Yellowstone Caldera's thermal output is to use satellites, which measure surface temperature and detect changes over time. One of the advantages of satellite-based thermal infrared remote sensing is that researchers can view nearly all of the thermal areas in the park at once. Unfortunately, this broad view comes at a cost - thermal infrared satellite images tend to have low spatial resolution, with pixels that are 90 meters (about 300 feet) on a side. Nevertheless, thermal infrared images of Yellowstone National Park have enough detail to make maps of temperature anomalies, which are especially useful in areas that are not easily accessible.

Satellite thermal infrared temperature anomaly map of Yellowstone National Park's thermal areas based on a Landsat-8 image from April 20, 2017. The warmest areas (yellow) are $20-30^{\circ} \mathrm{C}\left(68-86^{\circ} \mathrm{F}\right)$ above background; the cooler areas (purple) are $2-3^{\circ} \mathrm{C}\left(36-37^{\circ} \mathrm{F}\right)$ above background. By comparing maps like this for different times, scientists assess changes in thermal areas over time and estimate the total heat output from Yellowstone Caldera.

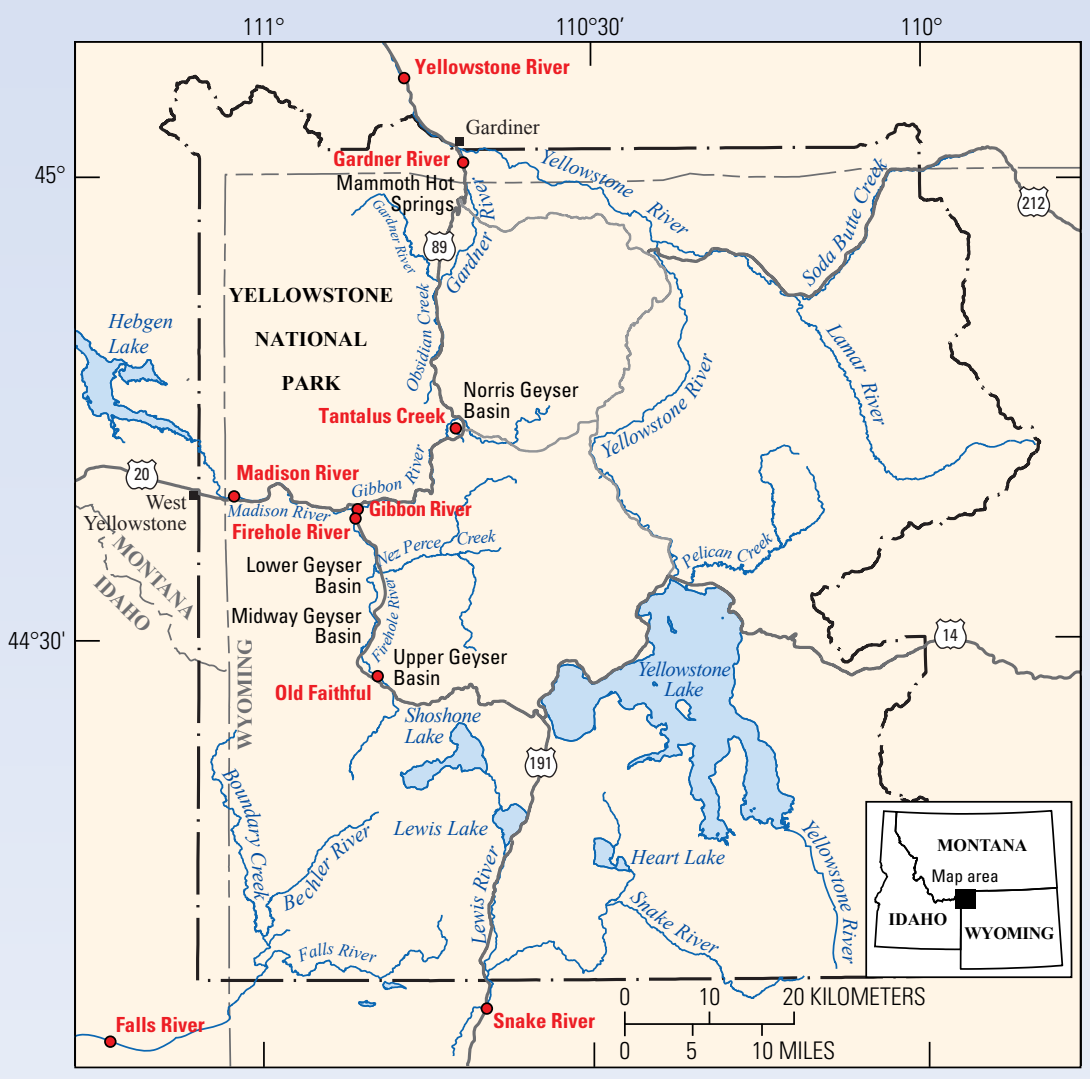

Map showing river chemistry monitoring sites (red dots) in Yellowstone National Park.

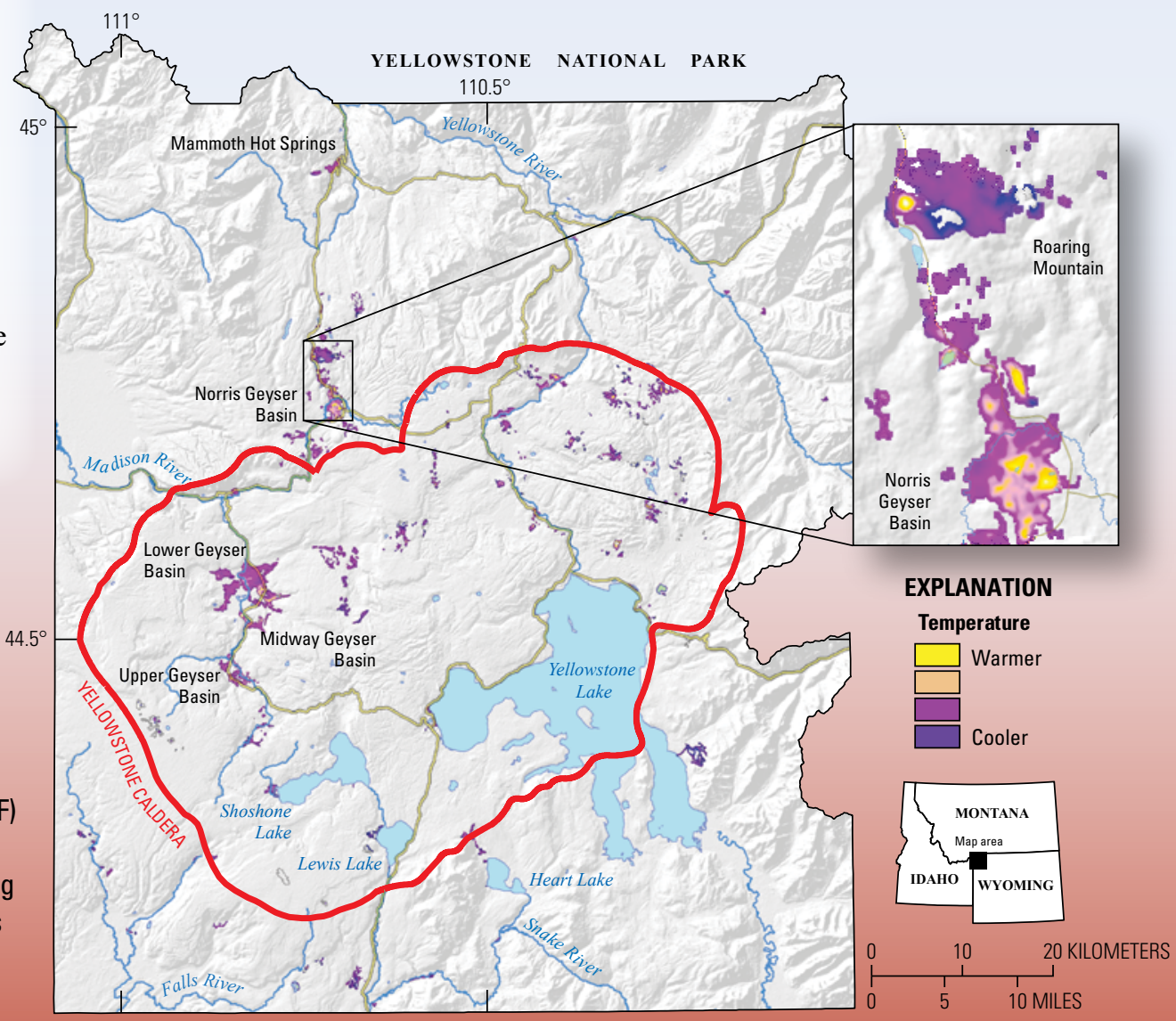




\section{Summary of Heat Flow Studies in 2018}

The total heat output from Yellowstone's thermal areas in 2018, as measured by satellite thermal infrared observations, was the same as in previous years. Likewise, chloride flux in Yellowstone's rivers, a proxy for geothermal heat output, was comparable to previous years. Together, the thermal infrared and chloride measurements indicate the total thermal discharge remained steady. In detail, however, the system was characteristically dynamic - a high resolution airborne thermal infrared survey discovered a new thermal area emerging near the previously mapped Tern Lake thermal area.

\section{Thermal Infrared Remote Sensing}

Analysis and interpretation of thermal infrared remote sensing data for characterizing Yellowstone's thermal areas has been ongoing for years. Satellite-based thermal infrared data with a spatial resolution of 90 to 100 meters per pixel are useful for mapping and quantifying the characteristics of most of Yellowstone's thermal areas on a regional to park-wide scale. Higher spatial resolution (1-2 meters per pixel) airborne thermal infrared data are useful for mapping thermal areas with greater detail and characterizing smaller areas that may not be clearly distinguishable using coarser satellite measurements. Such airborne thermal infrared surveys of selected thermal areas were conducted once or twice per year from 2005 to 2015 and have been very helpful for understanding small-scale spatial and temporal variations in individual thermal basins. This level of spatial detail is critical in supporting park-level decisions about infrastructure development, resource protection, and visitor safety.

Satellite-based thermal infrared data have been acquired intermittently over parts of Yellowstone with the Advanced Spaceborne Thermal Emission and Reflection Radiometer (ASTER) aboard the National Aeronautics and Space Administration's Terra satellite since the year 2000. Of the seven ASTER scenes that covered parts of Yellowstone in 2018 (three daytime and four nighttime), only one daytime image in April was partly free of clouds and it did not cover a significant area of the park. Because most surface heating is from the sun during the day, nighttime acquisitions of thermal infrared remote sensing data are best suited to evaluate the geothermal component of surface thermal metrics, such as geothermal radiant heat flux and geothermal radiative power output. Unfortunately, no clear nighttime ASTER scenes were acquired in 2018.

Landsat- 8 thermal infrared data have been regularly acquired since 2013 and continue to be acquired - nominally, every 16 days over Yellowstone. Daytime overpasses occur around noon local time and nighttime overpasses around 11:00 p.m. local time. Unfortunately, nighttime data are not always acquired owing to on-orbit calibration events or data capacity limitations. A total of 36 Landsat- 8 scenes were acquired over Yellowstone in 2018 (22 daytime and 14 nighttime scenes). Data acquired during wintertime are preferable to data from other seasons for two reasons. First, non-thermal background areas are cold in winter and there is greater thermal contrast between thermal areas and surrounding background. Another advantage of wintertime data is its utility for detecting thermal input to lakes, which in other seasons can be masked by the large heat capacity of water. Lakes with no significant thermal input typically stay frozen through the month of May, but thermal infrared images acquired in April and May commonly reveal lakes that have thermal input, either from the lake bottom or from nearby springs, because they are the first ones to start thawing. The earliest clear Landsat-8 nighttime thermal infrared image over Yellowstone in 2018 was acquired on May 9 (fig. 16); those data were processed and analyzed for this report.

The results of analyses of the May 9, 2018, satellite thermal infrared data were consistent with previous satellite data analyses. The thermal areas with the highest temperatures above background were Sulphur Hills, Midway Geyser Basin, and Lower Geyser Basin. The thermal areas with the highest geothermal radiant emittance (in watts per square meter) were Sulphur Hills, Roadside Springs, Mammoth Hot Springs, Beula Lake, Turbid Lake, and Norris Geyser Basin. The thermal areas with the highest total geothermal radiative power output (in megawatts, integrated over the area of the thermal area) include Lower, Midway, and Upper Geyser Basins, Sulphur Hills, Roaring Mountain, and the area known as "Painted Cliffs." Summation of the average geothermal radiative power output above background for all of Yellowstone's thermal areas measured from the May 9, 2018, Landsat- 8 thermal infrared image is about 1.3 gigawatts. This is the same as was determined from imagery acquired at a similar time of year in 2017 (see the 2017 YVO annual report).

\section{Tern Lake Thermal Area}

The geographic information system database of Yellowstone's thermal areas is continually being updated in an iterative fashion and is used to guide the mapping of warm pixels in thermal infrared imagery. Warm pixel areas detected in thermal infrared imagery that are not coincident with previously mapped thermal areas are compared to high-resolution visible imagery (acquired via satellite or from the air) to determine whether they can be interpreted as thermal areas and added to the polygon geodatabase. As an illustration of this process, in 2018 a new thermal area was discovered emerging near the previously mapped Tern Lake thermal area.

The Tern Lake thermal area, which shares a name with nearby Tern Lake and west Tern Lake, is located in the eastcentral part of the park along the northeast margin of the Sour Creek resurgent dome (figs. 16 and 17). This area is deep in Yellowstone's backcountry, about 0.8 kilometers from the nearest trail and about 18 kilometers from the nearest trailhead; therefore, few people have ever visited the site. Analysis of recent Landsat- 8 nighttime thermal infrared imagery revealed a warm area between west Tern Lake and the previously mapped Tern Lake thermal area. This mysterious patch of bright pixels in the thermal infrared imagery did not match any previously mapped thermal area and was not a thawing lake. 


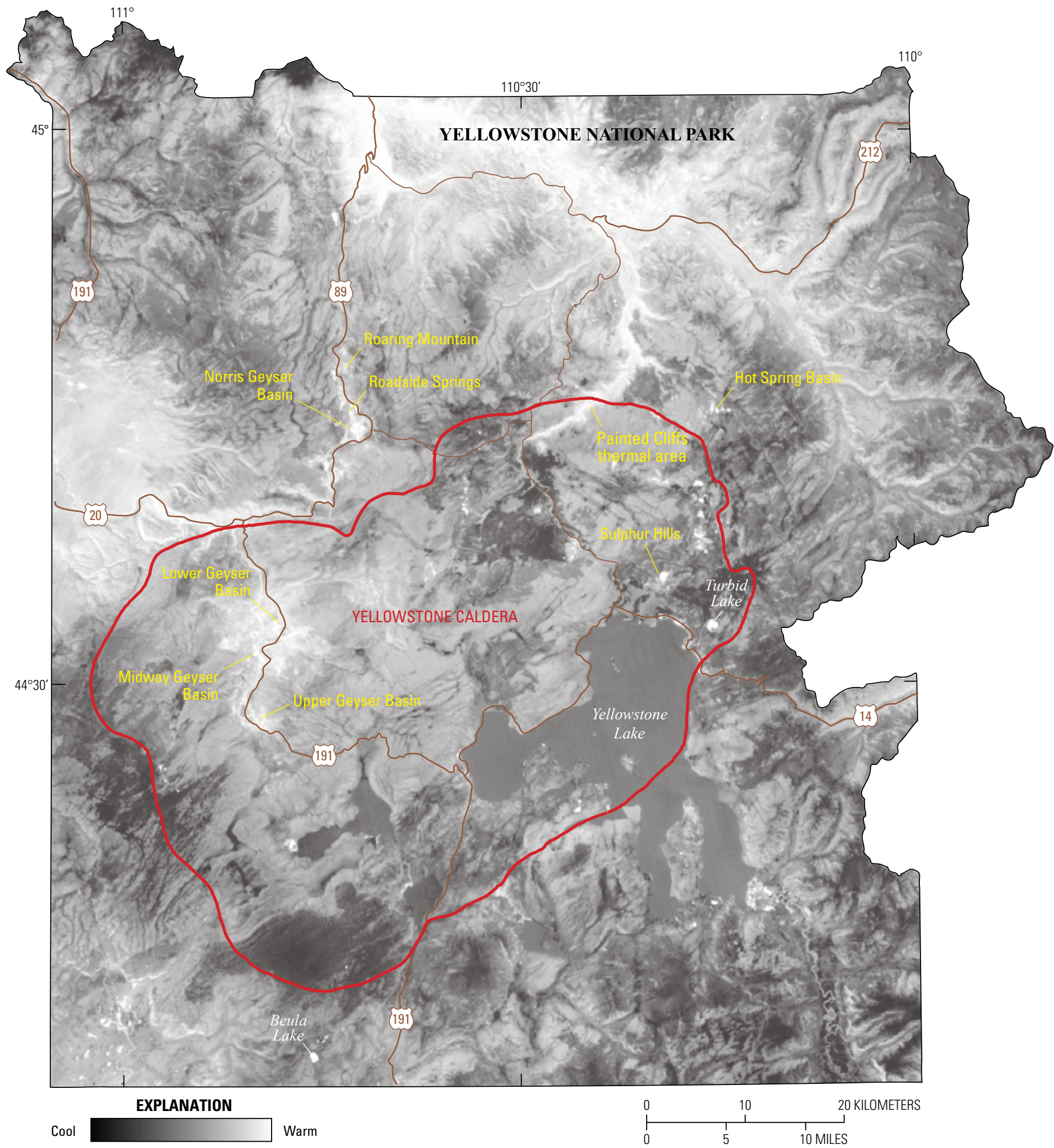

Figure 16. Satellite thermal infrared temperature image of Yellowstone National Park based on a Landsat-8 image from May 9 , 2018. Satellite-based thermal infrared imagery shows areas of ground that are warmer versus cooler, and it can be used to estimate the total heat output from the Yellowstone magmatic system. The warmest areas (lightest in shade) in this image are $20-30^{\circ} \mathrm{C}\left(36-54^{\circ} \mathrm{F}\right)$ above background. 

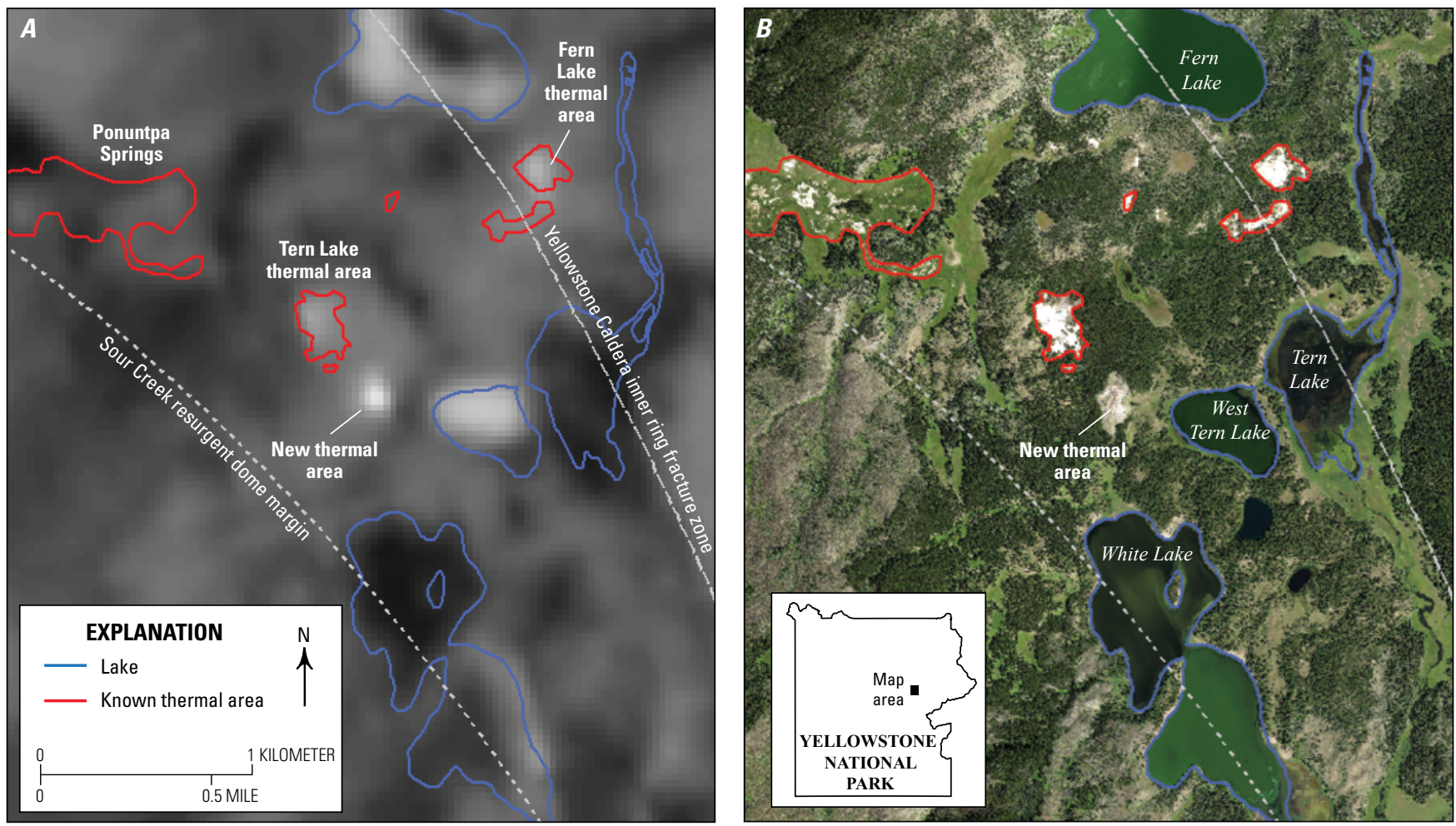

Figure 17. Map of Tern Lake thermal area and proximal surroundings. $A$, Landsat-8 nighttime thermal infrared image from April 20, 2017, with thermal areas annotated. B, National Agriculture Imagery Program visible image from August 18, 2017, with lakes annotated. Lakes and mapped thermal areas before the discovery of the new area are outlined.

High-resolution (1 meter per pixel) airborne visible images of the Tern Lake area were acquired as recently as 2017 as part of the National Agriculture Imagery Program (NAIP), administered by the U.S. Department of Agriculture's Farm Service Agency (fig. 17). The images clearly show the newly recognized thermal area, with a large patch of dead trees and bright soils that are indicative of hydrothermal alteration or hydrothermal mineral deposits. Archived data, both high-resolution airborne visible data from NAIP and moderate-resolution visible and nearinfrared satellite data from ASTER, show the area was healthy forest in the 1990s, and that around the year 2001 it started showing signs of vegetation stress. Since 2001, the area of dead or dying trees has grown to about 8 acres, as can be seen in the 2017 NAIP image. Archived thermal infrared data show the area started showing evidence of anomalous thermal output around 2006 , when it became spatially large enough to be detectable in ASTER's 90-meter thermal infrared pixels.

\section{Chloride Flux Measurements}

Measuring the thermal output of a magmatic system as large and complex as Yellowstone poses a difficult logistical problem: how do you capture and integrate the contributions from thousands of individual heat sources scattered over a vast area? One solution is to use the park's rivers as a collection and delivery system. Nearly all of the chloride in rivers that drain Yellowstone comes from emerging hot spring water heated underground by heat ultimately sourced from the underlying magma reservoir. Monitoring chloride flux in major rivers is thus an effective way to estimate total thermal output of Yellowstone's hydrothermal system. Any fluctuations in chloride production might signal a corresponding change in thermal activity. The USGS and National Park Service have collaborated on chloride flux monitoring in the park since the 1970s, mostly by collecting water samples, measuring chloride concentrations in the samples, and combining that information with river discharge measurements to calculate chloride flux.

Beginning in 2010, the USGS installed stations along major rivers to automatically measure specific conductance (an indication of how well water conducts an electrical current), which can be used as a proxy for chloride concentration. The use of specific conductance probes at various monitoring sites enables a more consistent estimate of chloride flux and can be used to identify changes in river chemistry associated with geyser eruptions, rain events, or changes in thermal inputs resulting from earthquakes or other natural events.

In 2018, automated specific conductance measurements were made every 15 minutes at monitoring sites along the Madison, Firehole, Gibbon, Snake, Gardner, Yellowstone, and Falls Rivers (see sidebar on thermal changes on page 26-27). In addition, telemetry systems were installed at the Madison, 
$\boldsymbol{A}$

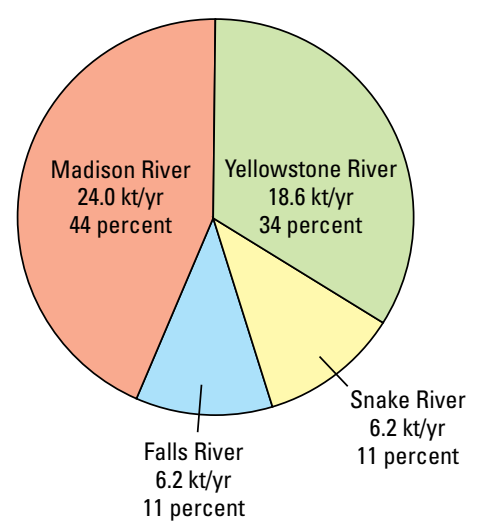

$B$

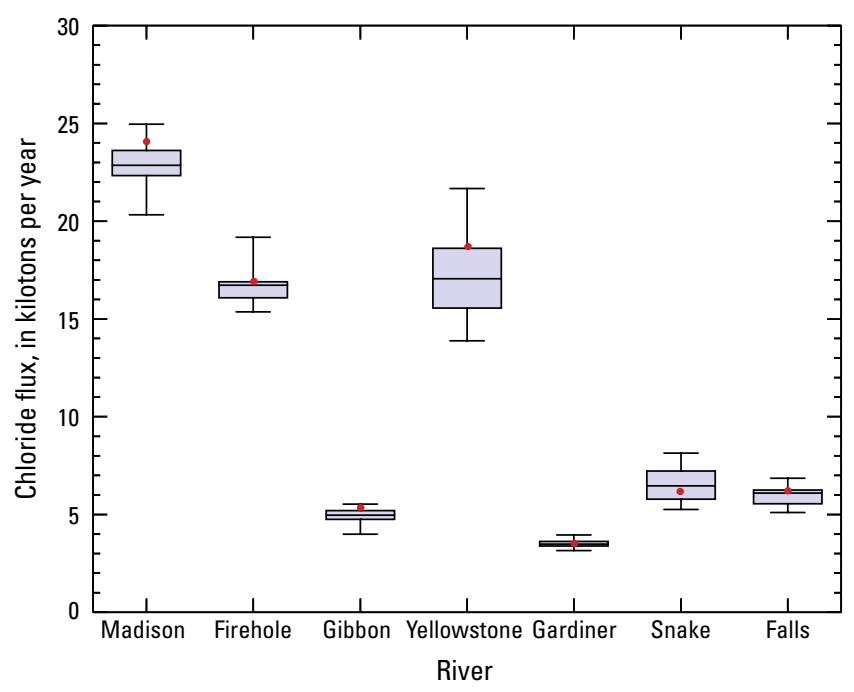

\section{EXPLANATION}

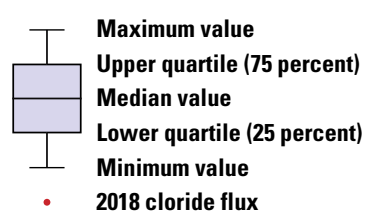

Figure 18. A, Pie diagram showing the 2018 chloride flux, in kilotons per year (kt/yr) and the percentage of the total flux (55.0 $\mathrm{kt} / \mathrm{yr}$ ) for the four major rivers (Madison, Yellowstone, Snake, and Falls Rivers) that drain the Yellowstone region. B, Boxplot showing the distribution of chloride flux measurements collected from 1983 to 2018. The 2018 chloride flux for each monitoring site is shown.

Firehole, Gibbon, and Yellowstone River monitoring sites. The use of specific conductance as a proxy for chloride requires quantification of the relation between specific conductance, chloride, and other geothermal solutes $\left(\mathrm{SO}_{4}, \mathrm{~F}, \mathrm{HCO}_{3}, \mathrm{SiO}_{2}\right.$, $\mathrm{K}, \mathrm{Li}, \mathrm{B}$, and $\mathrm{As}$ ), and the relation needs to be periodically assessed. Water samples were collected during three 2018 field trips to confirm the solute-specific conductance correlations. A computer program was implemented to rapidly calculate the geothermal solute flux from each monitoring site.
The total chloride flux leaving Yellowstone in 2018 was 55.0 kilotons, which was determined by summing the fluxes from the Madison, Yellowstone, Snake, and Falls Rivers (fig. $18 A$ ). The 2018 value is consistent with historical measurements of 52.6 \pm 4.1 kilotons (based on measurements collected since 1983). Furthermore, the percentages of the total flux from the Madison (44 percent), Yellowstone (34 percent), Snake (11 percent), and Falls (11 percent) Rivers for 2018 were similar to previous determinations. Finally, the chloride flux for each site is compared to historical fluxes (measured over 17-32 years, depending on the site) in figure $18 \mathrm{~B}$. At all monitoring sites, the 2018 chloride flux was within one standard deviation of the historical measurements. Based on these observations, the 2018 thermal flux was comparable to previous years and suggests that the overall hydrothermal discharge has remained steady.

\section{Geysers and Hot Springs}

Yellowstone hosts more than 10,000 thermal features, including geysers, hot springs, and mud pots. These features are incredibly dynamic, displaying a range of behaviors that vary over time. Some geysers, especially those that exist in comparative isolation, like Old Faithful, follow patterns that allow their activity to be forecast. The vast majority of Yellowstone's geysers, springs, and other thermal features have unpredictable behavior. Most of the myriad hydrothermal manifestations at Yellowstone remain unmonitored, but some features are tracked, and below we highlight a few examples of noteworthy changes that occurred at well-known thermal features in 2018.

\section{Summary of Geyser Activity in 2018}

Noteworthy geyser activity in Yellowstone National Park during 2018 was dominated by water eruptions from Steamboat Geyser, the tallest geyser in the world. The year also saw continued eruptions of Giant Geyser and a rare eruption of Ear Spring, both located in the Upper Geyser Basin near Old Faithful.

\section{Steamboat Geyser}

Steamboat Geyser is a prominent feature of Norris Geyser Basin. The feature experienced dozens of closely spaced eruptions during the 1960s and early 1980s, but the geyser averaged less than an eruption per year from the 1990s until 2018. Its last eruption prior to 2018 occurred on September 3, 2014. That quiescence was broken on March 15, 2018. Unfortunately, because Yellowstone National Park was still largely closed during the winter season, there were no witnesses to the start of the eruption. The eruption was recorded, however, as a spike in temperature on the Steamboat Geyser sensor within the Norris Geyser Basin temperature monitoring network (see sidebar on thermal changes on page 26-27) and as a burst of seismic noise on the YNM 
seismometer that is located inside the Norris Museum building (fig. 19). Although subsequent eruptions (table 1; fig. 20) were clearly manifested as surges in discharge at the stream gage on Tantalus Creek, through which water from Norris Geyser Basin drains, the March 15 eruption coincided with a period of heavy rain and thus was not distinct from the rainfall-related surge. Steamboat Geyser erupted again on April 19 and 27, and four times in May on its way to a total of 32 eruptions in 2018 - a new record for a calendar year.
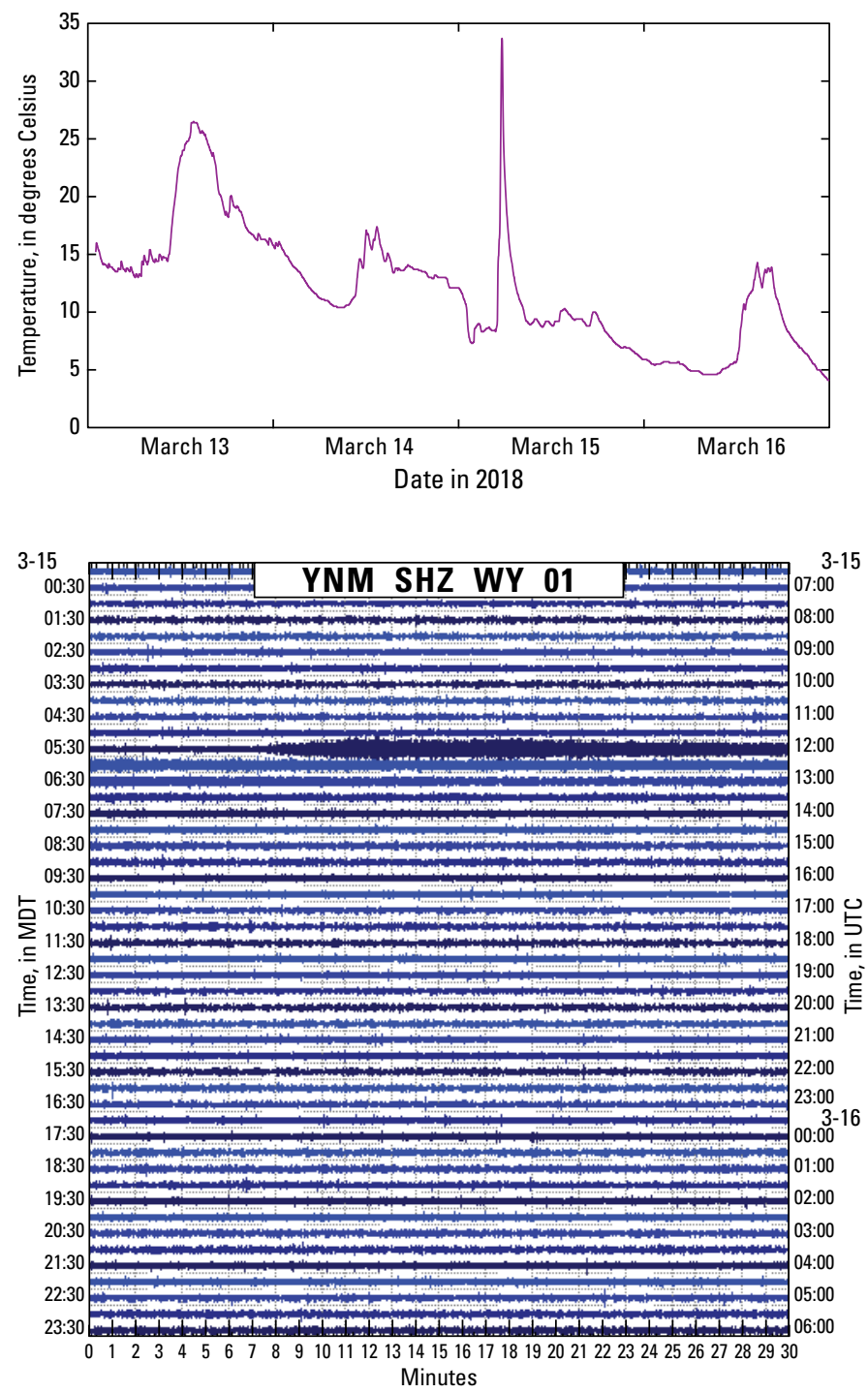

Figure 19. Temperature (top) and seismic (bottom) records of the March 15, 2018, eruption of Steamboat Geyser. The temperature record was recorded by a sensor located in the geyser's runoff channel; the spike marks the eruption, whereas other fluctuations are caused by a combination of water discharge and daily changes in air temperature. The seismometer is located in the museum building in Norris Geyser Basin; the thick lines starting at around 05:37 MDT mark the start of the eruption and more seismic energy release compared to background levels. MDT, Mountain Daylight Time; UTC, Coordinated Universal Time.
Each eruption of Steamboat Geyser followed the same general pattern - a water eruption lasting tens of minutes and reaching heights of more than 300 feet ( $\sim 100$ meters) was followed by a steam phase that lasted for about a day with gradually decreasing intensity. Also, as is common with Steamboat Geyser eruptions, Cistern Spring, located about 300 feet ( $\sim 100$ meters) downslope of Steamboat Geyser, drained within a day of each eruption and then gradually refilled over the following days. The frequent eruptions coated many of the

Table 1. Water eruptions of Steamboat Geyser in 2018.

[MDT, Mountain Daylight Time; MST, Mountain Standard Time]

\section{Eruption date and time}

March 15, 2018, 5:37 a.m. MDT

April 19, 2018, 4:30 p.m. MDT

April 27, 2018, 6:30 a.m. MDT

May 4, 2018, 11:50 p.m. MDT

May 13, 2018, 3:54 a.m. MDT

May 19, 2018, 9:49 p.m. MDT

May 27, 2018, 7:33 p.m. MDT

June 4, 2018, 9:05 a.m. MDT

June 11, 2018, 1:06 a.m. MDT

June 15, 2018, 4:55 p.m. MDT

July 6, 2018, 1:38 p.m. MDT

July 20, 2018, 10:36 p.m. MDT

August 4, 2018, 2:10 p.m. MDT

August 22, 2018, 11:44 a.m. MDT

August 27, 2018, 9:30 p.m. MDT

September 1, 2018, 11:21 p.m. MDT

September 7, 2018, 10:20 a.m. MDT

September 12, 2018, 4:23 a.m. MDT

September 17, 2018, 9:38 a.m. MDT

September 24, 2018, 5:18 a.m. MDT

September 30, 2018, 6:55 p.m. MDT

October 8, 2018, 10:25 a.m. MDT

October 15, 2018, 2:12 p.m. MDT

October 23, 2018, 9:29 p.m. MDT

October 31, 2018, 8:22 a.m. MDT

November 7, 2018, 4:16 p.m. MST

November 15, 2018, 11:04 a.m. MST

November 21, 2018, 7:10 p.m. MST

November 28, 2018, 8:37 p.m. MST

December 8, 2018, 1:07 a.m. MST

December 17, 2018, 12:30 p.m. MST

December 25, 2018, 11:21 p.m. MST 


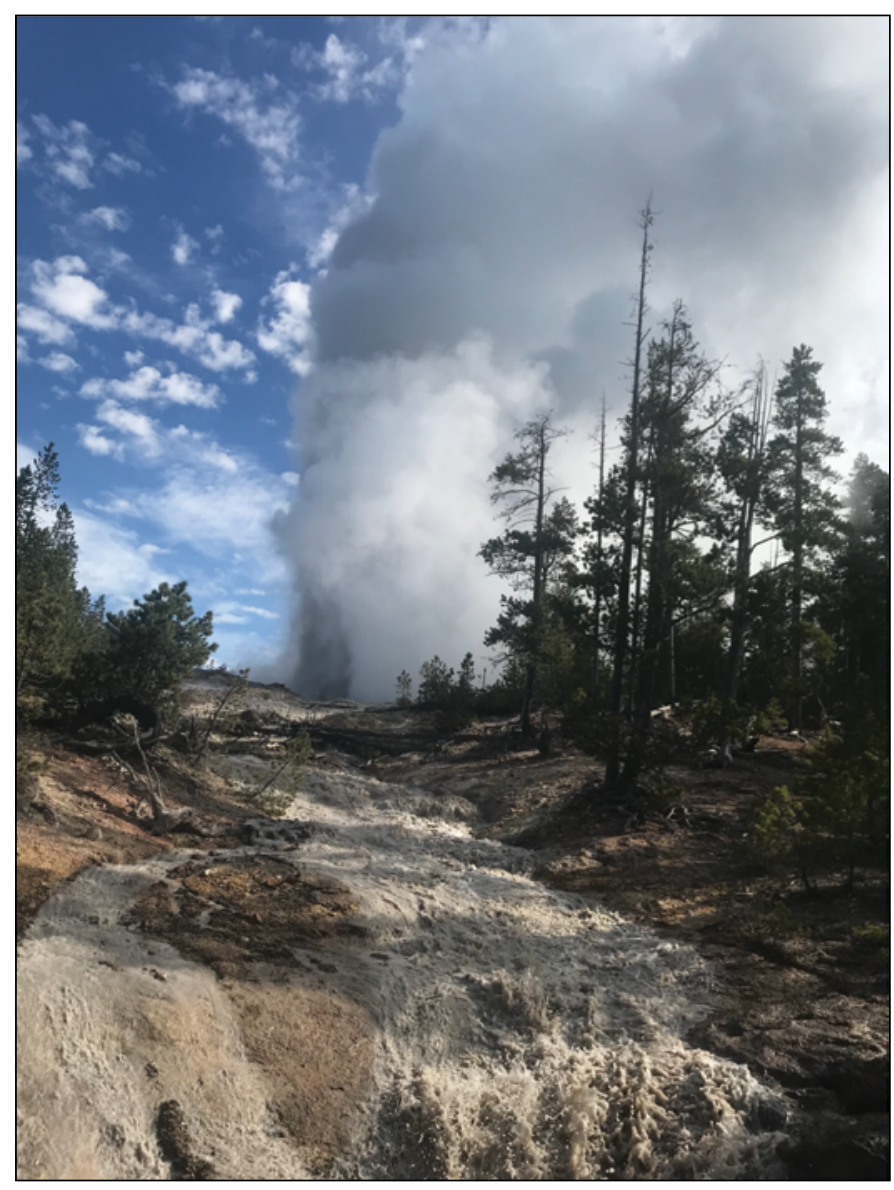

Figure 20. Steamboat Geyser in eruption, with geyser runoff in the foreground. The temperature sensor that records Steamboat Geyser eruptions is located in this channel, about halfway up the slope. Photograph by Jamie Farrell, University of Utah, on June 4, 2018.

trees between the geyser and the Norris Geyser Basin parking lot with mud and rock debris. An aerial view of the geyser clearly shows the damage to vegetation in that area (fig. 21).

There was no clear pattern to the 2018 eruptions of Steamboat Geyser. The times between eruptions varied widely, from 4 to 35 days, although for much of the year there was an uncanny almost weekly recurrence. Eruption volumes, based on the discharge calculated from the Tantalus Creek stream gage, were generally $200-400$ cubic meters (7,000-14,000 cubic feet). For comparison, this is ten times the volume of an average Old Faithful eruption. Beginning in June and especially apparent in July and August, major Steamboat Geyser eruptions were preceded by hours to days of nearly constant minor eruptive activity (fig. 22). These minor eruptions were recorded in the temperature record as elevated temperature with frequent spikes, indicating that the sensor was largely detecting changes in temperature related to differing water output in the geyser's discharge channel. After a major eruption, minor eruptions apparently ceased, since temperatures indicated that the sensor was solely exposed to air, and the spikes were absent. The temperature sensor suffered a mechanical failure in late August and could not be revived before the onset of winter; after that time, the main

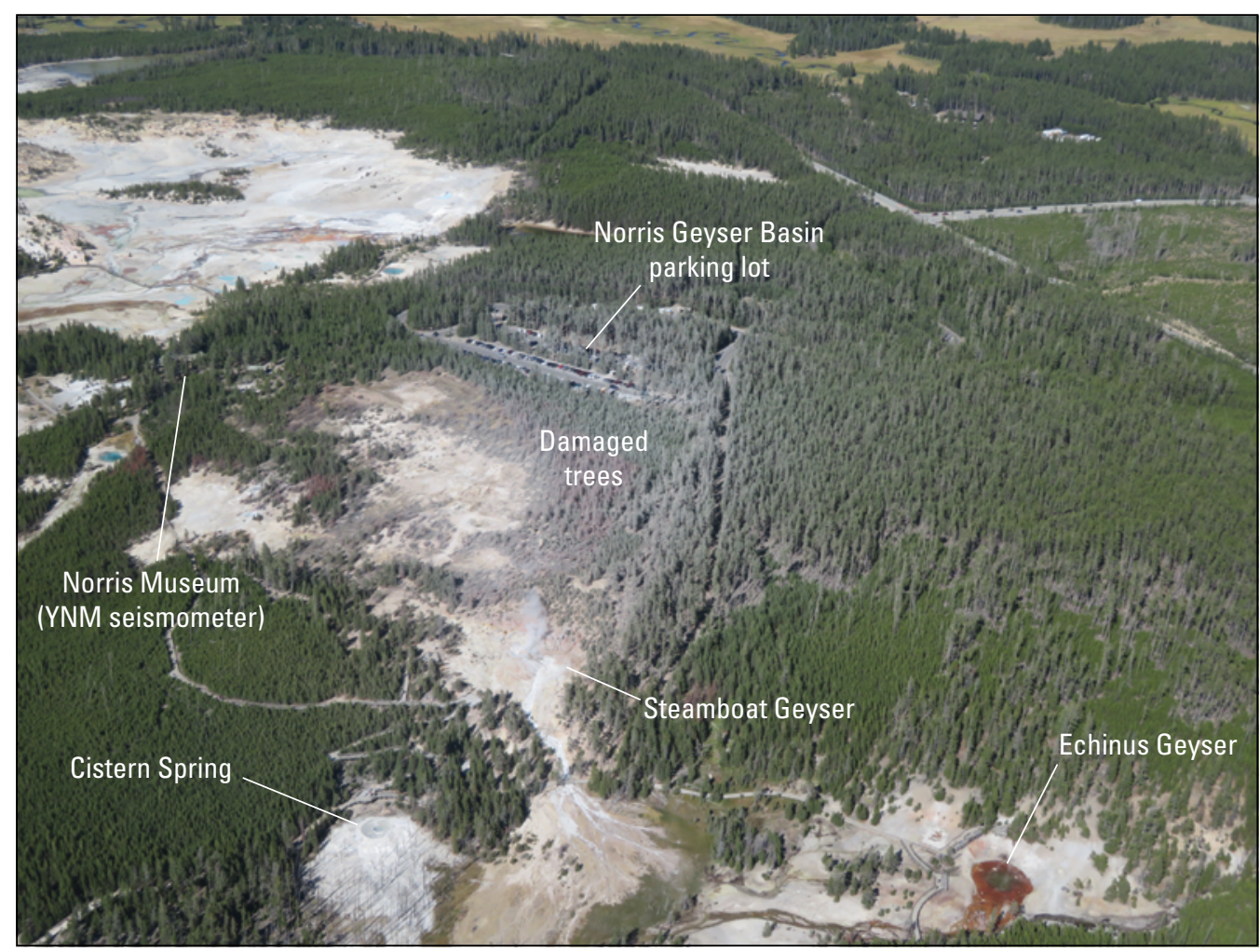

Figure 21. Aerial view of Steamboat Geyser and surroundings looking north. Photograph by Jamie Farrell, University of Utah, on August 29, 2018. 


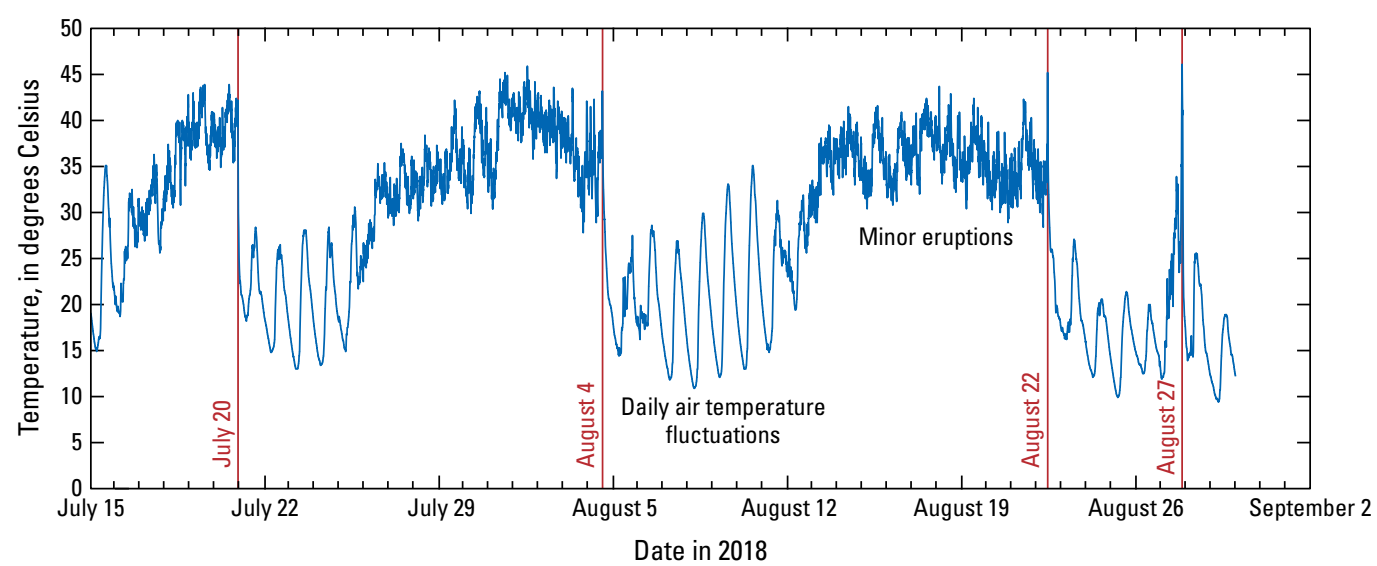

Figure 22. Temperature record for Steamboat Geyser during July-August 2018. Major eruptions are marked by red lines and dates. Smooth variations reflect times of no significant water eruptions and negligible outflow of water in the discharge channel. Elevated and noisy data reflect times when persistent minor eruptive activity caused high discharge (higher temperatures reflect water flow) and more muted diurnal temperature variations. In this time period, all major eruptions were preceded by minor activity. After each major eruption, geyser activity largely ceased for a few days before minor activity resumed.

indicators of Steamboat Geyser eruptions were the seismic record at station YNM and the discharge calculated at the Tantalus Creek stream gage.

\section{Giant Geyser}

Like Steamboat Geyser, Giant Geyser, located in the Upper Geyser Basin not far from Old Faithful, experiences cycles of frequent eruptions separated by periods of infrequent activity. The geyser was extremely active in 2008, but only erupted once in 2009, twice in 2010, and five times in 2015. Three eruptions took place in late 2017 (see the 2017 YVO annual report). By early 2018, it was clear that the late 2017 activity was the start of a new cycle - the geyser experienced more than two dozen eruptions in 2018, with periods as short as 4 days between activity.

\section{Ear Spring}

September 2018 provided another good example of the dynamic nature of Yellowstone's thermal areas. Geyser Hill, located across the Firehole River from Old Faithful in the Upper Geyser Basin, hosts dozens of hot springs, geysers, and fumaroles. In early September 2018, it was clear that a few normally calm hot pools were expelling more water than usual, and others were boiling. On September 15, a rare eruption of Ear Spring occurred, shooting water 6 to 9 meters (20 to 30 feet) high. In addition to water, the eruption ejected some rocks and a few decades' worth of human-derived debris, including coins, soda cans, a piece of a cinder block, and a baby's pacifier (figs. 23 and 24).
Following the eruption, hot water continued to overflow from the spring, occasionally spouting as high as 0.6 meters ( 2 feet) and killing the spring's surrounding orange-to-yellow bacterial mats with hot-water overflows. Also, on Geyser Hill

- A new thermal feature formed directly beneath the boardwalk, splashing hot water between the wooden slats of the boardwalk, and a new feature on the Solitary Geyser-Observation Point trail started splashing boiling water onto the trail, prompting the National Park Service to temporarily close the trail.

- Doublet Pool started exhibiting boiling surges as high as 0.6 meters ( 2 feet), resulting in overflow that killed some of its surrounding bacterial mats.

- An unnamed geyser on the Observation Point side of the boardwalk that had never been known to erupt, began erupting water 3 to 4.5 meters ( 10 to 15 feet) high.

- Lion Geyser, which typically erupts many times per day, went quiet for 3 days.

- North Goggles geyser erupted for the first time in about a month and began erupting at 12 - to 20 -minute intervals.

- Pump Geyser dried out to the point that its bacterial mats were no longer covered in water.

The September 2018 eruption of Ear Spring is not necessarily a unique event in the history of the feature. According to an article in Yellowstone Nature Notes ${ }^{3}$ (Gunzel,

${ }^{3}$ Thanks to M.A. Bellingham for sharing this account of the 1957 Ear Spring eruption. 

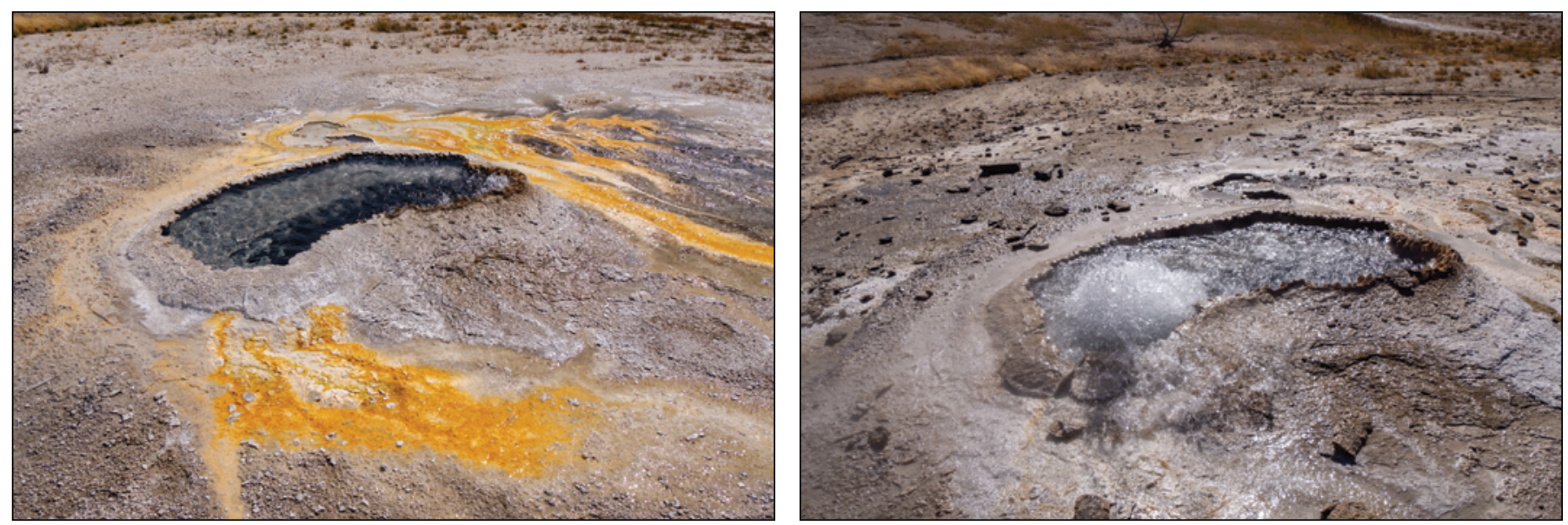

Figure 23. Ear Spring before and after its September 15, 2018, eruption. Left, Ear Spring on September 7, 2018. Right, Ear Spring on September 16, 2018. Note the rocky debris surrounding the spring, which is not present in the pre-eruption photograph. Human-derived debris had been removed by the time this image was taken. Photographs by Janet Jones, YellowstoneNaturalist.com, used with permission.

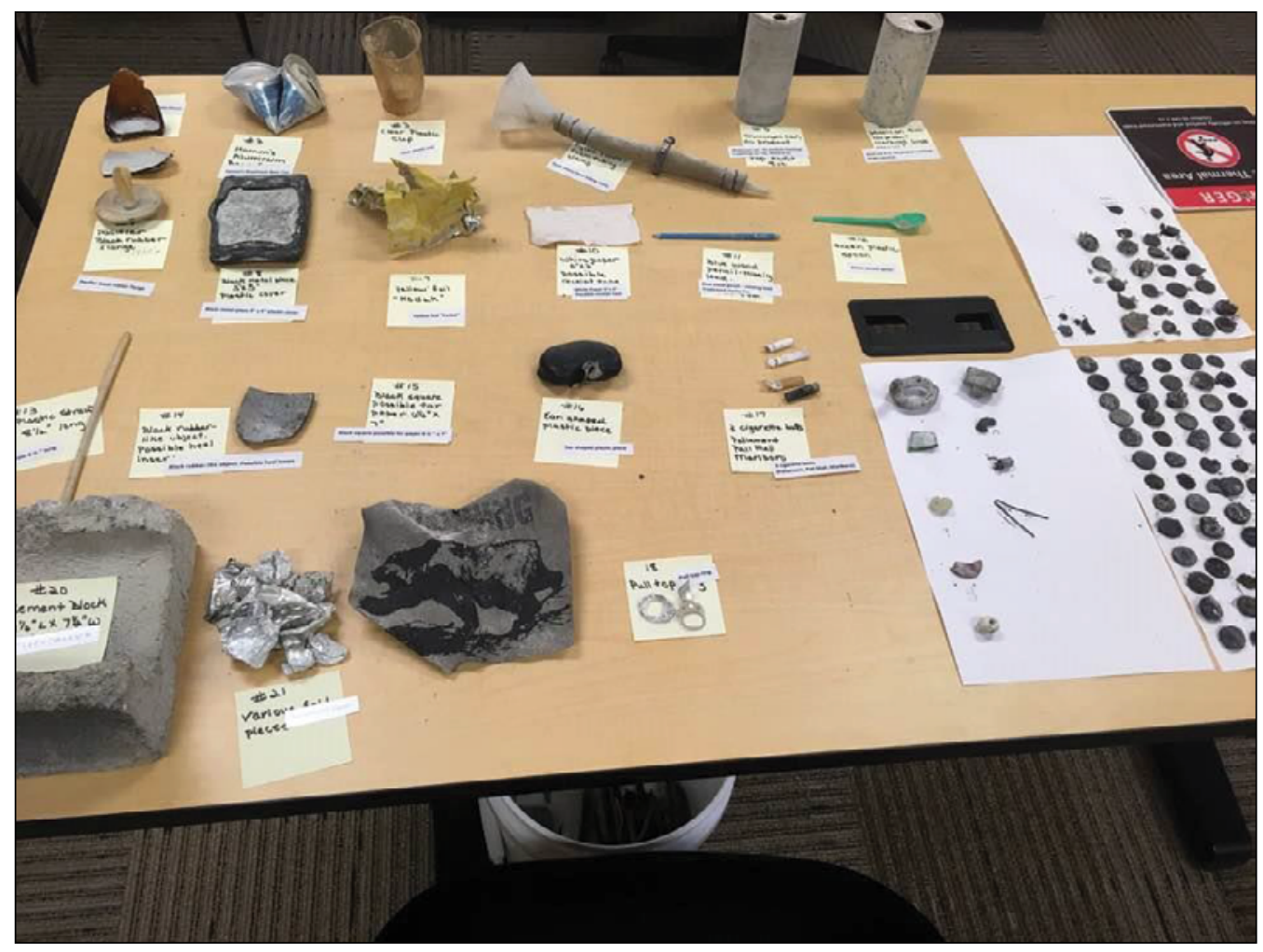

Figure 24. Photograph of human-derived debris erupted from Ear Spring on September 15, 2018. Yellowstone National Park photograph from September 17, 2018.

1957), District Ranger Louis L. Gunzel was on a routine ski patrol to the Old Faithful area during late January and early February 1957, when he noted that although Ear Spring appeared normal in terms of temperature and water content, "there were many rocks of various sizes scattered about the spring from the edge of the crater to approximately 15 feet away." There were also several "partially dissolved" pennies among the rocks, and "a few pieces of glass in the runoff channel.” This led Ranger Gunzel to conclude that Ear Spring had erupted in late 1956 or very early 1957 . This eruption may have been very similar to what occurred in 2018 .
By October, activity in the Geyser Hill area had largely returned to its previous state, and the new features had gone dormant.

\section{Hydrothermal Feature Survey}

During summer 2018, a team from Yellowstone National Park's Geology Program began a multi-year effort to visit and document every hydrothermal feature in the park, a daunting task to say the least. The initial inventory lasted from 1998 to 
2007. This first year of the updated inventory was focused at Norris Geyser Basin, where 916 features were identified south of the Gibbon River, compared to 493 in the initial inventory. The increase mostly reflects a change in protocol rather than an actual increase in the number of features. Smaller features that either were not included or were grouped together in the initial inventory are being listed as independent features in the updated one.

The new inventory will support the National Park Service's mission to preserve and protect natural resources for the enjoyment and education of present and future generations and provide a more detailed baseline against which future changes can be compared. In 2019, the focus of the inventory will shift to Upper Geyser Basin.

\section{Communications and Outreach}

In January of 2018, YVO initiated a new method of communicating with the public via a weekly series of articles titled "Yellowstone Caldera Chronicles." The column features YVO scientists and collaborators discussing geology, history, current activity, and other scientific issues related to Yellowstone. It is posted on the YVO website and advertised on@USGSVolcanoes social media channels (Twitter and Facebook) each Monday. In its first year of publication, Yellowstone Caldera Chronicles was picked up and regularly reprinted by several websites and newspapers that serve the greater Yellowstone area, including the Billings Gazette, Casper Star-Tribune, Montana Standard, National Parks Traveler, Helena Independent Record, Yellowstone Insider, and Mountain Journal. Social media followership spiked in the first week of January, which can be attributed to the launch of Yellowstone Caldera Chronicles.

The @USGSVolcanoes social media channels on Facebook and Twitter remained a primary two-way communication platform for YVO. Posts for the YVO monthly updates and weekly Yellowstone Caldera Chronicles received high amounts of engagement, and comments commonly included questions from followers. USGS staff see these questions as opportunities to engage with the community of followers and provide helpful and accessible information to the social media audience. In March, Michael Poland and Wendy Stovall from USGS and Jamie Farrell from the University of Utah held a Facebook Live question and answer session, which reached more than 70,000 people and had more than 6,000 engagements. The YVO Facebook Live event was also converted to a YouTube video, where it received more than 50,000 views.

Part of YVO's mission is to be coordinated, transparent, and proactive with all communications. A half day was dedicated to this topic during the biennial YVO meeting in May of 2018, and a YVO communications plan was developed based on these discussions. The plan outlines four goals for external communication, which are (1) to gain and maintain public trust, (2) to be the go-to source for information about Yellowstone, (3) to develop an informed public, and (4) to develop a public that

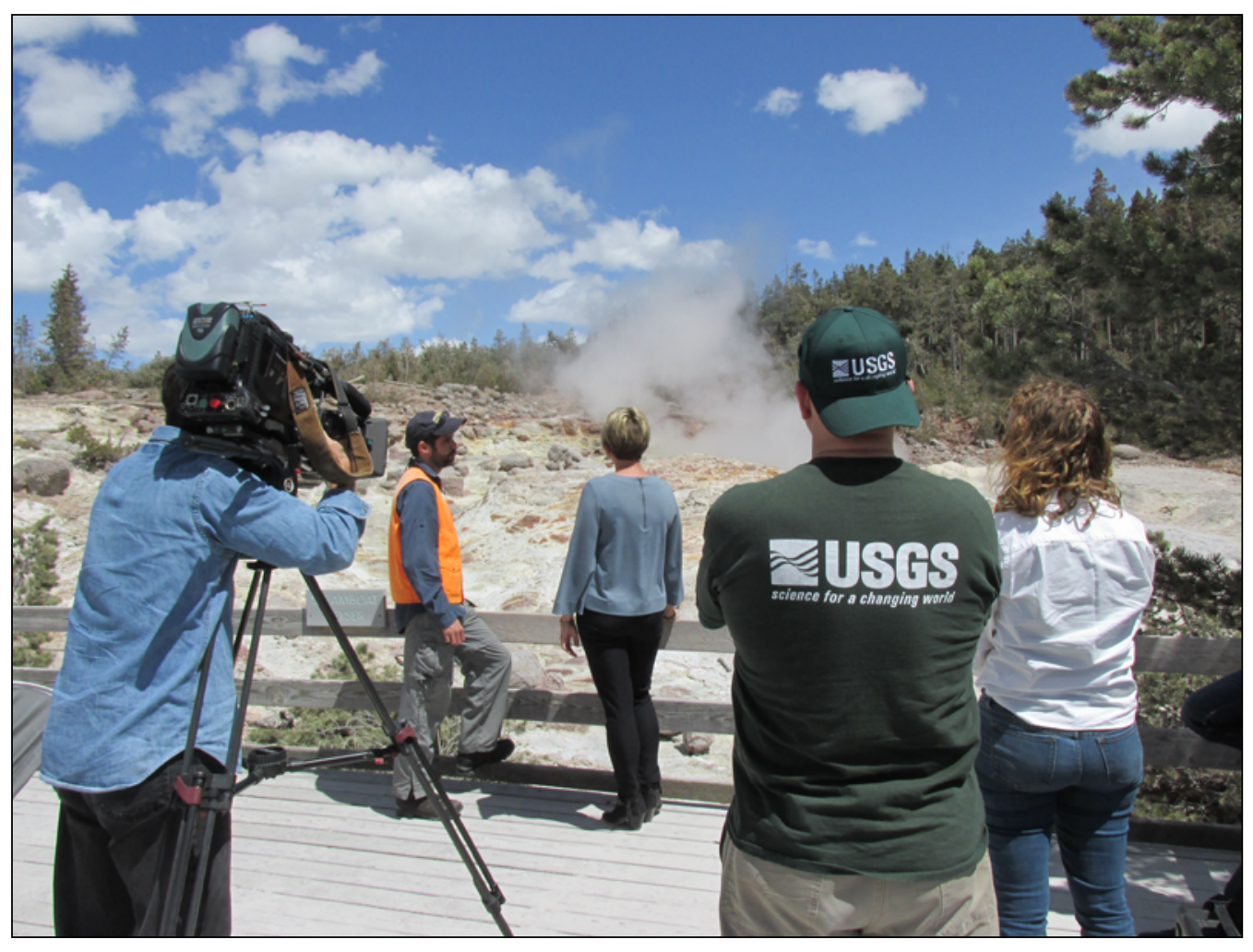

Figure 25. Photograph of a CBS News film crew interviewing Yellowstone Volcano Observatory scientists in front of Steamboat Geyser on May 10, 2018. 
is engaged in and understands the process of science. To ensure coordinated messaging in the case of a geologic event, internal communication guidelines outline a pathway of information flow to ensure all YVO partners are equipped with the same set of information. Both the internal and external communications plans were tested successfully with multiple eruptions of Steamboat Geyser and in September when the Upper Geyser Basin hydrothermal disturbance occurred at Ear Spring (see Geysers and Hot Springs section).

On May 7, 2018, YVO hosted a public event at the Gardiner Community Center in Gardiner, Mont. A panel of five scientists introduced their roles within YVO and the observatory's science and monitoring objectives in Yellowstone. An hour-long question-and-answer session followed. The audience was made up of approximately 70 people, from interested local residents to Yellowstone National Park guides, with a range of knowledge about the Yellowstone volcanic system. Both the public and scientists enjoyed the experience, and YVO hopes to make it a regular occurrence during future biennial YVO coordination meetings. YVO scientists were also interviewed during the coordination meeting by CBS News (fig. 25), and stories about Yellowstone geology and Steamboat Geyser in particular aired on both the morning and evening newscasts in June.

\section{Summary}

The most noteworthy events of 2018 were frequent eruptions of Steamboat Geyser and Giant Geyser, and a rare eruption of Ear Spring. Seismicity, including a continuation of the Maple Creek earthquake swarm that began in 2017, was at background levels. Previously established patterns of ground deformation continued, including subsidence of Yellowstone Caldera and uplift in the Norris Geyser Basin area. By the end of the year, uplift at Norris Geyser Basin had paused or stopped. Hydrothermal activity overall remained at background levels with no significant changes in gas or thermal emissions. Taken together, all available monitoring data indicated that volcanic and hydrothermal activity in the Yellowstone region were at background levels.

Many research efforts were substantially advanced during the year, including investigations of hydrothermal areas beneath Yellowstone Lake, dating of lava flows erupted during the third caldera cycle, seismic characteristics of Geyser Hill, Steamboat Geyser, and Yellowstone Lake, and gas and heat emissions both at selected thermal areas and from the magmatic system as a whole. These studies build on decades of prior research and will likely improve understanding of the hydrothermal, magmatic, and tectonic systems associated with Yellowstone Caldera. As they are finalized, the results of these studies are planned to be published in academic journals, as well as highlighted in future editions of YVO's new weekly series of online articles, Yellowstone Caldera Chronicles, which can be accessed at https://volcanoes.usgs.gov/volcanoes/yellowstone/article_home.html.

\section{Publications}

Farrell, J., Burlacu, R., Roberson, P.M., Hale, J.M., Parapuzha, A., Forbes, N., Koper, K.D., Smith, R.B., Pechmann, J.C., and Pankow, K.L., 2019, Earthquake activity in the Yellowstone region preliminary epicenters October 1-December 31, 2018 : University of Utah Seismograph Stations quarterly report, 18 p., available at https:/quake.utah.edu/wp-content/uploads/2018Q4Yell.pdf.

Farrell, J., Burlacu, R., Roberson, P.M., Hale, J.M., Parapuzha, A., Forbes, N., Koper, K.D., Smith, R.B., Pechmann, J.C., and Pankow, K.L., 2018, Earthquake activity in the Yellowstone region preliminary epicenters July 1-September 30, 2018: University of Utah Seismograph Stations quarterly report, 17 p., available at https://quake.utah.edu/wp-content/uploads/2018Q3-Yell.pdf.

Farrell, J., Burlacu, R., Roberson, P.M., Hale, J.M., Parapuzha, A., Forbes, N., Koper, K.D., Smith, R.B., Pechmann, J.C., and Pankow, K.L., 2018, Earthquake activity in the Yellowstone region preliminary epicenters April 1-June 30, 2018: University of Utah Seismograph Stations quarterly report, 19 p., available at https://quake.utah.edu/wp-content/uploads/2018Q2-Yell.pdf.

Farrell, J., Burlacu, R., Roberson, P.M., Hale, J.M., Parapuzha, A., Forbes, N., Koper, K.D., Smith, R.B., Pechmann, J.C., and Pankow, K.L., 2018, Earthquake activity in the Yellowstone region preliminary epicenters January 1-March 31, 2018: University of Utah Seismograph Stations quarterly report, $32 \mathrm{p}$., available at https:/quake.utah.edu/wp-content/uploads/2018Q1Yell.pdf.

Heasler, H., and Jaworowski, C., 2018, Hydrothermal monitoring of Norris Geyser Basin, Yellowstone National Park, USA, using airborne thermal infrared imagery: Geothermics, v. 72, p. 24 -46, https://doi.org/10.1016/j.geothermics.2017.10.016.

Jean, M.M., Christiansen, E.H., Champion, D.E., Vetter, S.K., Phillips, W.M., Schuth, S., and Shervais, J.W., 2018, Caldera life-cycles of the Yellowstone Hotspot track-Death and rebirth of the Heise Caldera: Journal of Petrology, v. 59, no. 8, p. 1,643-1,670, https://doi.org/10.1093/petrology/egy074.

Licciardi, J.M., and Pierce, K.L., 2018, History and dynamics of the Greater Yellowstone Glacial System during the last two glaciations: Quaternary Science Reviews, v. 200, p. 1-33.

Lynne, B.Y., Heasler, H., Jaworowski, C., Smith, G.J., Smith, I.J., and Foley, D., 2018, Ground penetrating radar documents shortterm near-surface hydrological changes around Old Faithful Geyser, Yellowstone National Park, USA: Journal of Volcanology and Geothermal Research, v. 354, p. 1-12, https://doi. org/10.1016/j.jvolgeores.2018.01.018.

Sohn, R., Harris, R., Linder, C., Luttrell, K., Lovalvo, D., Morgan, L., Seyfried, W., and Shanks, P., 2018, Exploring the restless floor of Yellowstone Lake: Eos Earth and Space Science News, v. 99 , no. 5, p. 27-31. 
Stelten, M.E., Champion, D.E., and Kuntz, M.A., 2018, The timing and origin of pre- and post-caldera volcanism associated with the Mesa Falls Tuff, Yellowstone Plateau volcanic field: Journal of Volcanology and Geothermal Research, v. 350, p. $47-60$.

Wilson, C.J.N., Stelten, M.E., and Lowenstern, J.B., 2018, Contrasting perspectives on the Lava Creek Tuff eruption, Yellowstone, from new $\mathrm{U}-\mathrm{Pb}$ and ${ }^{40} \mathrm{Ar} /{ }^{39} \mathrm{Ar}$ age determinations: Bulletin of Volcanology, v. 80, no. 53, 12 p.

\section{References Cited}

Bergfeld, D., Lowenstern, J.B., Hunt, A.G., Hurwitz, S., McCleskey, B.R., and Peek, S.E., 2019, Chemical and isotopic data on gases and waters for thermal and non-thermal features across Yellowstone National Park (ver. 2.0, March 2019): U.S. Geological Survey data release, https://doi.org/10.5066/ F7H13105.

Christiansen, R.L., Lowenstern, J.B., Smith, R.B., Heasler, H., Morgan, L.A., Nathenson, M., Mastin, L.G., Muffler, L.J.P., and Robinson, J.E., 2007, Preliminary assessment of volcanic and hydrothermal hazards in Yellowstone National Park and vicinity: U.S. Geological Survey Open-File Report 2007-1071, 94 p.

Dzurisin, D., Wicks, C.W, and Poland, M.P., 2012, History of surface displacements at the Yellowstone Caldera, Wyoming, from leveling surveys and InSAR observations, 1923-2008: U.S. Geological Survey Professional Paper 1788, 68 p., https://doi.org/10.3133/pp1788.

Gunzel, L.L., 1957, Eruption of Ear Spring: Yellowstone Nature Notes, v. 31, no. 3, p. 35.

Lewicki, J.L., Kelly, P.J., Bergfeld, D., Vaughan, R.G., and Lowenstern, J.B., 2017, Monitoring gas and heat emissions at Norris Geyser Basin, Yellowstone National Park, USA based on a combined eddy covariance and MultiGAS approach: Journal of Volcanology and Geothermal Research, v. 347, p. 312-326.

Lowenstern, J.B., Christiansen, R.L., Smith, R.B., Morgan, L.A., and Heasler, H., 2005, Steam explosions, earthquakes, and volcanic eruptions-What's in Yellowstone's future?: U.S. Geological Survey Fact Sheet 2005-3024, 6 p., https:// doi.org/10.3133/fs20053024.

McCleskey, R.B., Roth, D.A., Hurwitz, S., Bergfeld, D., Peek, S.E., Susong, D.D., White, E.B., Hungerford, J., Hunt, A.G., Paces, J.B., and Olson, L., 2019, Water chemistry data for selected hot springs and rivers in southwest Yellowstone National Park, Wyoming: U.S. Geological Survey data release, https://doi.org/10.5066/P9MJ0HYM.

Morgan, L.A., Shanks, W.C., III, Lovalvo, D., Johnson, S.Y., Stephenson, W., Pierce, K.L., Harlan, S., Finn, C., Lee, G., Webring, M., Schulze, B., Duhn, J., Sweeney, R., and Balistrieri, L., 2003, Exploration and discovery in Yellowstone Lake-Results from high-resolution sonar imaging, seismic reflection profiling, and submersible studies: Journal of Volcanology and Geothermal Research, v. 122, p. 221-242.

Smith, R.B, and Siegel, L.J., 2000, Windows into the Earth, The Geologic Story of Yellowstone and Grand Teton National Park: New York, Oxford University Press, Inc., 242 p.

Vaughan, R.G., Heasler, H., Jaworowski, C., Lowenstern, J.B., and Keszthelyi, L.P., 2014, Provisional maps of thermal areas in Yellowstone National Park based on satellite thermal infrared imaging and field observations: U.S. Geological Survey Scientific Investigations Report 2014-5137, 22 p.

Yellowstone Volcano Observatory [YVO], 2019, Yellowstone Volcano Observatory 2017 annual report: U.S. Geological Survey Circular 1456, 37 p, https://doi.org/10.3133/cir1456.
Moffett Field Publishing Service Center, California

Manuscript approved November 12, 2020

Edited by Monica Erdman

Layout and design by Katie Sullivan
Inside (facing) cover. Lava flows of Gardner River canyon. National Park Service photograph by Neal Herbert. 

